\title{
INVESTIGATION OF SURROGATE MEASURES FOR SAFETY ASSESSMENT OF TWO-WAY STOP CONTROLLED INTERSECTIONS
}

\author{
By \\ Adrian Lorion \\ Bachelor of Engineering, Ryerson University, Toronto, Ontario, Canada.
}

A thesis presented to Ryerson University

\author{
In partial fulfillment of the \\ requirements for the degree of \\ Master of Applied Science \\ in the Program of \\ Civil Engineering
}

Toronto, Ontario, Canada, 2014

(C) Adrian Lorion 2014 


\section{AUTHOR'S DECLARATION FOR ELECTRONIC SUBMISSION OF A THESIS}

I hereby declare that I am the sole author of this thesis. This is a true copy of the thesis, including any required final revisions, as accepted by my examiners.

I authorize Ryerson University to lend this thesis to other institutions or individuals for the purpose of scholarly research.

I further authorize Ryerson University to reproduce this thesis by photocopying or by other means, in total or in part, at the request of other institutions or individuals for the purpose of scholarly research.

I understand that my thesis may be made electronically available to the public. 


\title{
INVESTIGATION OF SURROGATE MEASURES FOR SAFETY ASSESSMENT OF TWO-WAY STOP CONTROLLED INTERSECTIONS
}

\author{
By \\ Adrian Lorion \\ Department of Civil Engineering \\ Ryerson University
}

\begin{abstract}
Crash prediction models used to estimate safety at intersections, road, and highway segments are traditionally developed using various traffic volume measures. There are issues with this approach and surrogate safety measures such as conflicts and delays can overcome them. This study investigates the relationships between crash frequencies and traffic volume, intersection delay, and conflicts to explore the viability of these models for estimating safety at two-way stop controlled intersections. The database used includes 78 three leg and 55 four leg intersections within the Greater Toronto Area. Crash prediction models were developed and evaluated based on goodness-of-fit measures and CURE plots. Two conflict estimation techniques are compared in order to determine which is best suited for two-way stop controlled intersection simulations. This study also investigates the use of the models for estimating the safety impact of implementing a left turn lane on a major approach of a three leg intersection.
\end{abstract}




\section{ACKNOWLEDGMENTS}

I would like to thank my family and friends for all of their continued support.

I would like to thank my supervisor Dr. Bhagwant Persaud for all the financial and educational support throughout my study.

For assisting with the data and software packages necessary for the completion of my thesis I would like to thank my colleague Taha Saleem.

For providing the data that made this study a possibility I would like to thank the City of Toronto Traffic Safety Unit. 


\section{Table of Contents}

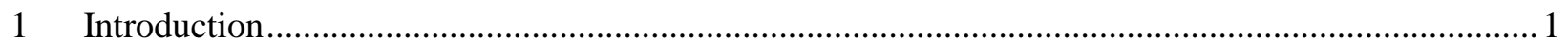

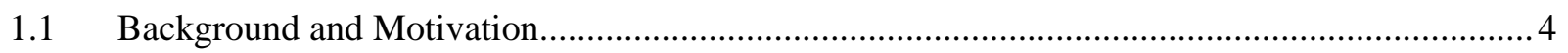

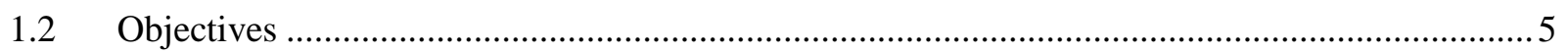

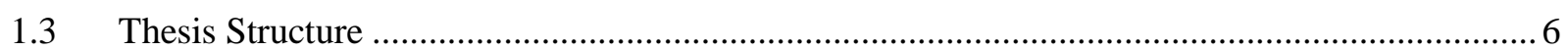

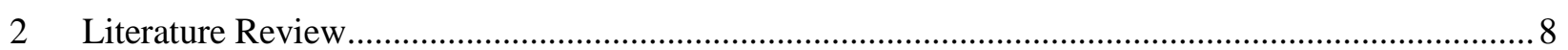

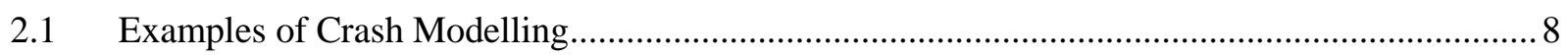

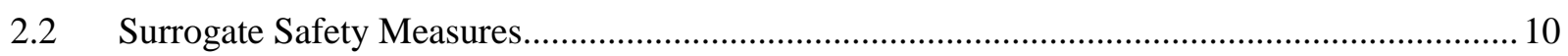

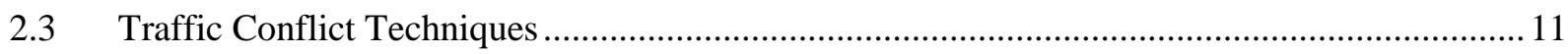

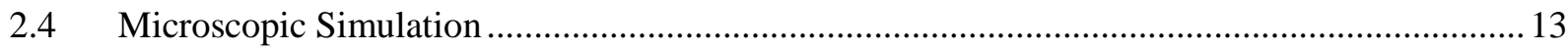

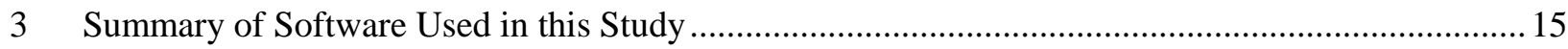

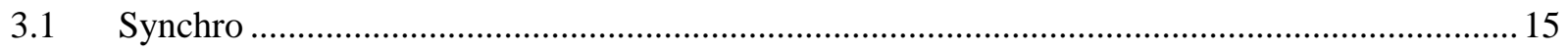

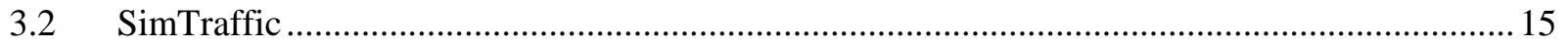

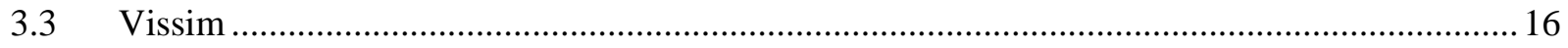

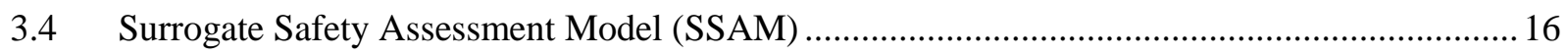

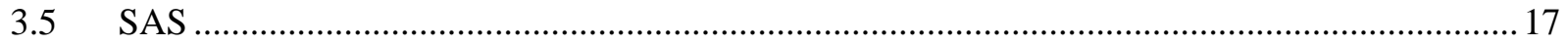

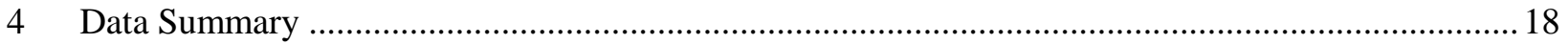

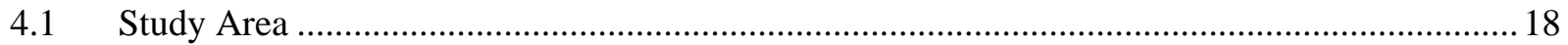

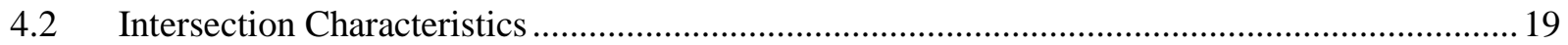

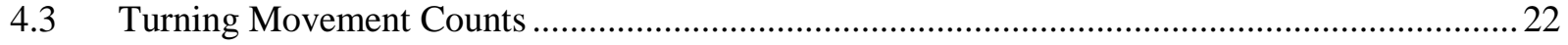

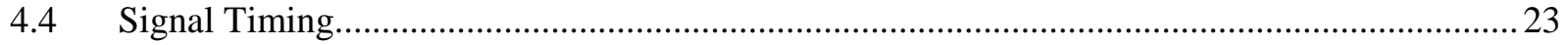

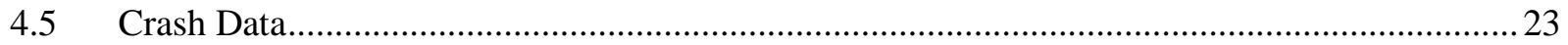

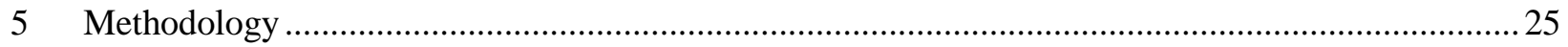

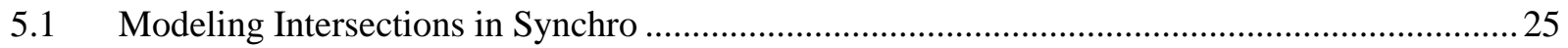

5.1.1 Collecting Two-Way Stop Controlled Stop Intersection Data........................................22

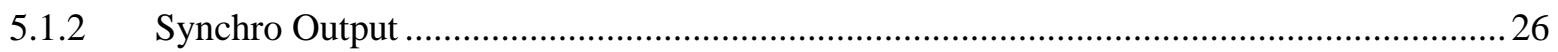

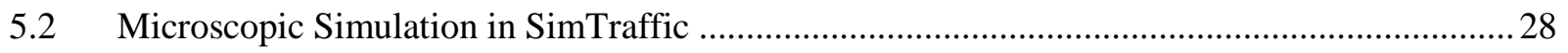

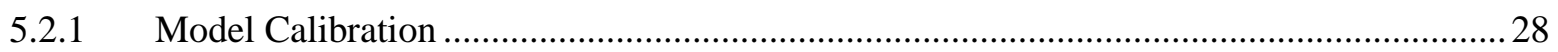

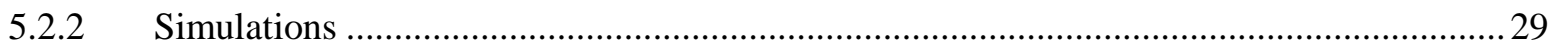

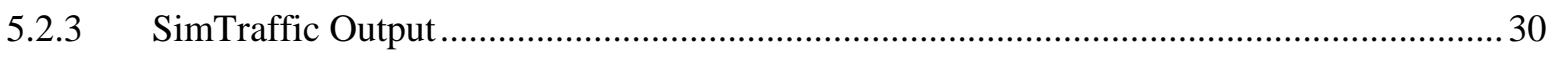

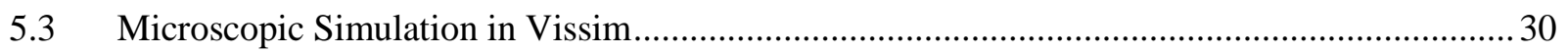

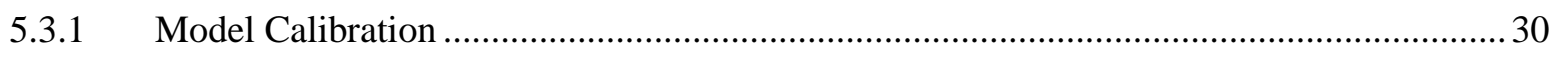

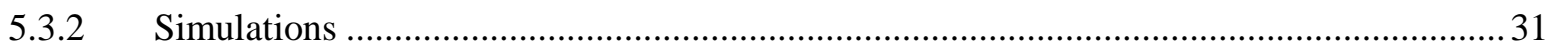




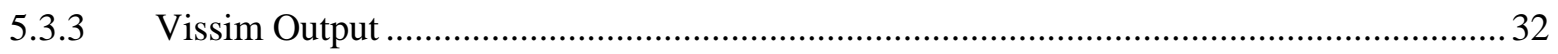

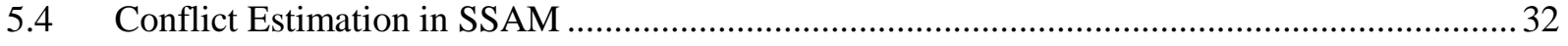

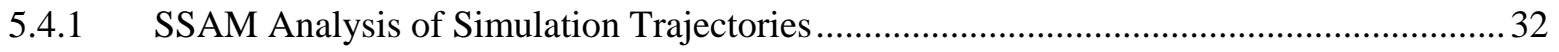

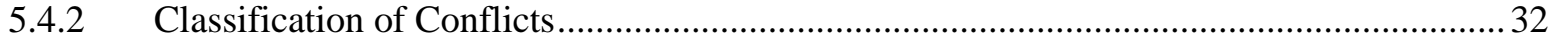

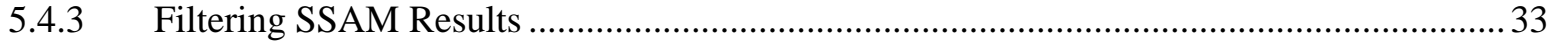

5.5 Crash Prediction Modeling ……....................................................................................... 34

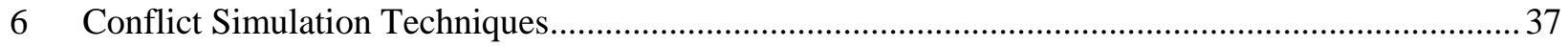

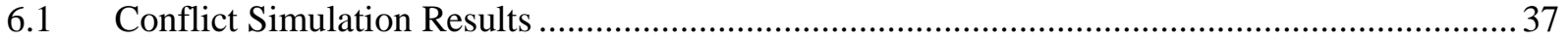

6.2 Conflict Estimation Technique Comparison ............................................................................. 39

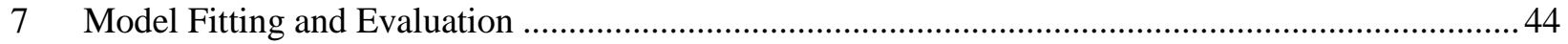

7.1 General Crash Prediction Models and Goodness-of-Fit Evaluation .........................................44

7.2 Volume Crash Prediction Models .............................................................................................. 46

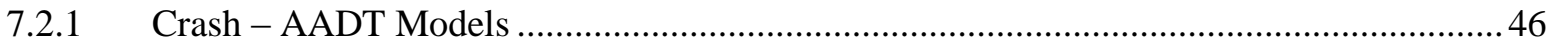

7.2.2 Crash - Delayed Volume and Non-Delayed Volume .................................................... 48

7.2.3 Additional Crash - Volume Models Attempted.................................................................52

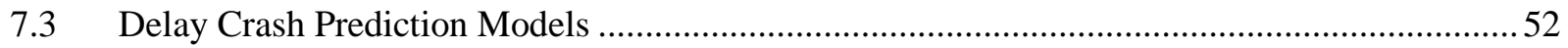

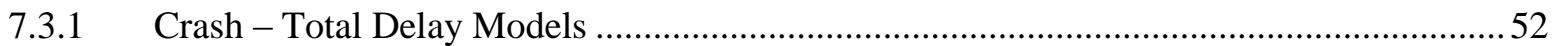

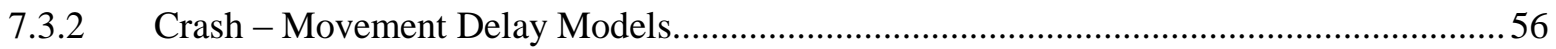

7.3.3 Additional Crash - Delay Models Attempted ...............................................................6 60

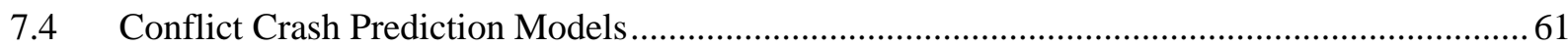

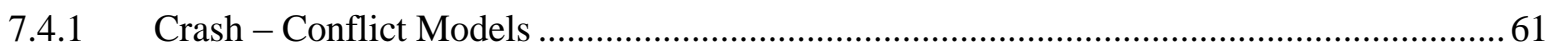

7.4.2 Additional Crash - Conflict Models Attempted ...........................................................69

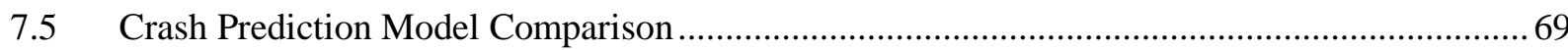

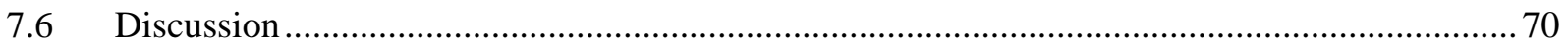

8 Applications of Crash-Delay and Crash-Conflict Models in Evaluating the Implementation of a Major Approach Left Turn Lane at Three Leg Intersections ............................................................... 72

8.1 Before and After Implementation Total Delay and Conflict Results ....................................... 72

8.2 Total Delay Crash Modification Factor Results..................................................................... 74

8.3 Conflict Crash Modification Factor Results ........................................................................... 75

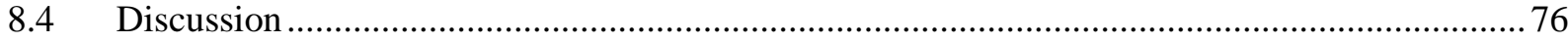

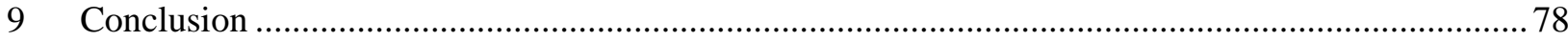

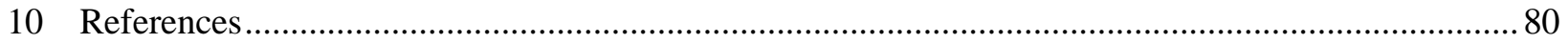




\section{List of Tables}

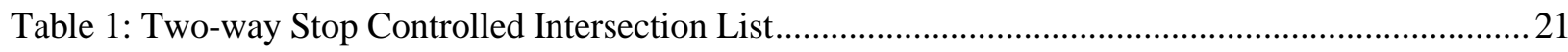

Table 2: Classifications of Intersection Entering Volumes for 8 Hour Total and AM Peak .....................22

Table 3: Intersection Statistics for 8 Hour Total and AM Peak Entering Volumes...................................22

Table 4: Crash Data Statistics for Two-way Stop Controlled Intersections ............................................24

Table 5: SimTraffic Estimated Conflict Summary Statistics ................................................................... 37

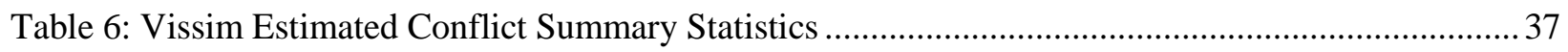

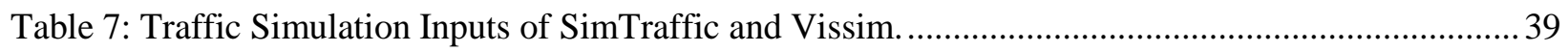

Table 8: SimTraffic and Vissim Total Crash Conflict Models ............................................................... 41

Table 9: SimTraffic and Vissim Injury Crash Conflict Models ............................................................ 41

Table 10: SimTraffic and Vissim Property Damage Only Crash Conflict Models .................................. 42

Table 11: Summary of Most Effective Conflict Estimation Techniques by Model................................... 42

Table 12: Crash - Entering AADT Model Results .............................................................................. 46

Table 13: Crash - Entering AADT Goodness-Of-Fit Results .............................................................. 47

Table 14: Crash - Delayed and Non-Delayed Volume Model Results.................................................... 49

Table 15: Crash - Delayed and Non-Delayed Volume Goodness-Of-Fit Results ...................................50

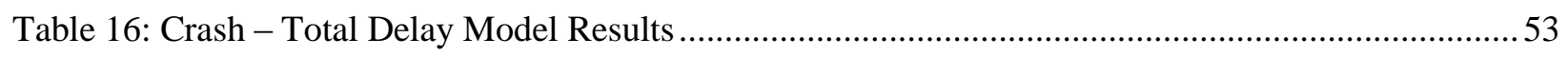

Table 17: Crash - Total Delay Goodness-Of-Fit Results ....................................................................5

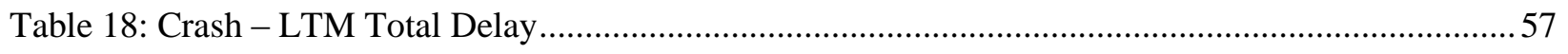

Table 19: Crash - LTM Total Delay Goodness-Of-Fit Results ............................................................5

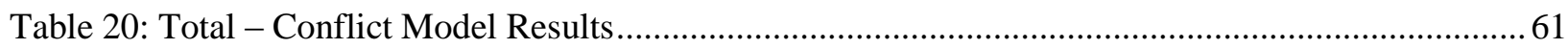

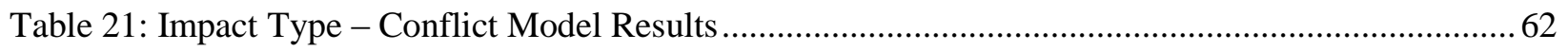

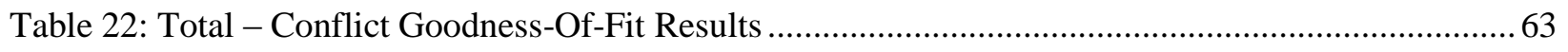

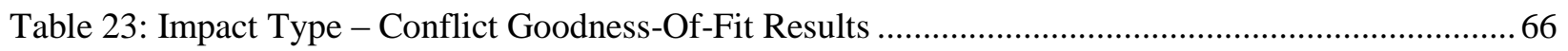

Table 24: Before and After Implementation Total Delay Results .........................................................73

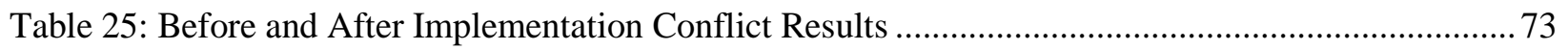

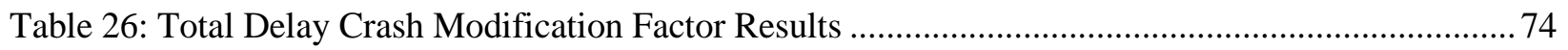

Table 27: Conflict Crash Modification Factor Results ......................................................................... 75 


\section{List of Figures}

Figure 1: Fatal Crashes from 1992 until 2011 (Transport Canada, 2011) ................................................ 1

Figure 2: Injury Crashes from 1992 until 2011 (Transport Canada, 2011).............................................2

Figure 3: 17.9 Billion Dollar Social Cost Distribution (Transport Canada, 2007) ...................................2

Figure 4: HTA Reported Crashes Distribution (Transport Canada, 2007) .............................................. 3

Figure 5: Road Safety Ranking Among OECD Countries (RSCC, 2011) ............................................... 3

Figure 6: Hydén Safety Pyramid (Hydén, 1987) ................................................................................. 12

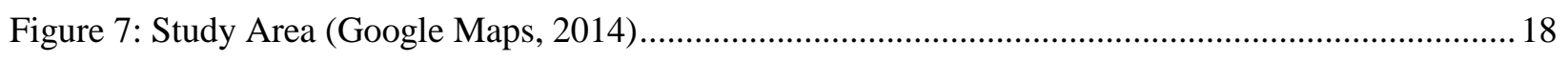

Figure 8: Two-way Stop Controlled Intersections (Google Maps, 2014) ............................................... 20

Figure 9: Avenue Road and Douglas Avenue Model ........................................................................26

Figure 10: Islington Avenue and Kingsview Boulevard Model .........................................................2

Figure 11: SimTraffic Simulation at Lawrence Avenue East and Wanless Crescent ...............................29

Figure 12: Vissim Simulation at Lawrence Avenue East and Wanless Crescent .................................... 31

Figure 13: Conflict Angle Diagram (Gettman et al., 2008) .................................................................. 33

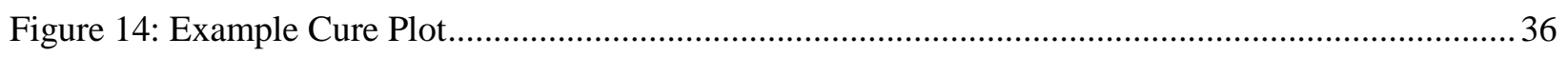

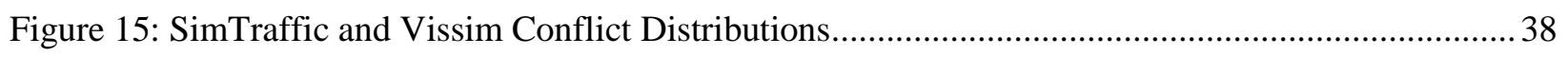

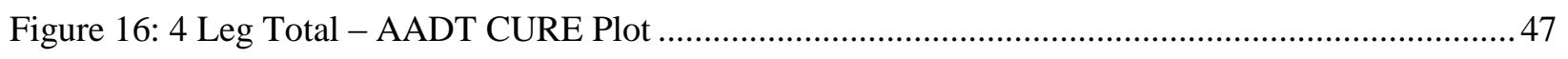

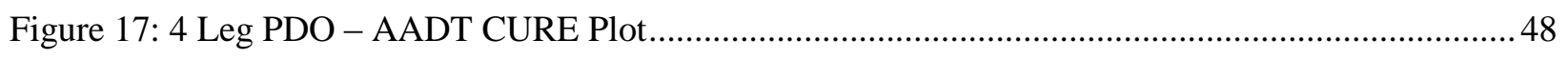

Figure 18: 4 Leg Total - Delayed and Non-Delayed Volume CURE Plots ............................................51

Figure 19: 4 Leg Injury - Delayed and Non-Delayed Volume CURE Plots ............................................51

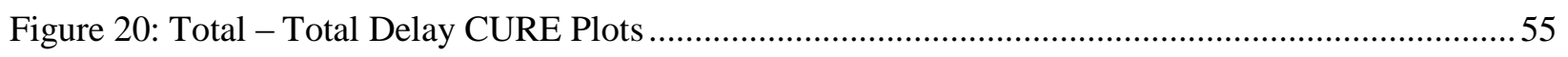

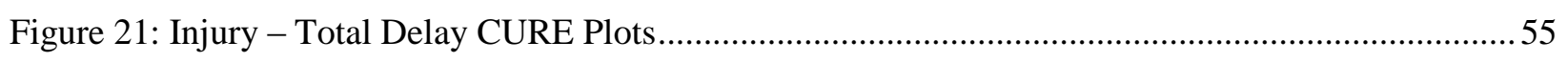

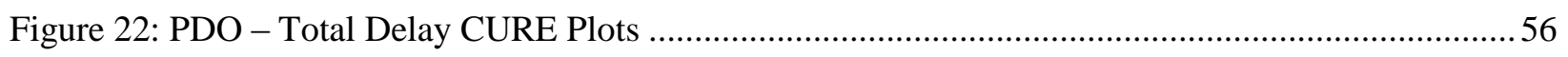

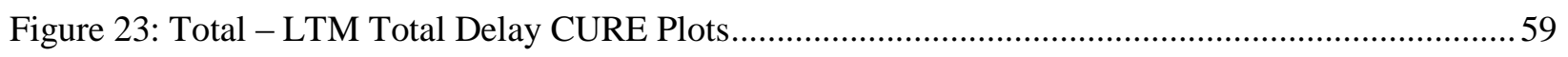

Figure 24: Injury - LTM Total Delay CURE Plots ...........................................................................5

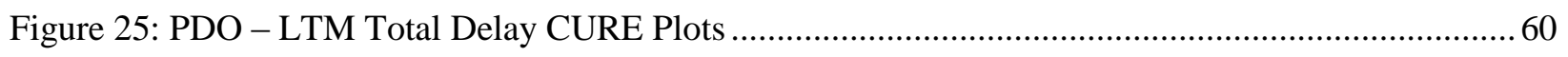

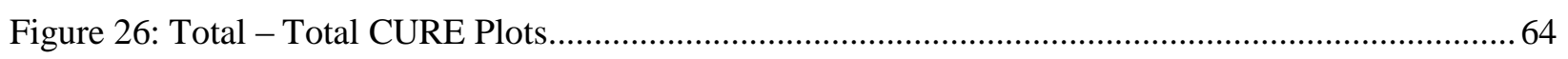

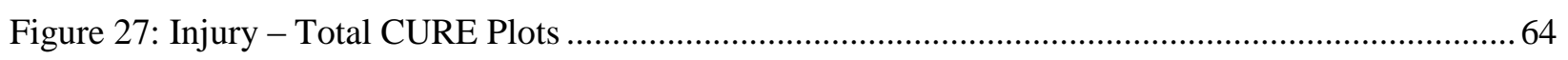

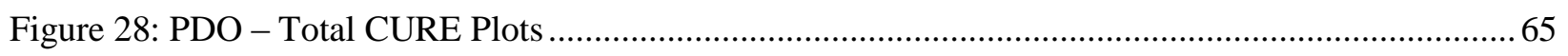

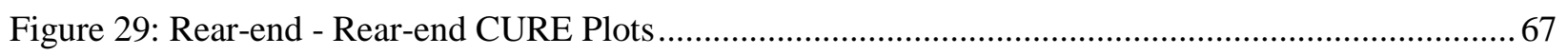

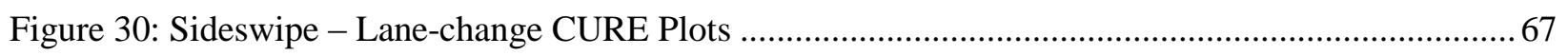

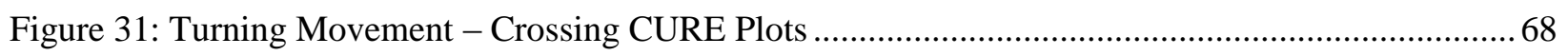




\section{Introduction}

Worldwide the number of fatalities due to road traffic crashes each year is estimated at approximately 1.2 million, and the number injured could be as high as 50 million (World Health Organization, 2004). Road traffic injuries are a major but neglected global public health problem, which requires concentrated efforts for effective and sustainable prevention. The World Health Organization's Global Burden of Disease model predicts that by 2020, road traffic deaths could rise to 2.34 million each year worldwide (World Health Organization, 2004). An increase in effort and initiative is critical in reducing the amount of road traffic deaths each year. Between 2000 and 2020, the number of road traffic deaths and injuries worldwide is expected to rise by $65 \%$ and by $80 \%$ in low and middle income countries (World Health Organization, 2004).

In 2011, Transport Canada recorded the lowest amount of fatal motor vehicle crashes since they began collecting data in the early 1970's (Transport Canada, 2011). In 2011 the number of motor vehicle fatalities and serious injuries were down 10.3\% from 2010. Figure 1 and Figure 2 illustrate the change in fatal and injury crashes each year from 1992 until 2011.

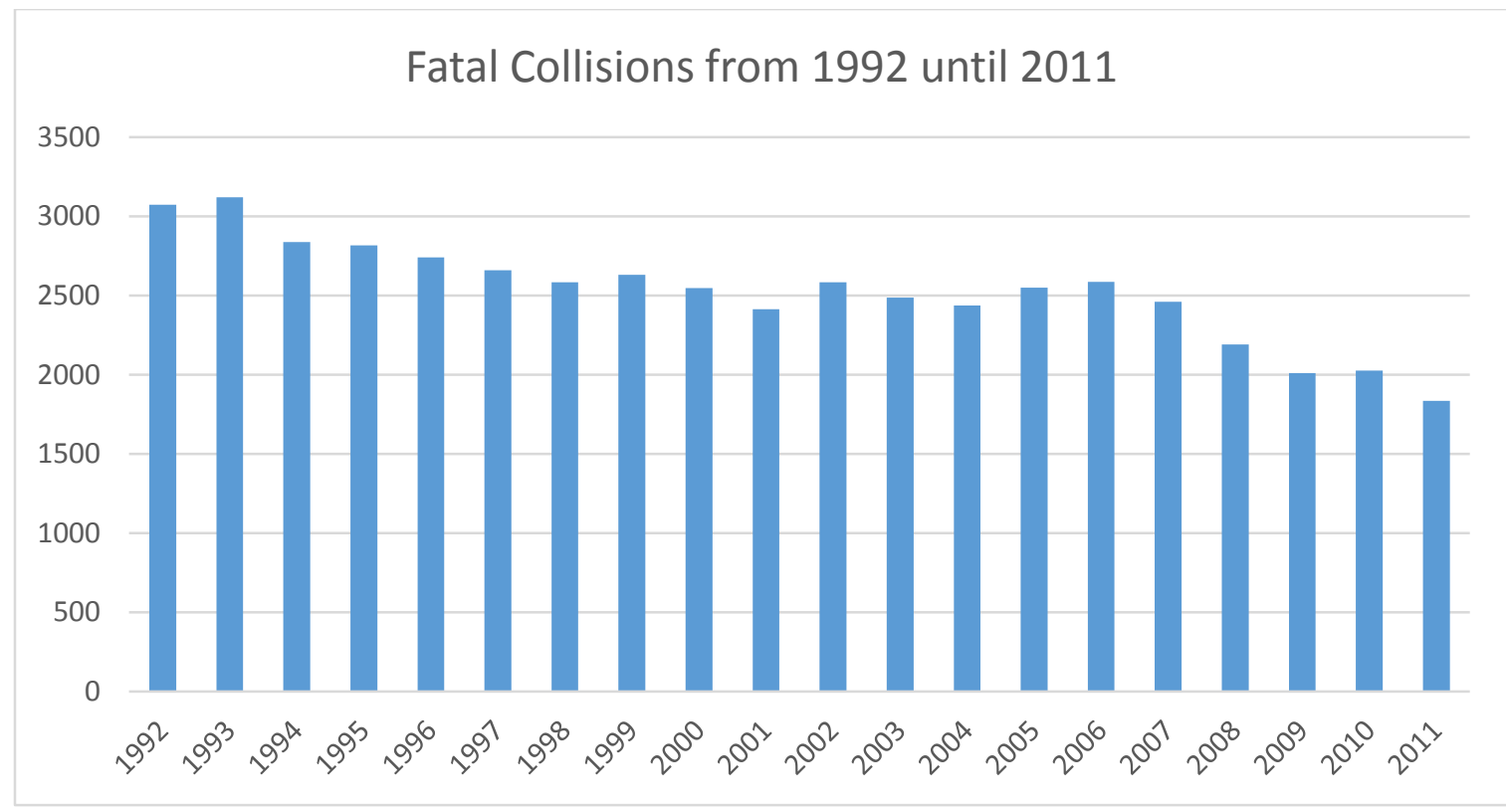

Figure 1: Fatal Crashes from 1992 until 2011 (Transport Canada, 2011) 


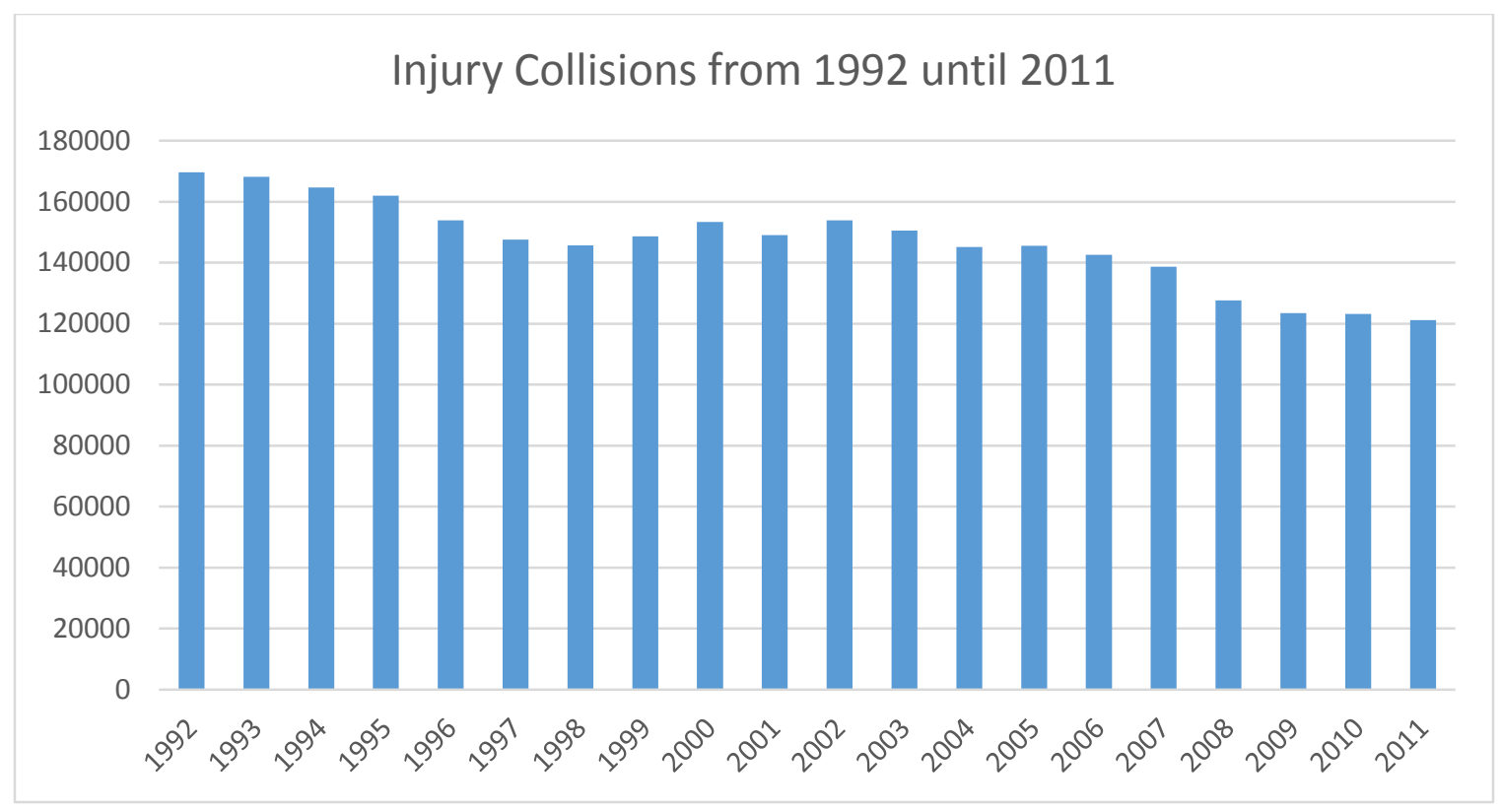

Figure 2: Injury Crashes from 1992 until 2011 (Transport Canada, 2011)

According to Transport Canada (2007) as of 2004 motor vehicle crashes had a social cost of 17.9 billion dollars in Ontario. Figure 3 illustrates the distribution of the social cost between Fatal, Injury, and Property Damage Only crashes. The average crash in 2004 had a social cost of $\$ 77000$ (Transport Canada, 2007). In 2004 the Highway Traffic Act (HTS) reported 231,548 crashes. Figure 4 illustrates the percentages of these that are Fatal, Injury, and Property Damage Only.

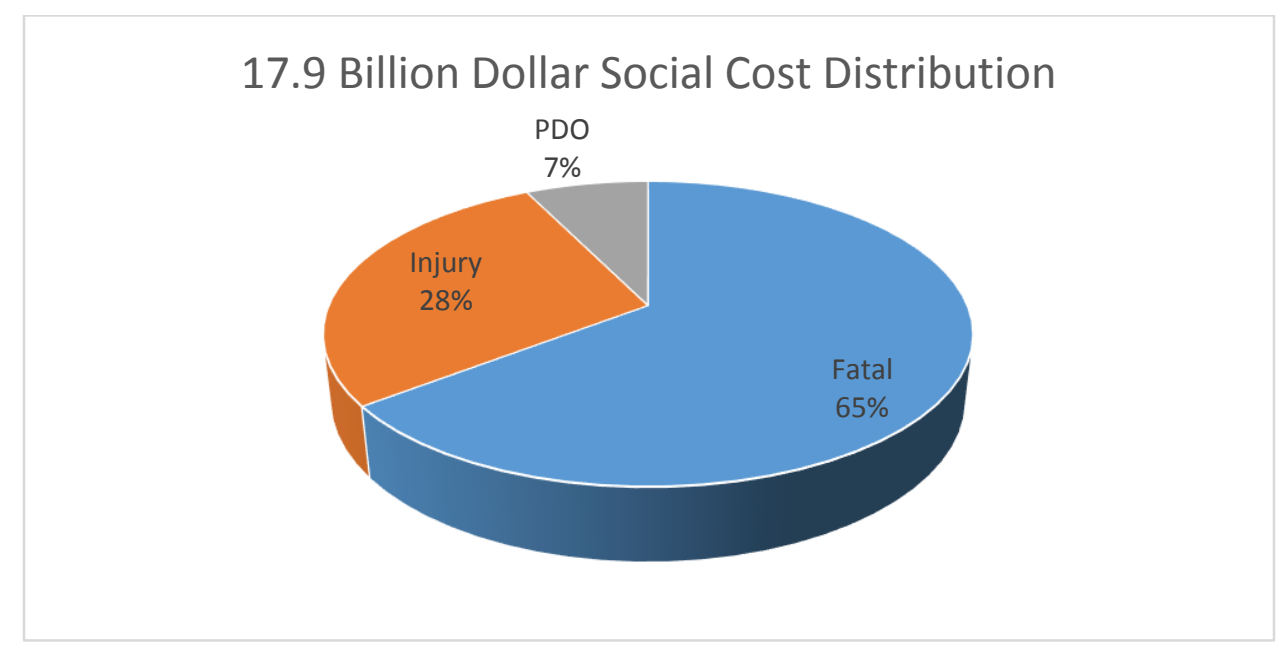

Figure 3: 17.9 Billion Dollar Social Cost Distribution (Transport Canada, 2007) 


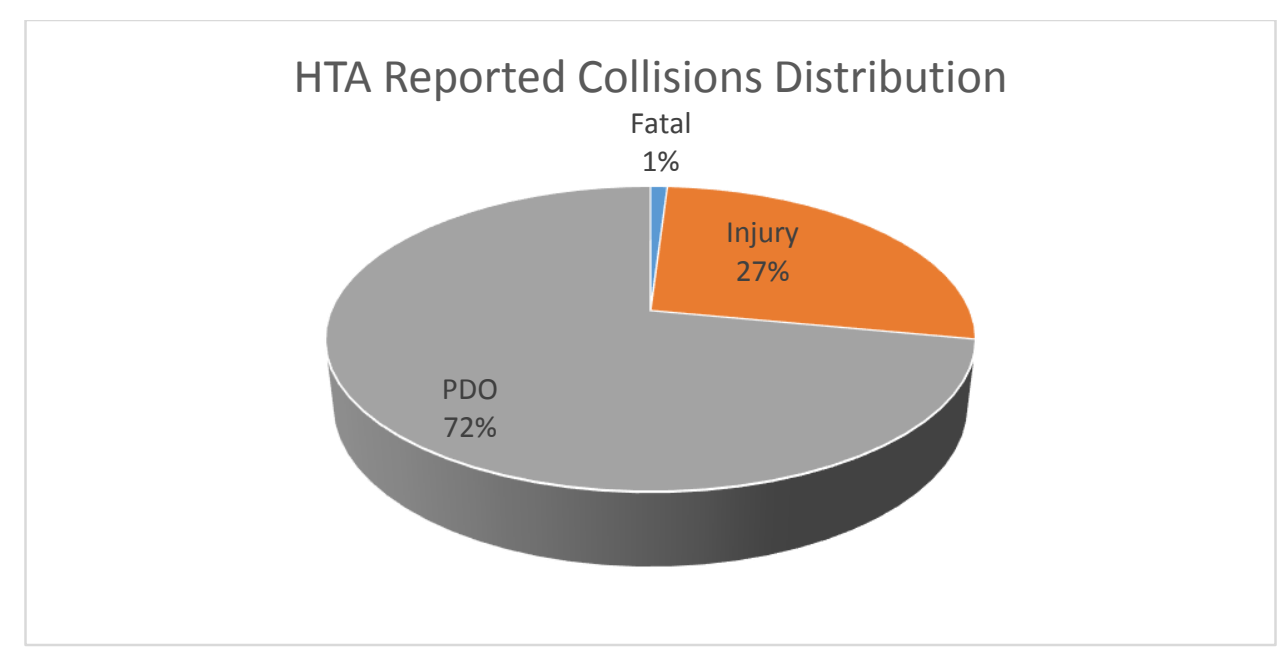

Figure 4: HTA Reported Crashes Distribution (Transport Canada, 2007)

Canada's Road Safety Strategy 2015 is the third series of national road safety programs, the first being Road Safety Vision 2001, followed by Road Safety Vision 2010 (Road Safety Canada Consulting, 2011). These programs have all been focused on making Canadian road the safest in the world by reducing the number of fatal and injury crashes. In 2008, Canada was ranked tenth for road safety compared to other Organization for Economic Cooperation and Development member countries (Figure 5).

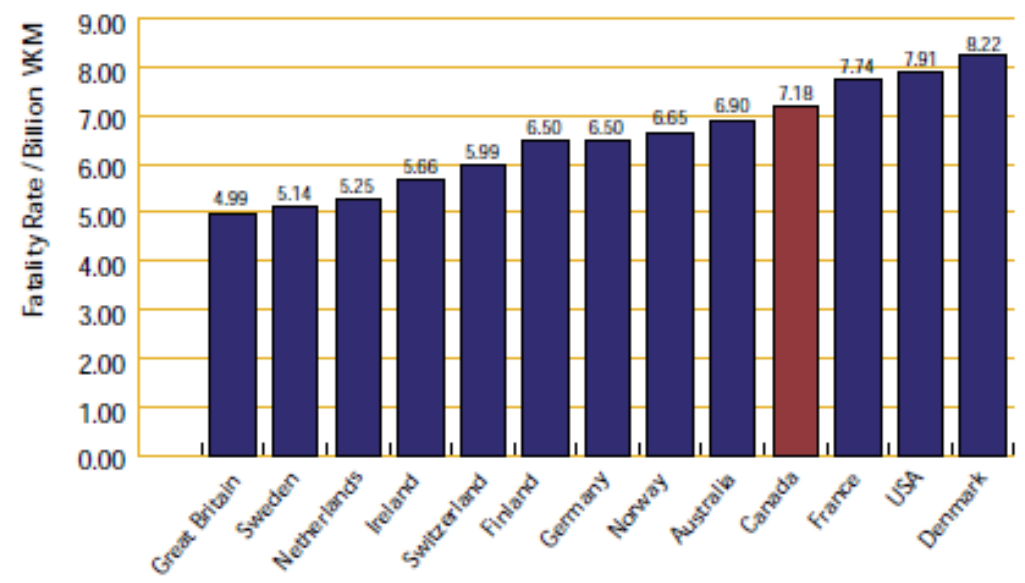

Figure 5: Road Safety Ranking Among OECD Countries (RSCC, 2011) 
Safety assessment tools are a key component in continuing to improve road safety in Canada. With the social costs of crashes being so large, it is important to minimize crashes as much as possible. By developing crash prediction models which utilize surrogate safety measures, road safety improvements can be effectively evaluated before and after implementation.

\subsection{Background and Motivation}

Crash prediction models are commonly developed in order to evaluate and improve traffic safety at roadways and intersections. These models are developed with historical crash data and statistics. Crash prediction models provide a relationship between crashes and explanatory variables such as the average annual daily traffic (AADT), geometric features (such as lane configurations), and traffic control features (Saleem, 2012). Applying a generalized linear regression modelling approach, the crash frequency is correlated with selected explanatory variables. These crash prediction models can then be used by safety analysts to evaluate safety at roadways and intersections.

Generally, crash prediction models are developed by relating crashes to traffic volumes. A study conducted by Sayed and Rodriguez (1999) developed crash prediction models relating crashes and traffic volume for 419 (186 three leg and 233 four leg) urban two-way stop controlled intersections in British Columbia. The resulting crash prediction models showed satisfactory goodness-of-fit (Sayed \& Rodriguez, 1999). This conventional study illustrates the modelling of crashes and traffic volumes; however it does not explore other explanatory variables. In some cases traffic volume alone will not provide adequate crash prediction models, thus the use of other explanatory variables should be explored.

The issue with modelling only traffic volume with crashes is that these crash statistics may not take into account all the aspects contributing to the occurrences of crashes and that crash records or traffic data may be incomplete, inaccurate, or even nonexistent. The use of traffic conflicts can assist with issues related to incomplete databases. Conflicts have an advantage over crashes as they occur more frequently and can be collected through methods such as field 
observations, microscopic simulation, and video camera data. If the traffic data are complete and detailed enough, intersection delay can be utilized as well.

The use of surrogate safety measures in predicting crashes can be a mechanism to improve on the traditional method of conducting crash based assessments in which a set of intersections is selected and the improvement is made. The before and after crash data are then collected to determine if the improvement was effective. The main issue with this method is that it takes several years to determine if the improvement was actually effective, and if an improvement is not effective it may actually cause unnecessary crashes. The use of surrogate safety measures can overcome this issue as they can be used to develop crash prediction models that relate measures such as conflicts or delay to crashes. By applying these models to the intersections before and after a contemplated improvement, the intersection delay or estimated conflicts can be used to determine the change in crash frequency. The use of simulated conflicts and delay can thus provide a method of effectively evaluating improvements prior to implementation. This approach has shown promise in studies conducted by Saleem (2012) and Sachi, Sayed and deLeur (2013) have explored the use of surrogate safety measures in developing conflict based crash prediction models for signalized intersections. These models were then used to explore the development of crash modification factors, for left turn protected phasing for the Saleem (2012) study, and for a right turn treatment for the Sacchi et al. (2013) study. This thesis builds on that research by developing delay and conflict based crash prediction models for two-way stop controlled intersections and exploring the application of these models for developing a CMF for a contemplated improvement - installation of a left turn lane on a major approach.

\subsection{Objectives}

The purpose of this thesis was to develop and evaluate the predictive capabilities of crash prediction models for two-way stop controlled intersections. The crash prediction models were developed to provide relationships between crashes and conflicts, delays, and volumes. This study includes 133 two-way stop controlled intersections located within the Greater Toronto Area (GTA), of which 78 are three leg and 55 are four leg intersections. Conflict data were estimated using the Surrogate Safety Analysis Model (SSAM) (Gettman, Pu, Sayed, \& Shelby, 
2008) to analyze the vehicle trajectory results provided by the microscopic simulation conducted with SimTraffic (Husch \& Albeck, 2012) and Vissim (PTV, 2013). Intersection delay data were collected by modelling the intersection geometric features and traffic data with Synchro (Husch \& Albeck, 2012). Vehicle volume data were provided by the City of Toronto Traffic Safety Unit. Two microscopic simulation techniques are applied in order to compare their results and determine which is more effective in estimating conflicts at two-way stop controlled intersections.

Crash prediction models were developed for all intersections and then for the three and four leg intersections separately in order to capture the impact that the number of approaches has on the occurrence of crashes. The crash-conflict prediction models relate crashes to conflicts classified as crossing, rear-end, lane change, and the overall total. The crash-delay models relate crashes to the intersection delay. Finally, the crash-volume models relate crashes to the average annual daily traffic (AADT) and the AM Peak Volume.

This study contributes to knowledge in the surrogate safety measures research area in establishing the viability of using surrogate measures for safety assessment of two-way stop controlled intersections. In so doing, it is the first study that investigates and compares the use of both delay and conflicts as surrogate safety measures for developing crash prediction models.

\subsection{Thesis Structure}

This thesis consists of nine chapters. The first chapter provides a brief description of the current state of road safety in Canada, the background and motivation behind this thesis, and identifies the thesis objectives before this section on the thesis structure.

Chapter two consists of a literature review conducted prior to beginning this thesis. This chapter begins by describing some examples of crash modelling, followed by a discussion on surrogate safety measures, traffic conflict techniques, and microscopic simulation.

Chapter three briefly introduces the different software packages required to conduct the study and chapter four explains what data were required and how they were collected. 
Chapter five focuses on the applied methodology. It describes how the two-way stop controlled intersections were modelled, how the traffic simulations were conducted, how the conflicts were identified, and the development of crash prediction models.

Chapter six provides conflict simulation results including statistics regarding the types of conflicts and the conflict distribution. This chapter the compares the conflict estimation techniques of SimTraffic and Vissim.

Chapter seven consists of the model fitting and evaluation. It describes the development of various crash prediction models and the evaluation of their predictive capabilities.

Chapter eight provides the analysis conducted on the implementation of an improvement. This chapter provides an approach to determining crash modification factors (CMF) through the implementation of a left turning lane on a major approach of a three leg intersection.

Chapter nine concludes this thesis by providing a brief summary of the research goals met and future work to be conducted. 


\section{Literature Review}

This chapter reviews the studied literature. The literature review includes topics such as: examples of crash modelling, surrogate safety measures, and traffic conflict techniques, and microscopic simulation.

\subsection{Examples of Crash Modelling}

There have been countless studies devoted to the development of crash modelling techniques. Development of these crash prediction models is imperative as safety analysts use them in evaluating the level of safety at various locations. The traditional approach to crash prediction modelling uses the traffic volumes in order to predict the amount of crashes. The following are examples of crash prediction models and their methodologies.

Sayed and Rodriguez (1999) developed accident prediction models in order to estimate safety performance at two-way stop controlled intersections. These models are a function of their traffic volumes and the type of intersection. They utilized a generalized linear modeling approach (GLIM) as a conventional linear regression model is unable to adequately describe characteristics of accidents such as: random, discrete, nonnegative, and infrequent events (Sayed \& Rodriguez, 1999). The Empirical Bayes (EB) approach was applied in this study as it makes use of an intersection's traffic, road characteristics, and historical accident data. By combining the observed number of accidents and the predicted number of accidents, the EB approach refines the estimates and reduces the regression to the mean bias (Sayed \& Rodriguez, 1999). The regression to the mean is a statistical phenomenon in which a large number of accidents during a before period is followed by a reduced number of accidents in a similar after period, even if measures have not been implemented (Sayed \& Rodriguez, 1999). Sayed and Rodriguez (1999) found that the accident prediction models they developed showed satisfactory goodness of fit.

Lyon, Haq, Persaud, and Kodama (2005) studied the development of safety performance functions (SPFs) (another name for crash prediction models) which relate the crashes at an intersection or road segment to the traffic, operational, and geometric characteristics. SPFs are 
predictive rather than causal models; thus the goal is to develop functions that provide the best predictive ability using available variables (Lyon et al., 2005). Two levels of models were created, the first being an annual average daily traffic (AADT) only SPF, includes only traffic volume variables. The second is a multivariate SPF including variables relating to pedestrian flows, left turn lanes, and right turn lanes (Lyon et al., 2005). These models were calibrated for three and four leg Toronto signalized intersections separately and for various road classes. The EB methodology was applied to evaluate the effectiveness of left turn priority phasing implemented at intersections. The SPF is used to estimate the number of expected crashes that would have occurred without treatment each year of the before and after period at similar intersections (Lyon et al., 2005). The main results of this study are published SPFs that can be used by researchers and practitioners in other jurisdictions with little to no calibration.

Caliendo and Guida (2012) state the need for a method of preventative safety analysis that does not require the occurrence of a crash. Their study aims to identify a relationship between simulated conflicts and recorded crashes, as well as test whether crashes at two-way stop controlled intersections correlate better with conflicts than traffic flow (Caliendo \& Guida, 2012). They developed a conflict based crash prediction model and a traditional traffic volume based crash prediction model. The study demonstrated a significant correlation between crashes and critical conflicts, and that conflict based models are a better fit to the accident data than the volume based model (Caliendo \& Guida, 2012).

El-Basyouny and Sayed (2013) proposed a two phase model in order to investigate the relationship between conflicts and crashes. The goal of this study is to provide a tool for evaluating the reduction in conflicts and collision frequency due to the implementation of countermeasures. The first phase applies a lognormal model to predict conflicts using traffic volume, area type, and geometric variables. The second phase uses a conflicts-based negative binomial safety performance function to predict crashes (El-Basyouny \& Sayed, 2013). The results of their study show that conflicts are significantly more likely in urban areas, conflicts are significantly less likely when a right turn lane is present at minor approaches, and there is a proportional relationship between conflicts and crashes (El-Basyouny \& Sayed, 2013). 
Crash modelling is a diverse field of study and the examples provided illustrate this point. This thesis reinforces and improves on the reviewed material by developing crash prediction models for two-way stop controlled intersections in the City of Toronto that incorporate conflicts as well as delay. This research complements the recent research by Saleem (2012) who estimated conflict based crash prediction models for signalized intersections in Toronto and investigated the use of these models for estimating crash modification factors.

\subsection{Surrogate Safety Measures}

Road safety analysis has traditionally been done using crash data. Crash data may be insufficient due to small sample sizes leading to inconclusive results, and a lack of details needed to improve our understanding of crash failure mechanisms and crash avoidance behavior (Tarko, Davis, Saunier, Sayed \& Washington, 2009). Due to this lack of or low quality accident data, other surrogate measures have been proposed as traffic safety estimates (El-Basyouny, 2006). ElBasyouny (2006) compiled the following list of surrogate safety measures:

- Delay

- Travel Time

- Approach Speed

- Percent Stops

- Queue Length

- Stop-bar Encroachments

- Red-light Violations

- Percent Left Turns

- $\quad$ Stop Speed

- Speed Distribution

- Deceleration Distribution

- Traffic Conflict Technique

Tarko et al. (2009) identified two conditions that must be met before a surrogate safety measure can be useful in a transportation safety application. First, a surrogate safety measure should be based on an observable non-crash event that is physically related to crashes. Second, 
there should be a practical method for converting the non-crash events into corresponding crash frequency and possibly crash severity. Traffic volume is a commonly used indicator of road safety. However, traffic volume does not satisfy the second condition of a useful surrogate safety measure because most safety treatments will not have a direct impact on the traffic volumes (Tarko et al., 2009). An important area of surrogate safety measures research is the development of methods for measuring vehicle interactions. Tarko et al. (2009) identify conflicts and near crash as the two approaches in defining crash surrogate events. A conflict is an observable situation in which two or more road users approach each other in space and time with a risk of crash unless they change their movements (El-Basyouny \& Sayed, 2013). A near crash is any circumstance that requires a rapid evasive maneuver (steering, braking, accelerating, or any combination of control inputs) by any vehicle, pedestrian, cyclist, or animal to avoid a crash (Tarko et al., 2009). Both of these describe a surrogate event, where a crash would have occurred if an evasive action was not performed. Intersection delay is another surrogate safety measure that can be applied. The use of delay satisfies both conditions as it is an observable non-crash event and can be converted into crash frequencies. This study utilizes traffic conflicts and intersection delay as surrogate safety measures.

\subsection{Traffic Conflict Techniques}

Perkins and Harris (1967) first developed the traffic conflict technique (TCT) while working as engineers for General Motors. They developed TCT in order to identify safety issues related to vehicle construction. Their study determined relationships between conflict patterns and accident type and they concluded that the occurrence of conflicts is a more useful measure of risk than accident rate (Perkins \& Harris, 1967). Conflicts can be defined as situations where two or more road users would collide if neither of them made an evasive maneuver as suggested by Hydén (1987) who related time to crash (TTC) values with speeds to determine conflict severity. Figure 6 illustrates the relationship between severity and frequency of elementary events in traffic with a safety pyramid as proposed by Laureshyn, Svensson, and Hydén (2010). 


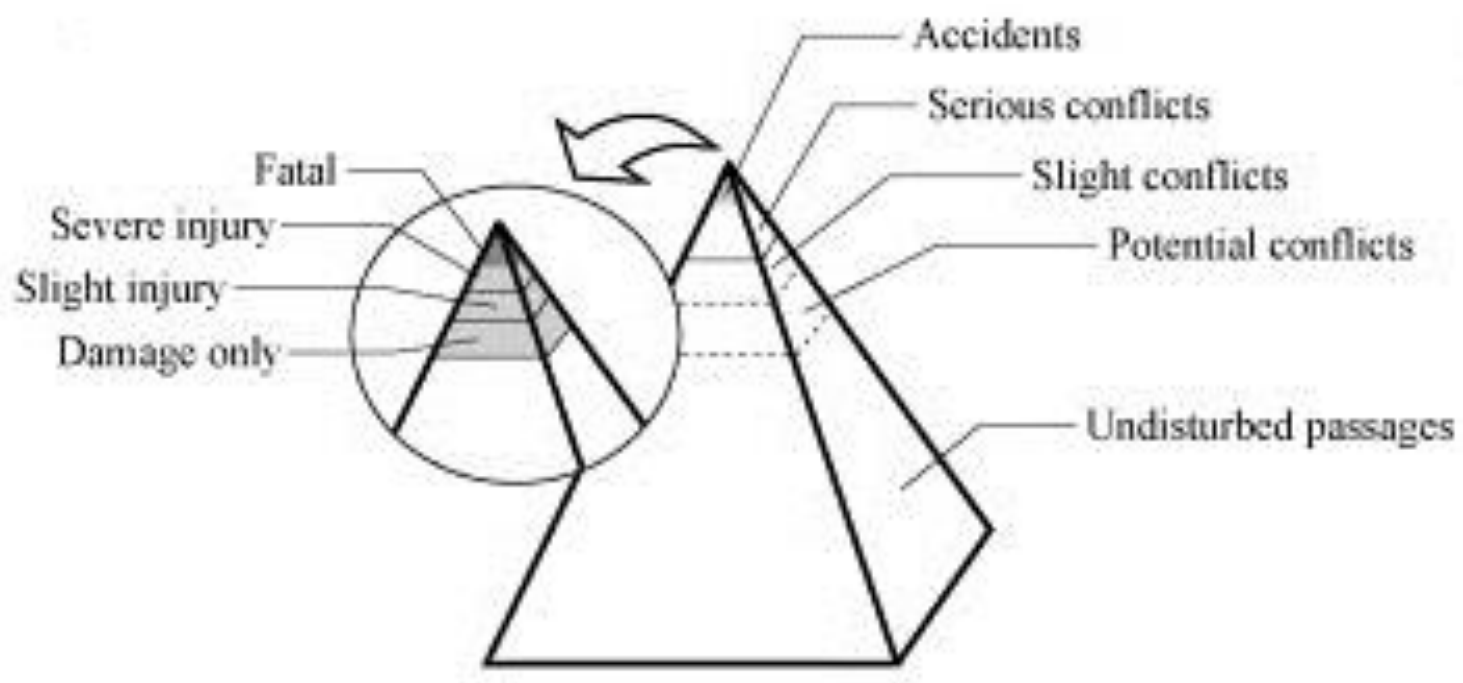

Figure 6: Hydén Safety Pyramid (Hydén, 1987)

Studies have demonstrated conflict data collecting methods such as field observations, microscopic simulation models, and video cameras (El-Basyouny \& Sayed, 2013). Regardless of which method is applied, the approach offers traffic analysts the opportunity to observe unsafe vehicle interaction and identify failure mechanisms that lead to unsafe behavior (El-Basyouny \& Sayed, 2013). Once conflict data are collected, safety indicators are utilized in identifying and classifying conflicts.

Traditionally the most popular safety indicators include time to collision, post encroachment time, time gap, time headway, and initial deceleration rate (Caliendo and Guida, 2012). The following briefly describes these safety indicators (Saleem, 2012):

- Time To Collision (TTC): the expected time for two vehicles to collide if they remain at their present speed and direction

- Post Encroachment Time (PET): the time between when the first vehicle occupied a position and when the second vehicle arrived in the same position

- Time Gap: time interval between one vehicle passing and the next vehicle arriving

- Time Headway $(\mathrm{H})$ : time between the front of a vehicle passing a point and the front of a following vehicle passing the same point

- Initial Deceleration Rate (DR): the deceleration rate of a vehicle required to avoid a collision 
Once conflicts have been identified and classified, this surrogate for traffic crashes can be related to crash frequency, traffic volume, and intersection delay. The resulting models can be

used by safety analysts and practitioners to evaluate safety improvements. The study by Caliendo and Guida (2012) previously discussed is an example of this process. The motivation behind their study was to prove the potential of microscopic simulation models in assessing safety at two-way stop controlled intersections using conflicts as a surrogate safety measure. El-Basyouny and Sayed (2013) state that establishing the relationship between crashes and conflicts is important before applying traffic conflict techniques for safety improvements.

This thesis reinforces Caliendo and Guida's (2012) approach by utilizing conflicts as a surrogate safety measure. Additionally this thesis further explores the use of delay as a surrogate safety measures.

\subsection{Microscopic Simulation}

Many studies have demonstrated the feasibility of collecting conflict data through field observations, microscopic simulation models, and video cameras (El-Basyouny \& Sayed, 2013). Field observations may be the most practical option but can be expensive and may provide inconsistent results. Simulation models can account for the limitations of field observations but it may be difficult to simulate the less predictable driver behavior in real road traffic. Automated video camera methods can address the issues of both the field observations and simulation approaches however this method is still under development and not widely spread. This study utilizes the microscopic simulation method because it is more efficient than conducting field observations especially with a large number of intersections. This method has been successfully applied in many studies as well. Microscopic simulation is better suited for this study because it can be applied in situations where the impact of an improvement is evaluated before it is actually implemented. There is a variety of microscopic simulation programs available, some of which are: Vissim, SimTraffic, Paramics, and TSIS-CORSIM.

Sayed, Brown, and Navin (1994) developed a traffic conflicts computer simulation model for both three and four leg two-way stop controlled intersections. They studied traffic conflicts and the impact that driver and traffic parameters had on the occurrence of these conflicts. Some 
studies have focused solely on the accuracy of microscopic simulation by calibrating and validating these models. For example, Park and Schneeberger (2003) proposed a procedure for calibrating and validating a microscopic simulation model and then conducted a case study with actual traffic data. Park, Wan, and Yun (2006) adapted a previously developed simulation model calibration and validation procedure by applying it to an urban arterial network of 12 signalized intersections. Cunto and Saccomanno (2008) described a systematic procedure for calibrating and validating microscopic models of safety performance. In summary, microscopic simulation models have been used by many researchers to collect conflict data and, if this continues, these models will improve over time. 


\section{Summary of Software Used in this Study}

In order to conduct this study, five software packages were utilized extensively. The following briefly describes each of the software packages and their contributions to the study.

\subsection{Synchro}

Synchro is a program included in Synchro Studio which was developed by Trafficware. It can design, model, and optimize traffic signal infrastructure (Trafficware, 2013) and is a macroscopic analysis and optimization program (Husch \& Albeck, 2012). Some key features of this software are its ability to calculate capacity and delays as well as optimize cycle lengths, split times, offsets, and phase sequence in order to minimize driver stops and delay. Synchro implements the Intersection Capacity Utilization (ICU) 2003 method and the 2000 and 2010 Highway Capacity Manual (HCM) methods (Husch \& Albeck, 2012). Synchro is user-friendly and can make accurately modelling intersections simple. Synchro was utilized in this study to model intersection features such as the number of links, link offsets, lane configurations, intersection control type, turning movement count data, and pedestrian and cyclist data. Synchro provided the intersection delay data used in this study.

\subsection{SimTraffic}

SimTraffic is a program of the Synchro Studio software used in the study. SimTraffic utilizes the intersections modeled in Synchro and performs micro simulation and animation of vehicle traffic and pedestrians (Husch \& Albeck, 2012). This software can be used to simulate cars, trucks, buses, pedestrians, and cyclists on signalized and two-way stop controlled intersections, roundabouts, and freeway sections. SimTraffic provides a tool to visually observe the operation of an intersection. Both two and three dimensional recordings of the simulations can be created (Husch \& Albeck, 2012). In this study, SimTraffic provides visual representations of the simulations and most importantly trajectories of the vehicles, pedestrians, and cyclists. These trajectory files are used on the Surrogate Safety Assessment Model (SSAM) software to determine the amount of conflicts in the simulations. 


\subsection{Vissim}

Vissim is a program included in the Vision Traffic Suite software. Vissim is a microscopic, behaviour-based simulation tool for modeling traffic as well as pedestrian flows (PTV, 2013). This software includes the ability to import intersection models from Synchro making this an efficient program. Vissim realistically models traffic flows and intersection systems in order to conduct capacity analysis. Simulations are analyzed according to various traffic parameters such as: speed, queue length, travel time and delays (PTV, 2013). Vissim uses the psycho-physical perception model developed in 1974 by Wiedemann to simulate driver behaviour (PTV, 2013). In the study, Vissim provides visual representations of the simulations as well as trajectory files similar to those of SimTraffic. These Trajectory files were then imported into the Surrogate Safety Assessment Model (SSAM) software and the amount of conflicts in each simulation were determined.

\subsection{Surrogate Safety Assessment Model (SSAM)}

The Surrogate Safety Assessment Model (SSAM) software is designed to perform statistical analysis of vehicle trajectory data ( $\mathrm{Pu} \&$ Joshi, 2008). SSAM processes data describing trajectories of vehicles driving through a traffic facility such as a signalized or two-way stop controlled intersection (Gettman et al., 2008). SimTraffic and Vissim were used in this study to provide the vehicle trajectory input data that SSAM used to identify conflicts. The software calculates the surrogate measures of safety that corresponds to each vehicle-to-vehicle interaction and then determines whether or not these interactions are classified as conflicts (Gettman et al., 2008). When SSAM has finished determining the conflicts the results are presented in a table. The resulting conflicts can then be filtered according to the user's criteria in order to remove any irrelevant results. 


\subsection{SAS}

SAS is a software suite developed by SAS Institute for advanced analytics, business intelligence, data management, and predictive analytics. High performance analytics enable quick analysis of large amounts of data (SAS Institute, 2013). The results determined with Synchro, SimTraffic, Vissim, and SSAM were compiled and imported into SAS. The software was then used to create models of various relationships between certain results and determine the accuracy of these models. SAS is important in this study because it can analyze large amounts of data efficiently and accurately. 


\section{Data Summary}

Data are the foundation of this study. In order to yield accurate results, the utilized data should be as detailed as possible. The following describes the different types of data and their sources.

\subsection{Study Area}

This study consisted of 133 two-way stop controlled intersections within the Greater Toronto Area, Ontario. Intersections are located within the Toronto, Etobicoke, York, East York, North York, and Scarborough districts. The following is a figure illustrating the study area and the parts of Toronto where the intersections are located.

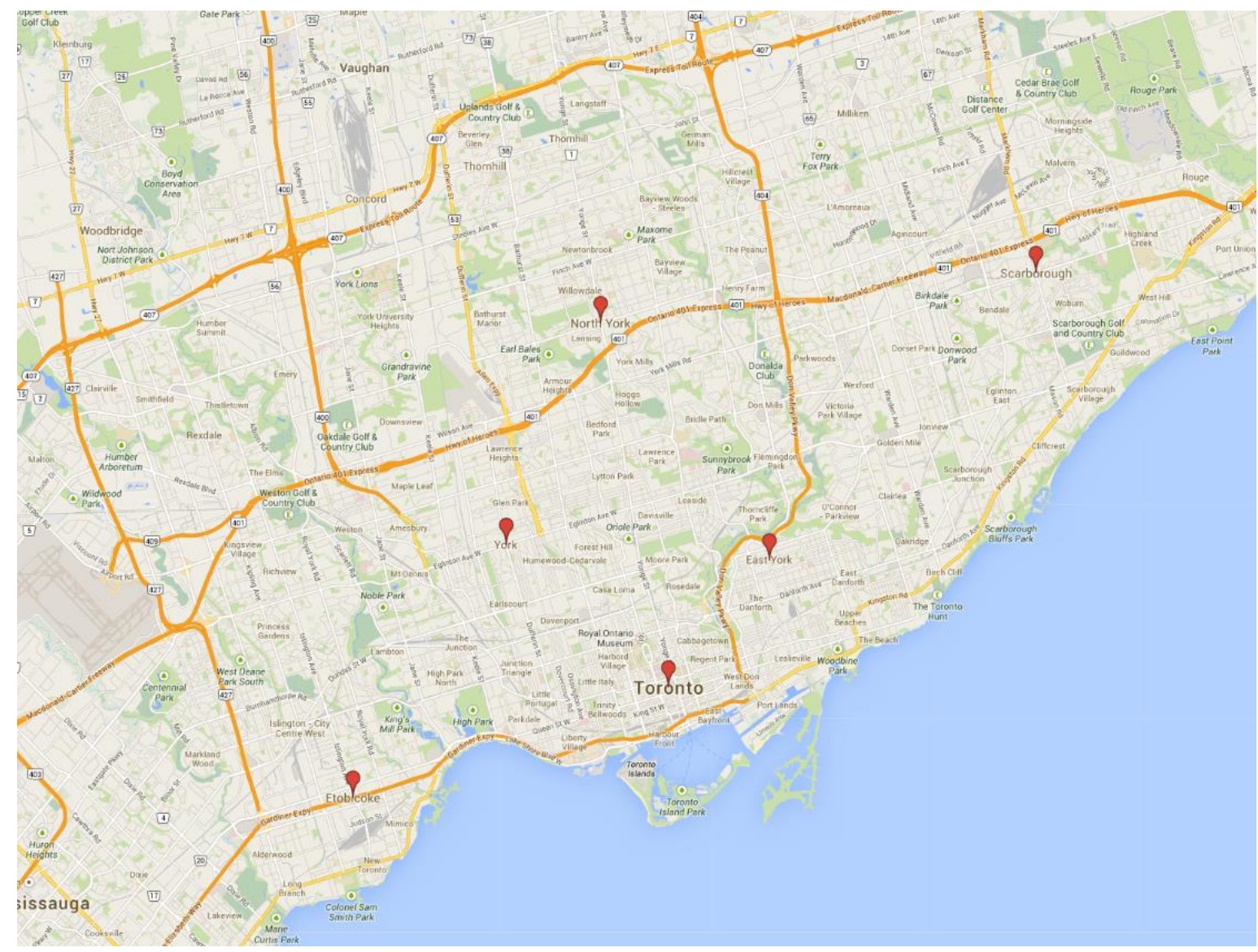

Figure 7: Study Area (Google Maps, 2014) 


\subsection{Intersection Characteristics}

There are many characteristics that an accurate intersection model requires. Characteristics can be categorized as node, link, or network characteristics. Node characteristics consist of the intersection control types such as: pre-timed, semi-actuated-uncoordinated, actuated-uncoordinated, actuated-coordinated, two-way stop controlled, and roundabouts (Husch \& Albeck, 2012). The following summarizes the link characteristics collected and included in the intersection models:

- Number of lanes at each approach as well as how many approaches

- Turning movements

- Dedicated turning lanes including their storage length and taper length

- Channelized turning lanes

- Lane widths, offsets, lengths, curvature, and speed limit

- Lane medians

The only network characteristic to be considered is whether there are any upstream signalized intersections. Due to the fact that this study's focus is on two-way stop controlled intersections, upstream signalized intersections will have an impact on the vehicle traffic configurations. The intersection characteristics were collected using Google Maps, Google Street View, and site visits and the intersections were modeled with Synchro.

This study includes a total of 133 two-way stop controlled intersections, of which 78 are three leg and 55 are four leg intersections. Figure 8 shows the locations of the intersections in the study area. Table 1 contains the street names of each intersection and whether they are three or four leg. 


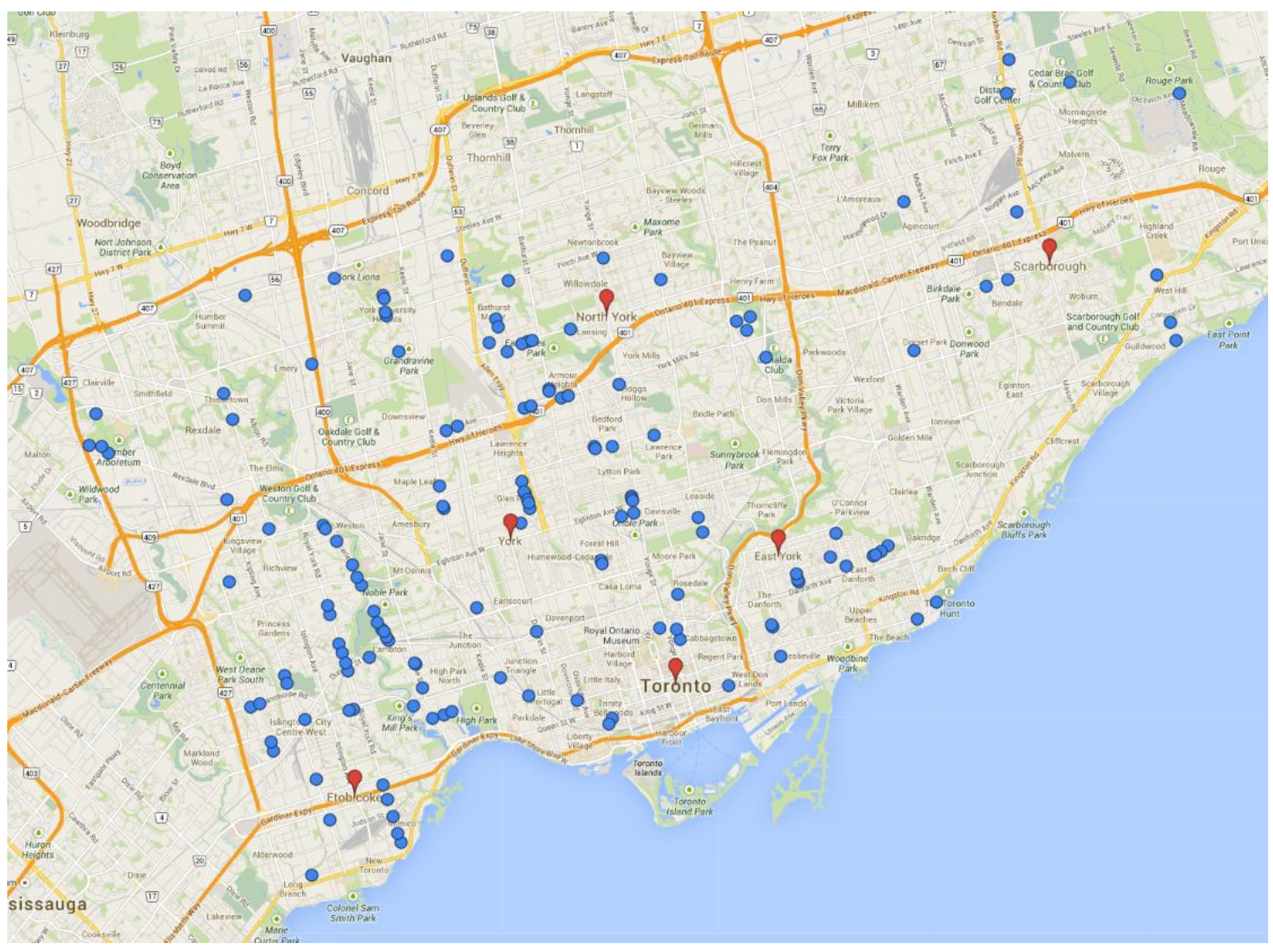

Figure 8: Two-way Stop Controlled Intersections (Google Maps, 2014) 
Table 1: Two-way Stop Controlled Intersection List

\begin{tabular}{|c|c|c|c|c|c|c|}
\hline \multirow{2}{*}{ \# } & \multicolumn{4}{|c|}{ Intersection } & \multirow{2}{*}{$\begin{array}{l}\text { \# of } \\
\text { Legs }\end{array}$} & \multirow{2}{*}{ Area } \\
\hline & Street Name 1 & Type 1 & Street Name 2 & Type 2 & & \\
\hline 1 & ACTON & AVEN & WILMINGTON & AVEN & 4 & NORTH YORK \\
\hline 2 & ALLARD & AVEN & WILSON & AVEN & 3 & NORTH YORK \\
\hline 3 & ALLINGHAM & GDNS & BATHURST & STREET & 3 & NORTH YORK \\
\hline 4 & ALNESS & STREET & DOLOMITE & DRIVE & 3 & NORTH YORK \\
\hline 5 & ANDERSON & AVEN & ORIOLE & PARK & 3 & TORONTO \\
\hline 6 & ANGLESEY & BOUL & ROYAL YORK & ROAD & 3 & ETOBICOKE \\
\hline 7 & APEX LANE & AVEN & WILSON AVE & AVEN & 3 & NORTH YORK \\
\hline 8 & ARROW & ROAD & DEERHIDE & CRES & 3 & NORTH YORK \\
\hline 9 & ASHLEY & ROAD & ROYAL YORK & ROAD & 3 & ETOBICOKE \\
\hline 10 & ASSINIBOINE & ROAD & SENTINEL & ROAD & 4 & NORTH YORK \\
\hline 11 & AVENUE & ROAD & DOUGLAS & AVEN & 4 & NORTH YORK \\
\hline 12 & AVENUE & ROAD & GLENGARRY & AVEN & 4 & NORTH YORK \\
\hline 13 & BARKER & AVEN & ISLINGTON & AVEN & 3 & ETOBICOKE \\
\hline 14 & BATHURST & STREET & DELHI & AVEN & 3 & NORTH YORK \\
\hline 15 & BAY & STREET & CUMBERLAND & STREET & 4 & TORONTO \\
\hline 16 & BAYVIEW & AVEN & DAVISVILLE & AVEN & 3 & EAST YORK \\
\hline 17 & BAYVIEW & AVEN & HILLCREST & AVEN & 3 & NORTH YORK \\
\hline 18 & BAYVIEW & AVEN & SUTHERLAND & DRIVE & 3 & EAST YORK \\
\hline 19 & BELGREEN & AVEN & HUNTINGWOOD & DRIVE & 4 & SCARBOROUGH \\
\hline 20 & BERNICE & CRES & SCARLETT & ROAD & 4 & YORK \\
\hline 21 & BIRCHMOUNT & ROAD & MERRYFIELD & DRIVE & 4 & SCARBOROUGH \\
\hline 22 & BLOOR & STREET & BRENTWOOD & ROAD & 4 & ETOBICOKE \\
\hline 23 & BLOOR & STREET & BRULE & TERR & 3 & ETOBICOKE \\
\hline 24 & BLOOR & STREET & COSMO & ROAD & 4 & YORK \\
\hline 25 & BLOOR & STREET & DORVAL & ROAD & 3 & ETOBICOKE \\
\hline 26 & BRAEBURN & AVEN & SCARLETT & ROAD & 4 & ETOBICOKE \\
\hline 27 & BRENTWOOD & AVEN & EASTON & ROAD & 4 & NORTH YORK \\
\hline 28 & BRYANT & AVEN & SHEPPARD & ROAD & 4 & NORTH YORK \\
\hline 29 & BURNHAMTHORPE & ROAD & LAUREL & AVEN & 3 & ETOBICOKE \\
\hline 30 & BURNHAMTHORPE & ROAD & SHAVER N & AVEN & 4 & ETOBICOKE \\
\hline 31 & BYWOOD & DRIVE & KIPLING & AVEN & 3 & ETOBICOKE \\
\hline 32 & CALLOWHILL & DRIVE & THE WESTWAY & ROAD & 3 & ETOBICOKE \\
\hline 33 & CARLAW & AVEN & COLGATE & AVEN & 3 & TORONTO \\
\hline 34 & CAVELL & AVEN & ROYAL YORK & ROAD & 4 & ETOBICOKE \\
\hline 35 & CHAMPLAIN & BOUL & WILSON & AVEN & 3 & NORTH YORK \\
\hline 36 & CHAPMAN & ROAD & SCARLETT & ROAD & 3 & ETOBICOKE \\
\hline 37 & $\mathrm{CHURCH}$ & STREET & GLOUCESTER & STREET & 4 & TORONTO \\
\hline 38 & $\mathrm{CHURCH}$ & STREET & HAYDEN & STREET & 4 & TORONTO \\
\hline 39 & CLAIRTON & CRES & SCARLETT & ROAD & 3 & YORK \\
\hline 40 & CLYDE & AVEN & WILSON & AVEN & 3 & NORTH YORK \\
\hline 41 & CODSELL & AVEN & WILSON HEIGHTS & BOUL & 4 & NORTH YORK \\
\hline 42 & COLBECK & STREET & JANE & STREET & 3 & ETOBICOKE \\
\hline 43 & COLVILLE & ROAD & KEELE & STREET & 3 & YORK \\
\hline 44 & COOK & ROAD & SENTINEL & ROAD & 4 & NORTH YORK \\
\hline 45 & COULSON & AVEN & SPADINA & ROAD & 3 & SCARBOROUGH \\
\hline 46 & COUNTRY CLUB & DRIVE & ROYAL YORK & ROAD & 3 & YORK \\
\hline 47 & CUMBER & AVEN & FORDOVER & AVEN & 4 & EAST YORK \\
\hline 48 & DALESFORD & ROAD & ROYAL YORK & STREET & 4 & ETOBICOKE \\
\hline 49 & DAWES & ROAD & GOODWOOD & PARK & 3 & EAST YORK \\
\hline 50 & DELAHAYE & STREET & WILSON & AVEN & 3 & NORTH YORK \\
\hline 51 & DELEMERE & AVEN & SCARLETT & ROAD & 3 & YORK \\
\hline 52 & DONMILLS & ROAD & KERN & ROAD & 4 & NORTH YORK \\
\hline 53 & DUFFERIN & STREET & GEARY & AVEN & 4 & YORK \\
\hline 54 & DUNBLOOR & ROAD & DUNDAS W & STREET & 3 & ETOBICOKE \\
\hline 55 & DUNCAN MILL & ROAD & LESMILL & ROAD & 3 & NORTH YORK \\
\hline 56 & DUNCAN MILL & ROAD & VALLEYBROOK & DRIVE & 3 & NORTH YORK \\
\hline 57 & DUNDAS & STREET & GROVE & AVEN & 3 & TORONTO \\
\hline 58 & DUNDAS & STREET & OLD DUNDAS & STREET & 3 & ETOBICOKE \\
\hline 59 & DUNDAS & STREET & STERLING & ROAD & 3 & TORONTO \\
\hline 60 & DUPLEX & AVEN & HELENDALE & AVEN & 4 & TORONTO \\
\hline 61 & EASTDALE & AVEN & SECORD & AVEN & 3 & EAST YORK \\
\hline 62 & EDINBOROUGH & CRES & SCARLETT & ROAD & 3 & YORK \\
\hline 63 & EILEEN & AVEN & SCARLETT & ROAD & 4 & YORK \\
\hline 64 & ELLESMERE & ROAD & GRANGEWAY & AVEN & 3 & SCARBOROUGH \\
\hline 65 & ELLESMERE & ROAD & PACKARD & BLVD & 3 & SCARBOROUGH \\
\hline 66 & FAYWOOD & BLVD & NORCROSS & ROAD & 3 & NORTH YORK \\
\hline 67 & FINCH & AVEN & GOLDFINCH & COUR & 4 & NORTH YORK \\
\hline
\end{tabular}

\begin{tabular}{|c|c|c|c|c|c|c|}
\hline \multirow{2}{*}{ \# } & \multicolumn{4}{|c|}{ Intersection } & \multirow{2}{*}{$\begin{array}{l}\text { \# of } \\
\text { Legs }\end{array}$} & \multirow{2}{*}{ Area } \\
\hline & Street Name 1 & Type 1 & Street Name 2 & Type 2 & & \\
\hline 68 & FOUNTAINHEAD & ROAD & SENTINEL & ROAD & 3 & NORTH YORK \\
\hline 69 & FOUR WINDS & DRIVE & SENTINEL & ROAD & 3 & NORTH YORK \\
\hline 70 & FOXWELL & STREET & SCARLETT & ROAD & 3 & YORK \\
\hline 71 & FONTENAY & CRES & SCARLETT & ROAD & 3 & ETOBICOKE \\
\hline 72 & GARDENTREE & STREET & MORNINGSIDE & AVEN & 4 & SCARBOROUGH \\
\hline 73 & GEORGE BUTCHAR & רRIVE & KEELE & STREET & 3 & YORK \\
\hline 74 & GLEBEHOLME & BOUL & GREENWOOD & AVEN & 4 & EAST YORK \\
\hline 75 & GLEBEMOUNT & AVEN & MORTIMER & AVEN & 3 & EAST YORK \\
\hline 76 & GLENGROVE & AVEN & MARLEE & AVEN & 4 & YORK \\
\hline 77 & GLEN PARK & AVEN & MARLEE & AVEN & 4 & YORK \\
\hline 78 & GOVERNMENT & ROAD & ROYAL YORK & ROAD & 3 & ETOBICOKE \\
\hline 79 & GRACEFIELD & AVEN & KEELE & STREET & 3 & YORK \\
\hline 80 & GREENWOOD & AVEN & MILVERTON & BLVD & 4 & EAST YORK \\
\hline 81 & GREENWOOD & AVEN & QUEENSDALE & AVEN & 3 & EAST YORK \\
\hline 82 & GREER & ROAD & LAWRENCE W & AVEN & 4 & NORTH YORK \\
\hline 83 & HANLEY & STREET & JANE & STREET & 3 & ETOBICOKE \\
\hline 84 & HARLOCK & AVEN & SHEPPARD & BOUL & 4 & NORTH YORK \\
\hline 85 & HILLMOUNT & AVEN & MARLEE & AVEN & 4 & YORK \\
\hline 86 & HILLSIDE & AVEN & ROYAL YORK & ROAD & 4 & ETOBICOKE \\
\hline 87 & HOVE & STREET & SHEPPARD & AVEN & 3 & NORTH YORK \\
\hline 88 & HULLMAR & DRIVE & JANE & STREET & 3 & NORTH YORK \\
\hline 89 & HULLRICK & DRIVE & HUMBERWOOD & BLVD & 3 & ETOBICOKE \\
\hline 90 & HUMBERWOOD & BLVD & KINGSPLATE & CRES & 4 & ETOBICOKE \\
\hline 91 & HUMBERWOOD & BLVD & VIEW GREEN & CRES & 4 & ETOBICOKE \\
\hline 92 & ISLINGTON & AVEN & KINGSVIEW & BOUL & 4 & ETOBICOKE \\
\hline 93 & ISLINGTON & AVEN & WARDLAW & CRES & 3 & ETOBICOKE \\
\hline 94 & JANE & STREET & ST MARKS & ROAD & 3 & ETOBICOKE \\
\hline 95 & JUTLAND & ROAD & KIPLING & AVEN & 3 & ETOBICOKE \\
\hline 96 & KENNARD & AVEN & WILMINGTON & AVEN & 3 & NORTH YORK \\
\hline 97 & KING & STREET & STANLEY & TERR & 4 & TORONTO \\
\hline 98 & KING & STREET & TRINITY & STREET & 3 & TORONTO \\
\hline 99 & KIPLING & AVEN & NAMCO & ROAD & 3 & ETOBICOKE \\
\hline 100 & KIPLING & AVEN & TORLAKE & CRES & 3 & ETOBICOKE \\
\hline 101 & KIPLING & AVEN & WINGROVE & HILL & 3 & ETOBICOKE \\
\hline 102 & LAMBETH & ROAD & ROYAL YORK & CRES & 3 & ETOBICOKE \\
\hline 103 & LAVINIA & AVEN & MORNINGSIDE & AVEN & 4 & ETOBICOKE \\
\hline 104 & LAWRENCE & AVEN & WANLESS & CRES & 4 & NORTH YORK \\
\hline 105 & LESMILL & ROAD & VALLEYBROOK & DRIVE & 3 & NORTH YORK \\
\hline 106 & LOCKHEED & BOUL & SCARLETT & ROAD & 4 & ETOBICOKE \\
\hline 107 & MARKHAM & ROAD & TURBINA & AVEN & 3 & SCARBOROUGH \\
\hline 108 & MARLEE & AVEN & STAYNER & AVEN & 4 & YORK \\
\hline 109 & MARLEE & AVEN & VIEWMOUNT & AVEN & 4 & YORK \\
\hline 110 & MARLEE & AVEN & WENDERLY & DRIVE & 3 & YORK \\
\hline 111 & MASSIE & STREET & SHEPPARD E & AVEN & 3 & SCARBOROUGH \\
\hline 112 & MCGLASHAN RD & ROAD & YONGE ST & STREET & 4 & NORTH YORK \\
\hline 113 & MELROSE & STREET & ROYAL YORK & ROAD & 4 & ETOBICOKE \\
\hline 114 & MILVERTON & BOUL & WOODBINE & AVEN & 4 & EAST YORK \\
\hline 115 & MORNINGSIDE & AVEN & RUNNYMEDE & ROAD & 3 & ETOBICOKE \\
\hline 116 & MORNINGSIDE & AVEN & SOUTH KINGSWAY & ROAD & 4 & ETOBICOKE \\
\hline 117 & MORNINGSIDE & AVEN & WARNSWORTH & STREET & 3 & SCARBOROUGH \\
\hline 118 & MOUNT PLEASANT & ROAD & ROXBOROUGH & DRIVE & 3 & EAST YORK \\
\hline 119 & MURRAY & ROAD & WILSON & AVEN & 4 & NORTH YORK \\
\hline 120 & NORTH & DRIVE & ROYAL YORK & ROAD & 3 & YORK \\
\hline 121 & OLD WESTON & ROAD & ROCKWELL & AVEN & 3 & YORK \\
\hline 122 & OLIVE & AVEN & DORIS & AVEN & 3 & NORTH YORK \\
\hline 123 & OVIDA & AVEN & SHAVER S & AVEN & 4 & ЕTOBICOKE \\
\hline 124 & PLAINS & ROAD & WOODBINE & AVEN & 3 & EAST YORK \\
\hline 125 & QUEEN & STREET & SILVER BIRCH & AVEN & 4 & EAST YORK \\
\hline 126 & RAYMORE & DRIVE & SCARLETT & ROAD & 3 & ETOBICOKE \\
\hline 127 & RICHVIEW & ROAD & SCARLETT & ROAD & 3 & ETOBICOKE \\
\hline 128 & ROSELAWN & AVEN & TIMES & ROAD & 4 & YORK \\
\hline 129 & ROYAL YORK & ROAD & SYMONS & STREET & 4 & ETOBICOKE \\
\hline 130 & SHAVER & AVEN & STATLER & AVEN & 4 & ETOBICOKE \\
\hline 131 & SPADINA & ROAD & THELMA & AVEN & 3 & SCARBOROUGH \\
\hline 132 & STEELES & AVEN & TAPSCOTT & ROAD & 3 & SCARBOROUGH \\
\hline 133 & STEELES & AVEN & TURBINE & DRIVE & 4 & ETOBICOKE \\
\hline
\end{tabular}




\subsection{Turning Movement Counts}

Turning movement count data were provided by the City of Toronto Traffic Safety Unit. For each intersection there is a turning movement count summary report. The street names at the intersection and survey date are identified on the report. The report provides the turning movement counts of cars, trucks, and buses for the following time periods: AM peak, PM peak, off hour average, two hour AM, two hour PM, and eight hour. For each of these time periods the total pedestrian and cyclists counts are provided. The report provides a total vehicle volume, total cyclist volume and total intersection volume for the eight hour period. These reports allow for realistic vehicle turning movements, pedestrian and cyclist counts, and heavy vehicle percentages in the intersection models. For the purpose of this study, the AM peak hour turning counts, pedestrian counts and cyclist counts as well as the total eight hour vehicle volumes were utilized in the Synchro models. The turning movement counts indicate that 16 intersections have major and minor road volumes that could potentially justify signalization according to Ministry of Transportation, Ontario (MTO) warrants requiring major and minor volumes greater than 720 and 170 respectively for each hour of the eight hours for signals to be considered (MTO, 2007).

Table 2: Classifications of Intersection Entering Volumes for 8 Hour Total and AM Peak

\begin{tabular}{|lcll|llll|}
\hline \multicolumn{7}{|l|}{ Two-way Stop Controlled Intersection Classification by Volume } \\
\hline 8 Hour Total & & \multicolumn{3}{l|}{ AM Peak } \\
From & To & \multicolumn{2}{|c|}{ Classification } & \multicolumn{2}{l|}{ From } & To & \multicolumn{2}{c|}{ Classification } \\
0 & 4000 & Very Low & 7 & 0 & 600 & Very Low & 7 \\
4001 & 8000 & Low & 33 & 601 & 1200 & Low & 33 \\
8001 & 12000 & Medium & 43 & 1201 & 1800 & Medium & 43 \\
12001 & 16000 & High & 30 & 1801 & 2400 & High & 30 \\
16001 & $\infty$ & Very High & 20 & 2401 & $\infty$ & Very High & 20 \\
\hline
\end{tabular}

Table 3: Intersection Statistics for 8 Hour Total and AM Peak Entering Volumes

\begin{tabular}{|lrr|}
\hline \multicolumn{3}{|c|}{ Volume Statistics } \\
\hline & 8Hour Total & AM Peak \\
Mean & 10815 & 1635 \\
Minimum & 2064 & 375 \\
Maximum & 23775 & 3802 \\
\hline
\end{tabular}




\subsection{Signal Timing}

Signal timing data were provided by the City of Toronto Traffic Safety Unit. Signal timing data were needed in order to accurately model the impact of upstream signalized intersections on two-way stop controlled intersections. The report provides the street names of the intersection and the issue date. Timings for the AM peak, PM peak, and off peak are included in the report. The signal timings include the green, yellow, and all red timings as well as the pedestrian walk times for both the East-West and North-South directions. Cycle lengths and offsets are provided for each intersection. The study utilized the AM peak signal timings in the Synchro models.

\subsection{Crash Data}

The crash data were provided by the City of Toronto Traffic Safety Unit. The crash data were required when modeling the traffic volume, intersection delay, and conflicts with crashes at the various intersections. There are 12 years of crash data from 1999 to 2010 applied in this study. The 12 years of data were necessary due to the small amount of crashes occurring at the two-way stop controlled intersections. The following is a list of some of the data available for each crash:

- $\quad$ Street names and types

- Day, time, and year of the crash

- Traffic control types

- Accident class

- Impact type

The crash data were filtered initially by traffic control types and then by street names. For each crash the accident class and impact type was determined. The crashes of each individual intersection were then totaled. Injury and property damage only are the crash classes included in the study. Fatal crashes were not included in the models as there were not a significant amount of occurrences. Impact types include: unclassified, approaching, angle, rear end, side swipe, and turning movement. The various types of crashes were summed to find the total crashes at each 
intersection. The following figure summarizes statistics related to the accident class and impact type data.

Table 4: Crash Data Statistics for Two-way Stop Controlled Intersections

\begin{tabular}{|lrrr|}
\hline & Minimum & Maximum & Average \\
\hline Total & 0 & 53 & 6.722 \\
Fatal & 0 & 1 & 0.015 \\
Pnjury & 0 & 18 & 2.248 \\
Unclassified & 0 & 36 & 4.459 \\
Approaching & 0 & 3 & 0.383 \\
Angle & 0 & 3 & 0.203 \\
Rear End & 0 & 32 & 2.466 \\
Side Swipe & 0 & 6 & 0.820 \\
Turning Movement & 0 & 3 & 0.406 \\
\hline
\end{tabular}

The crash data statistics assist in determining which accident crashes and impact types will yield significant results. The statistics for the fatal, injury, and property damage only crashes illustrates why fatal crashes were not included in this study. The average fatal crash count is 0.015 and the largest amount of fatal crashes at an intersection is only 1 . These statistics illustrate that there are not enough fatal crashes present in the crash data to develop effective models. Two-way stop controlled intersections usually have lower speed limits and traffic volumes than those of signalized intersections which would reduce the severity and frequency of crashes. 


\section{Methodology}

This section describes the steps taken in completing the intersection modeling, microscopic simulations, conflict estimation, and the development of crash prediction models.

\subsection{Modeling Intersections in Synchro}

Initially, data were collected and used to effectively model the geometric features and traffic volumes of the two-way stop controlled intersections. Synchro was selected to model the two-way stop controlled intersections. The modeling could have been completed with Vissim; however Synchro simplifies the process of modeling and inputting data.

\subsubsection{Collecting Two-Way Stop Controlled Stop Intersection Data}

Intersection geometric data were collected through Google Maps, Google Street View, and site visits. Google Maps and Google Street View provided an effective method in collecting geometric data. The required traffic data were provided by the City of Toronto Traffic Safety Unit. The following is a list of data entered in Synchro to model the two-way stop controlled intersections:

- Number of approaches at each intersection

- Traffic control type

- The intersection approaches that are stop controlled

- Lane configurations for each intersection approach

- Storage and taper lengths of turning lanes

- Channelized right turns and control type

- Posted speed limit

- Lane widths

- Median widths

- Peak hour traffic volume and the percent of heavy vehicles

- Peak hour pedestrian volumes

- Presence of upstream signalized intersections 
If a two-way stop controlled intersection has upstream signalized intersections, these signalized intersections must be modeled as well in order to capture their effects. Synchro includes an upstream filtering adjustment factor that accounts for the effect of an upstream signal on vehicle arrivals (Husch \& Albeck, 2012). The data required to model these intersections is similar with the addition of signal timings provided by the City of Toronto Traffic Safety Unit.

\subsubsection{Synchro Output}

Once all the data had been inputted into Synchro, the resulting model was be exported in a comma separated values (csv) file. This file was then used in SimTraffic and Vissim in order to import the two-way stop controlled intersection models. Synchro also yields intersection variables utilized in crash prediction model development such as average delay, total delay, delayed volume, and non-delayed volume. Figure 9 and Figure 10 display examples of Synchro intersection models. Avenue Road and Douglas Avenue is a four leg intersection. Islington Avenue and Kingsview Boulevard is a four leg intersection that includes an upstream signalized intersection at Dixon Road and Islington Avenue.

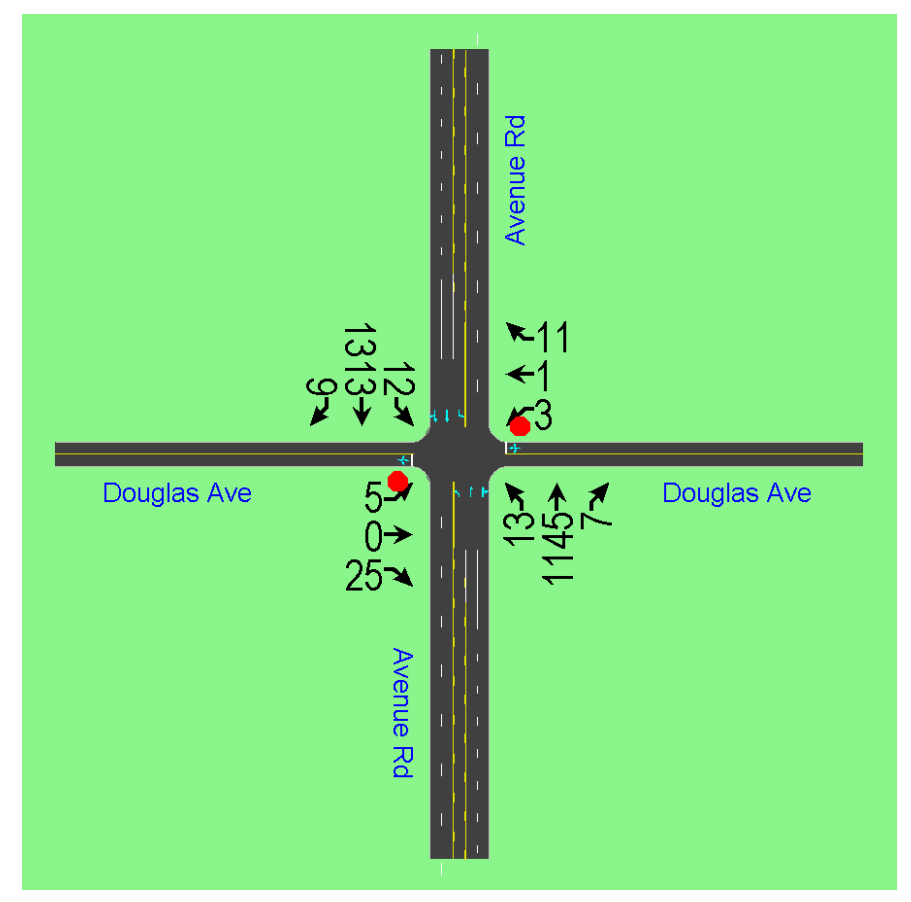

Figure 9: Avenue Road and Douglas Avenue Model 


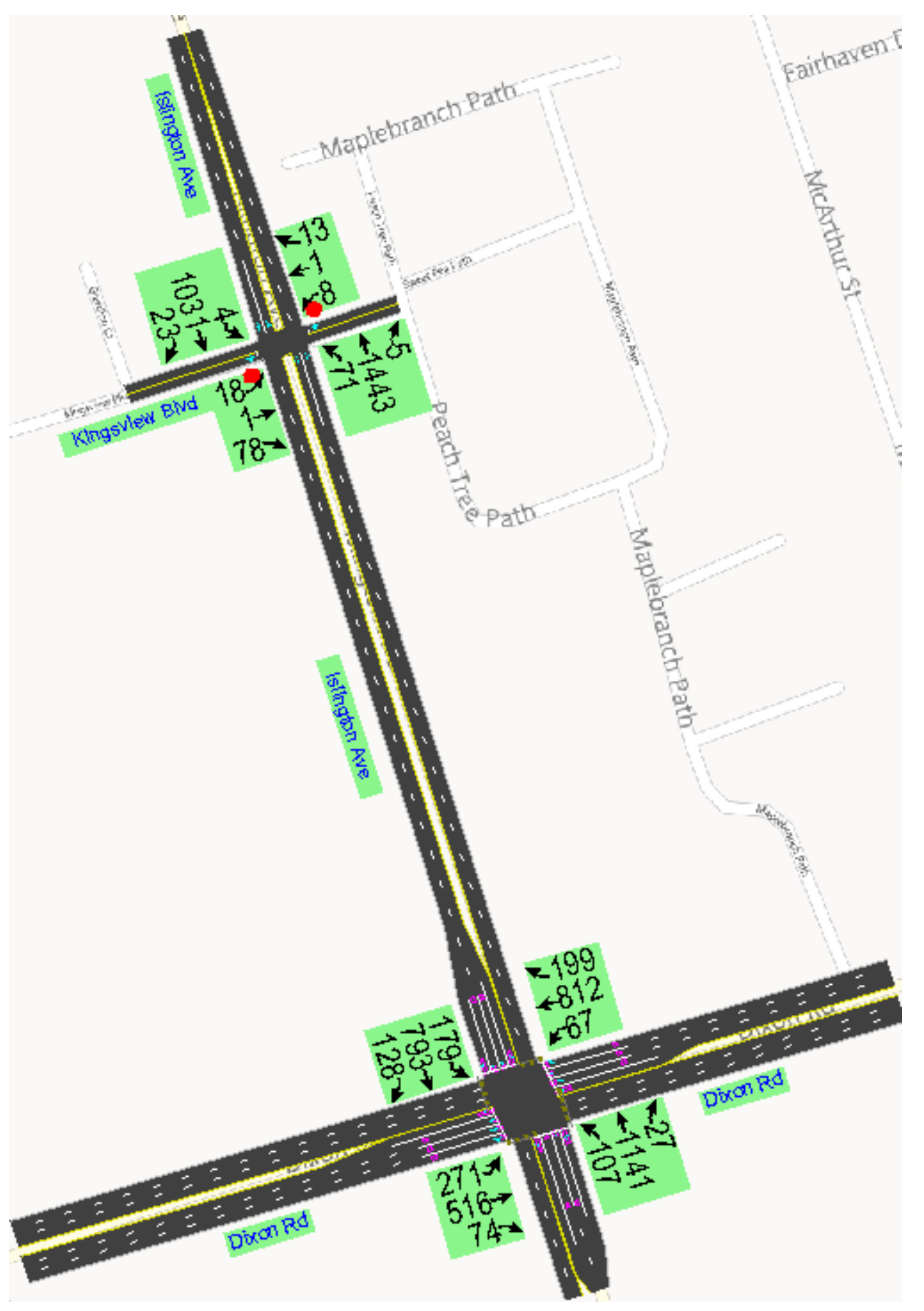

Figure 10: Islington Avenue and Kingsview Boulevard Model 


\subsection{Microscopic Simulation in SimTraffic}

The two-way stop controlled intersections modelled in Synchro were imported into SimTraffic in order to conduct the simulations to generate vehicle trajectories used to estimate conflicts.

\subsubsection{Model Calibration}

This study applies the default model provided by SimTraffic. The following will describe each of the components included in the SimTraffic model (Husch \& Albeck, 2012):

- Traffic Generation: Trips are added at the entry points based on the volume counts.

- Route Assignment: A turn or series of turns is assigned to each vehicle that is added onto a link.

- Car Following: Depending on how far ahead the leading vehicle is either fast following or slow following is applied.

- Speed Selection: Each vehicle has a cruise speed, acceleration rate depending on the vehicle type, and deceleration rate depending on the stopping situation.

- Lane Changes: Comprised of a mandatory distance from the stop bar where a lane change must commence and a positioning distance back from the mandatory point where a vehicle first attempts a lane change.

- Two-way Stop Controlled Intersection Operation: Includes crash avoidance logic, pedestrian vehicle interactions, vehicle approval systems, and stop and yield sign operation.

Approach lengths were assumed to be 250 meters in the simulations. Although this may not be the case for all of the two-way stop controlled intersections analyzed, only conflicts within 50 meters of each approach are considered. This ensured that conflict results were representative of crashes counted towards the intersections. 


\subsubsection{Simulations}

Simulations were conducted and the following summarizes some of the simulation inputs applied at each two-way stop controlled intersection (Husch \& Albeck, 2012):

- Simulation duration of 60 minutes representing the peak hour.

- Seeding time was set to three minutes to ensure the intersection contained traffic when simulation recording began.

- Number of simulation runs was set to 10 .

- Simulation resolution, which determines how frequently vehicle positions are recalculated, is set to 0.5 seconds by default.

- Random seed, which initializes a random number generator that affects variations in vehicle arrivals, was set to 10 .

A visual inspection was conducted during the simulations to ensure the traffic behavior was being modelled correctly. Figure 11 is a 3D image of a SimTraffic simulation of the twoway stop controlled intersection at Lawrence Avenue East and Wanless Crescent.

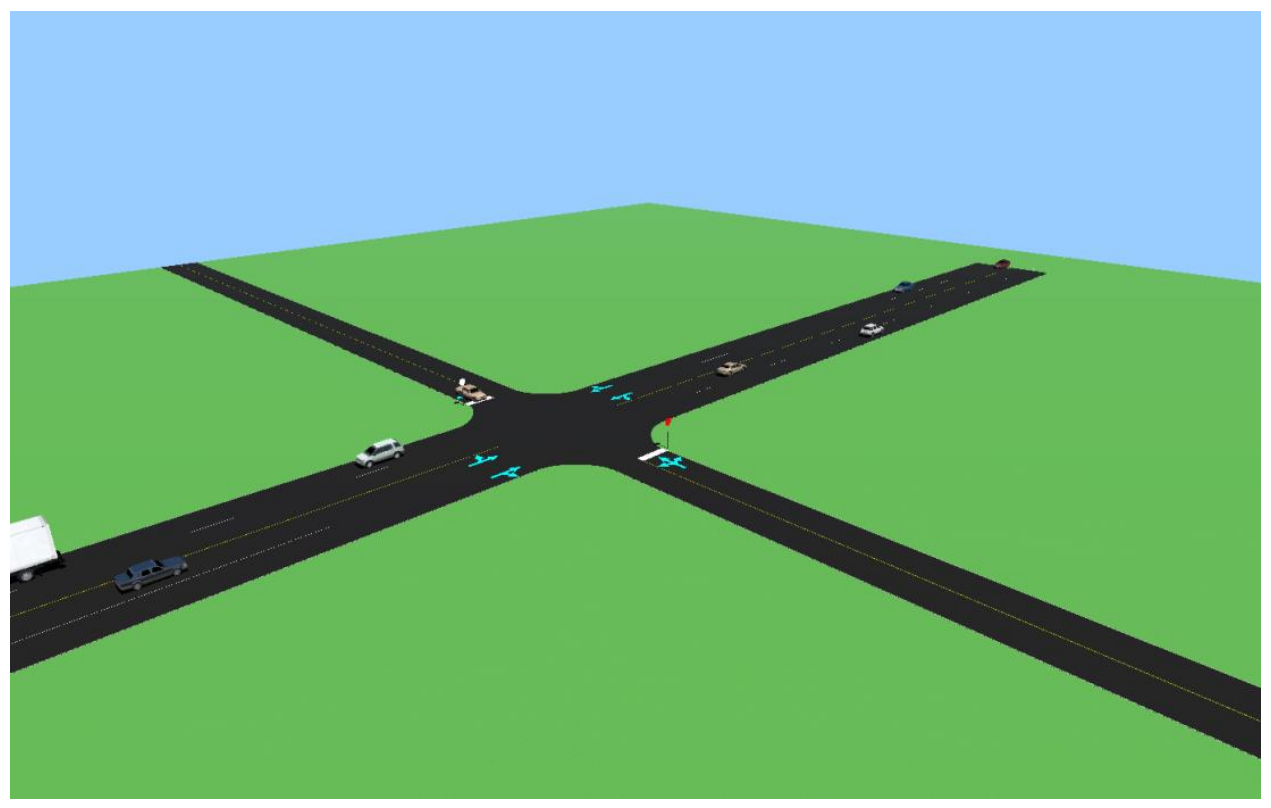

Figure 11: SimTraffic Simulation at Lawrence Avenue East and Wanless Crescent 


\subsubsection{SimTraffic Output}

SimTraffic includes an option to export the results as a SSAM file. This function provides trajectory files for each simulation. The trajectory files were inputted into SSAM to identify and classify the conflicts.

\subsection{Microscopic Simulation in Vissim}

The two-way stop controlled intersections modelled with Synchro were exported as a csv file. This file was then imported into Vissim so that the simulations could be conducted.

\subsubsection{Model Calibration}

This study applied one of the default models provided by Vissim. The preset values are the model calibration results from the Wiedemann 99 Car-Following model for right side motorized rule traffic behavior (Menneni, Sun \& Vortisch, 2009). Many studies have examined and identified the most important Wiedemann 99 variables. Cunto and Saccomanno (2008) studied fifteen inputs required in Vissim's car-following model, ten inputs for the lane change model, and eight driver behaviour inputs. They narrowed this set of variables down to the following parameters: desired deceleration, standstill distance, and headway time (Cunto \& Saccomanno, 2008). Kim, Kim, and Rilett (2005) conducted a study on the driver behaviour parameters included in Vissim. They focused on the following parameters: number of observed preceding vehicles, forward perception distance, average standstill distance, desired safety distance, and lane change distance (Kim, Kim \& Rilett, 2005).

In the simulations, the approach lengths were assumed to be 250 meters. The approach lengths vary at each intersection and a value of 250 meters is an accurate representation. Only conflicts within a 50 meter radius of the intersection are considered to ensure that conflict results are representative of crashes counted towards the intersections. Also, including conflicts within a 50 meter radius of the intersection will remove any errors due to the approach lengths. 


\subsubsection{Simulations}

Simulations were conducted for each two-way stop controlled intersection and the following summarizes some of the simulation settings applied (PTV, 2013):

- Simulation duration of 3600 seconds representing the peak hour.

- Number of simulation runs was set to 10 .

- Simulation resolution, which determines how frequently vehicle positions are recalculated within a simulation second, was set to 10 .

- Random seed, which initializes a random number generator that affects variations in vehicle arrivals, was set to 10 .

- Random seed increment, which determines the difference between random seeds when you perform multiple simulation runs, was set to 10 .

- Simulation speed was set to maximum as it only influences how quickly the visualization is run but the simulation results are unaffected.

The simulations were observed in order to ensure the traffic behavior was being modelled correctly. Figure 12 is a 3D image of the two-way stop controlled intersection at Lawrence Avenue East and Wanless Crescent during a Vissim simulation.

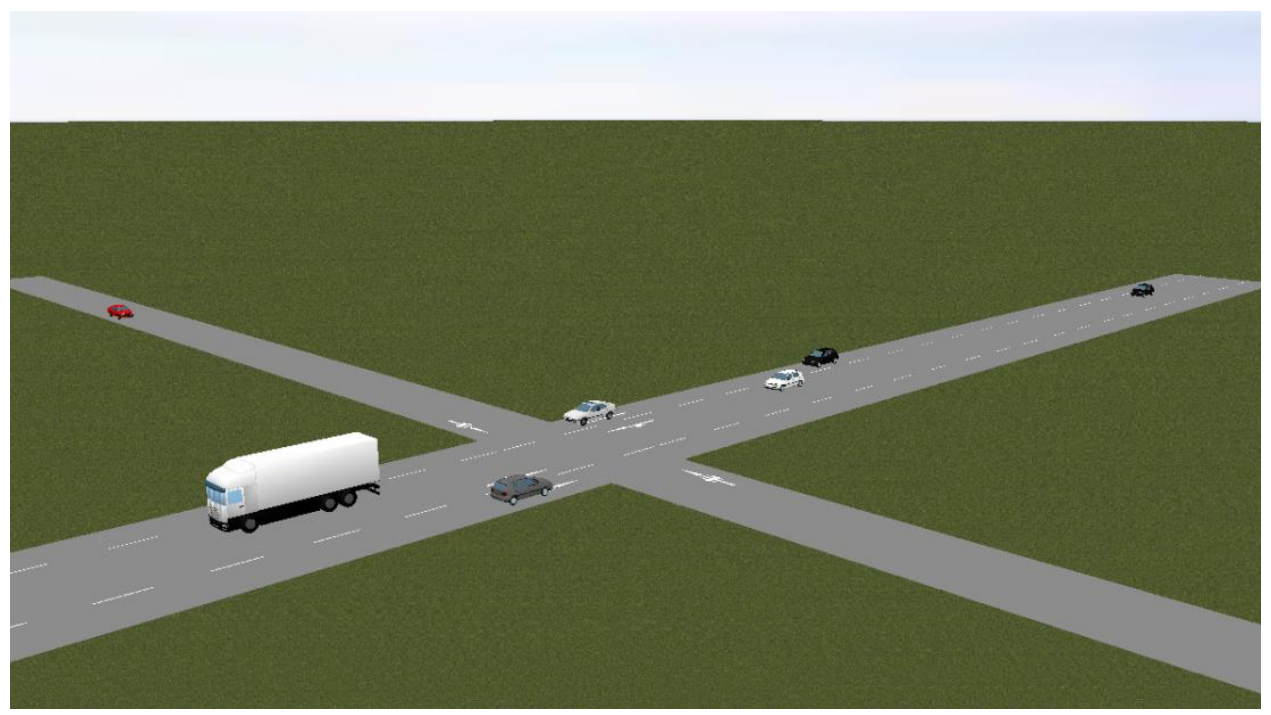

Figure 12: Vissim Simulation at Lawrence Avenue East and Wanless Crescent 


\subsubsection{Vissim Output}

The results of the simulations were in the form of trajectory files. These trajectory files are required by SSAM in order to analyze the vehicle movements to identify and classify the conflicts.

\subsection{Conflict Estimation in SSAM}

The trajectory files from both SimTraffic and Vissim can be imported into SSAM in order to find conflict data at each two-way stop controlled intersection.

\subsubsection{SSAM Analysis of Simulation Trajectories}

The trajectory files generated by SimTraffic and Vissim for the 10 simulations at each two-way stop controlled intersection were analyzed using SSAM. The analysis results of SSAM provided the conflicts for each simulation file as well as an overall total. The conflicts used in the crash prediction models are the average result of the 10 simulations.

\subsubsection{Classification of Conflicts}

Conflicts identified by SSAM are classified into four categories (Pu \& Joshi, 2008): crossing, rear-end, lane-change, and unclassified. Classification of conflicts is based on the conflict angle calculated for each pair of conflicting vehicles ( $\mathrm{Pu} \&$ Joshi, 2008). The following list and Figure 13 illustrate the criteria applied in classifying the conflicts by conflict angle.

- Crossing - conflict angle greater than 85 degrees

- Rear-end - conflict angle less than 30 degrees

- Lane-change - conflict angle between 30 degrees and 85 degrees

- Unclassified - unknown conflict angle 

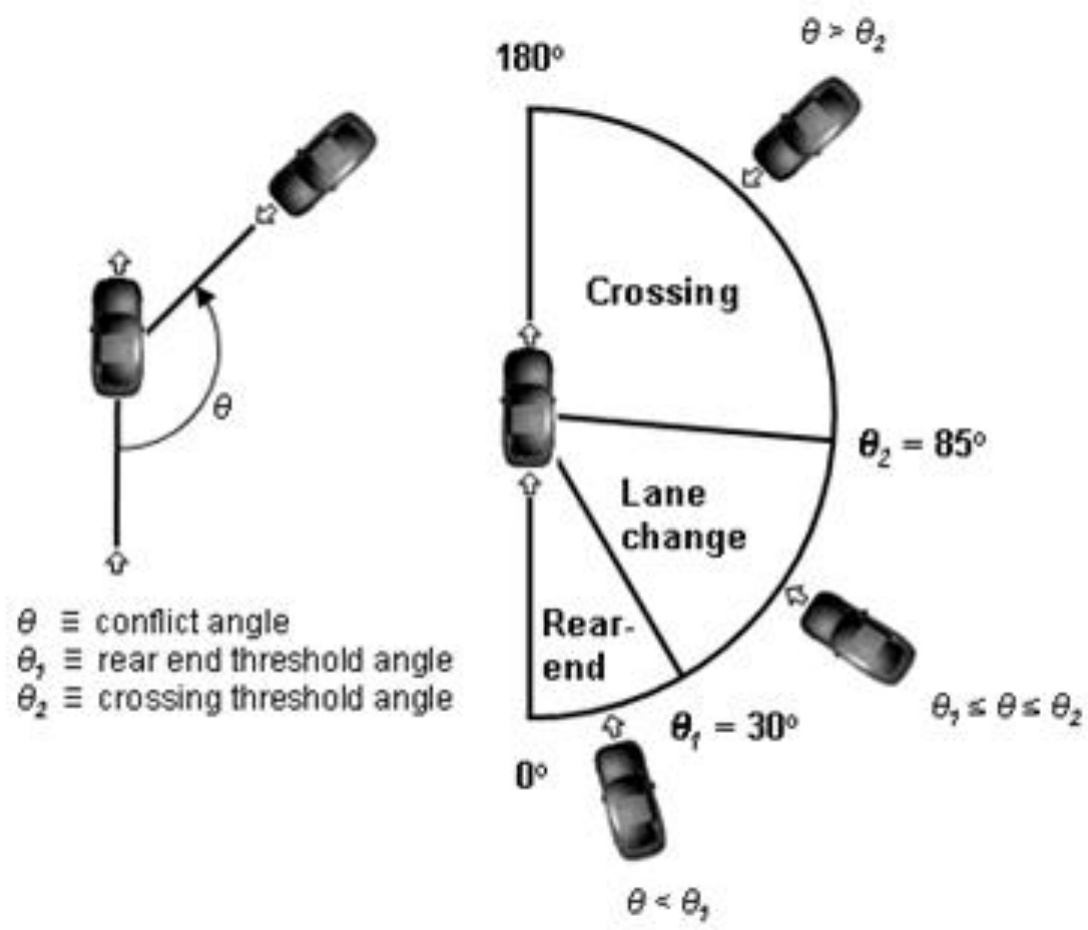

Figure 13: Conflict Angle Diagram (Gettman et al., 2008)

\subsubsection{Filtering SSAM Results}

Once the SSAM analysis was complete, the conflict results were filtered in order to remove any errors. The data can be filtered by surrogate thresholds, conflict types, approaches, trajectory files, and area.

The first conflict filter applied was surrogate threshold filters on the time to crash (TTC) and the post encroachment time (PET). Any conflicts with zero values of TTC and PET were removed as these conflicts are caused by errors in the simulation. The last conflict filter applied was related to the area. Any conflicts outside of a 50 meter radius of the intersection were removed. By only including the conflicts within the 50 meter radius we can ensure they are located at the intersection and not the approach. Similarly crashes on the intersection approaches would be recorded for that road segment instead of the nearest intersection. 


\subsection{Crash Prediction Modeling}

Traditionally, conventional linear regression modeling and generalized linear regression modeling (GLM) approaches have been used in developing crash prediction models. However, developing crash prediction models has recently strictly used generalized linear regression modeling. Studies such as Jovanis and Chang (1986), Hauer, Ng, and Lovell (1988), and Miaou and Lum (1993) have demonstrated that conventional linear regression is not adequate in modeling crashes because they are discrete, non-negative, and rare events. The generalized linear regression modeling approach overcomes the limitations of conventional linear regression. GLM allows a Poisson or Negative Binomial error structure. Many studies have identified crash data as being over-dispersed with a variance that is larger than the mean (Lord \& Park, 2008; Hauer, 2001). When data is over-dispersed a Poisson distribution may lead to inaccurate results as it requires the mean and variance to be equal. However, a Negative Binomial distribution can overcome issues due to over-dispersion as it does not require the variance and mean to be equal (Mitra \& Washington, 2007).

Similarly to Persaud, Saleem, Lyon, and Chen (2012), Caliendo and Guida (2012), and D’Agostino (2014), this study applied a generalized linear regression modelling approach with the specification of a negative binomial error structure in developing the crash prediction models. These crash prediction models can contain a variety of variables such as:

- Conflicts - Number of conflicts: total, crossing, lane-change, rear-end, and unclassified

- Average Delay - Average delay per vehicle

- Total Delay - Total delay of all vehicles

- Entering AADT - Total entering average annual daily traffic

- Major and Minor AADT - Total average annual daily traffic on the major and minor approaches

- Entering AM Peak Volume

- Major and Minor AM Peak Volume

- Geometric Features - the presence of features such as turning lanes 
The following is the general crash prediction model form (Persaud et al., 2012):

Crashes $=e^{\alpha} *$ Variable $1^{\beta_{1}} *$ Variable $2^{\beta_{2}} * \ldots *$ Years

(Equation 1)

Where;

$\alpha=$ Intercept estimate

Variable1, Variable2, etc $=$ Explanatory variables selected

$\beta_{1}, \beta_{2}$, etc $=$ Coefficient estimates for the selected explanatory variables

Years $=$ Number of years of crash data

Many models were developed to relate crashes to conflicts, average annual daily traffic, and delay. These models include:

- Crash - Entering AADT or Major and Minor AADT

- Crash - Entering AM Peak Volume or Major and Minor AM Peak Volume

- Crash - Total Delay

- Crash - Movement Delay

- Crash - Conflict

Once the models were developed, their goodness of prediction was evaluated. Goodness of prediction measures applied in this study include:

- Plots of cumulative residuals (difference between observed and predicted crash frequency) against each variable in the model (CURE plots)

- Mean prediction bias (MPB) - The square root of the sum of squared differences between observed and predicted crash frequency divided by the sample size

- Mean absolute deviation (MAD) - The absolute value of the total difference between observed and predicted crash frequency divided by the sample size

- Mean squared error (MSE) - The sum of squared differences between observed and predicted crash frequency divided by the sample size minus the number of model variables 
- Mean squared prediction error (MSPE) - The sum of squared differences between observed and predicted crash frequency divided by the sample size

- Over-dispersion parameter (k) - A smaller over-dispersion parameter value identifies a model that better captures the over-dispersion in the data. Crash data tends to be overdispersed, thus a GLM with a Negative Binomial error structure is applied.

The use of a cumulative residuals (CURE) method is very important in this study. This method plots the difference between the number of observed and predicted accidents for each site (Hauer \& Bamfo, 1997). The CURE plot includes the cumulative residuals in increasing order and the 95\% confidence limits. If the model contains no bias, the CURE plot will oscillate without systematic over and under prediction and not exceed the confidence limits (Hauer \& Bamfo, 1997). The CURE plot illustrates the goodness of fit of the model in terms of each individual covariate. Figure 14 is an example of a CURE plot for a model with no model prediction biases.

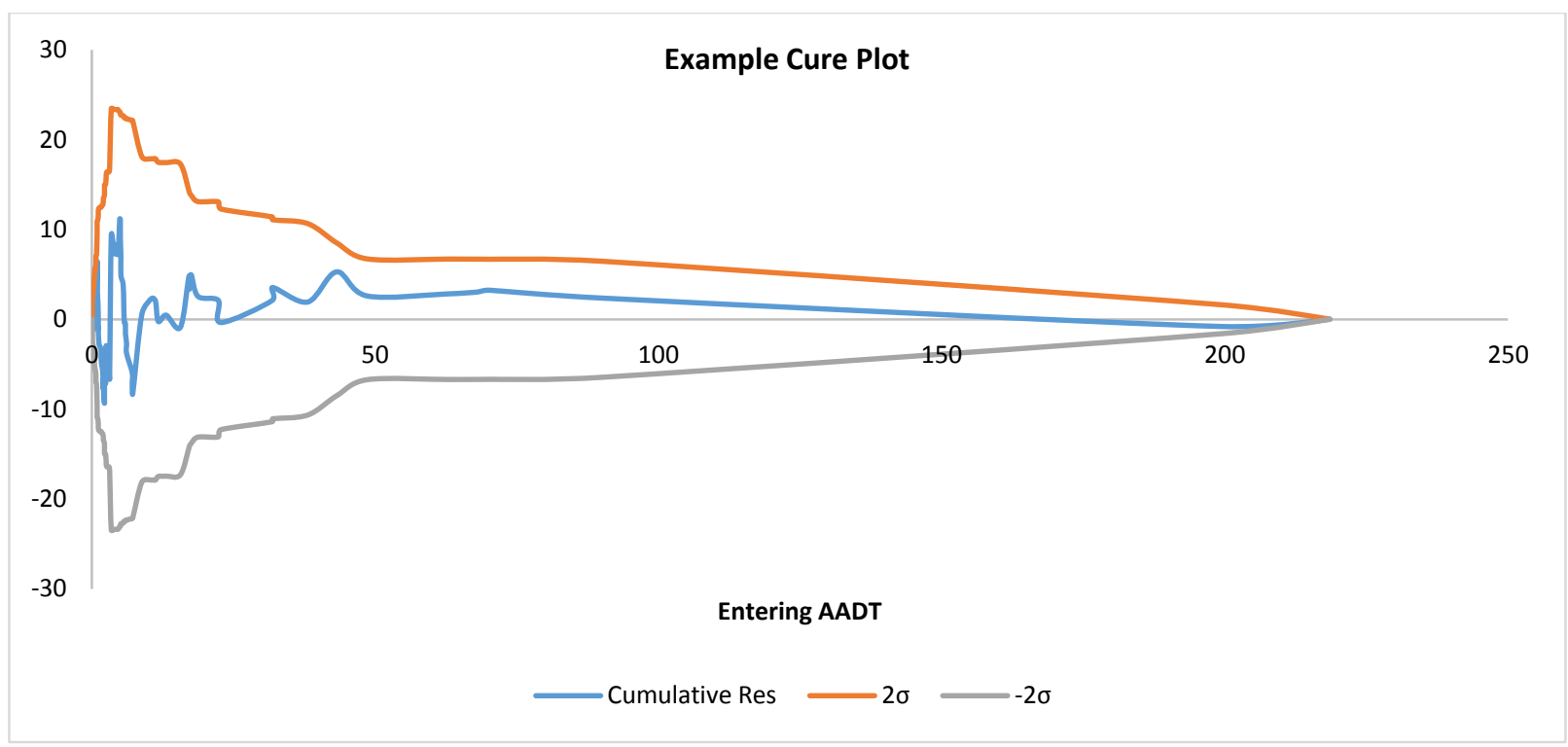

Figure 14: Example Cure Plot 


\section{Conflict Simulation Techniques}

\subsection{Conflict Simulation Results}

As previously discussed, simulation results from both SimTraffic and Vissim were imported into SSAM and the resulting conflicts were identified. Tables 5 and 6 provide statistics of estimated conflicts for both SimTraffic and Vissim respectively. Figure 14 illustrates the conflict distribution of both SimTraffic and Vissim.

Table 5: SimTraffic Estimated Conflict Summary Statistics

\begin{tabular}{|lrrrr|}
\hline \multicolumn{5}{c}{ SimTraffic Conflict Estimation Statistics } \\
\hline & Minimum & Maximum & Mean & Percentage \\
Total & 0.0 & 145.0 & 15.7 & $100.00 \%$ \\
Crossing & 0.0 & 0.6 & 0.0 & $0.13 \%$ \\
Rear End & 0.0 & 144.3 & 14.3 & $90.55 \%$ \\
Lane Change & 0.0 & 18.7 & 1.5 & $9.32 \%$ \\
\hline
\end{tabular}

Table 6: Vissim Estimated Conflict Summary Statistics

\begin{tabular}{|lrrrr|}
\hline \multicolumn{5}{c}{ Vissim Conflict Estimation Statistics } \\
\hline & Minimum & Maximum & Mean & Percentage \\
Total & 0.0 & 458.5 & 20.6 & $100.00 \%$ \\
Crossing & 0.0 & 5.3 & 0.5 & $2.64 \%$ \\
Rear End & 0.0 & 429.7 & 18.1 & $87.86 \%$ \\
Lane Change & 0.0 & 27.7 & 2.0 & $9.51 \%$ \\
\hline
\end{tabular}

The mean values for each conflict type are slightly larger for Vissim than for SimTraffic (Tables 5 and 6). Overall the simulation results show that Vissim estimates on average more conflicts than SimTraffic. A contributing factor to these differences in conflict estimation is the different approaches used by the software to model traffic and driver behaviour. The simulation results will differ between SimTraffic and Vissim because their simulation approaches are different. 
Figure 15 compares the conflict distributions of the two conflict sets. For both conflict sets, the distributions are similar with rear-end conflicts having the highest percentage and crossing and lane-change having very small percentages.

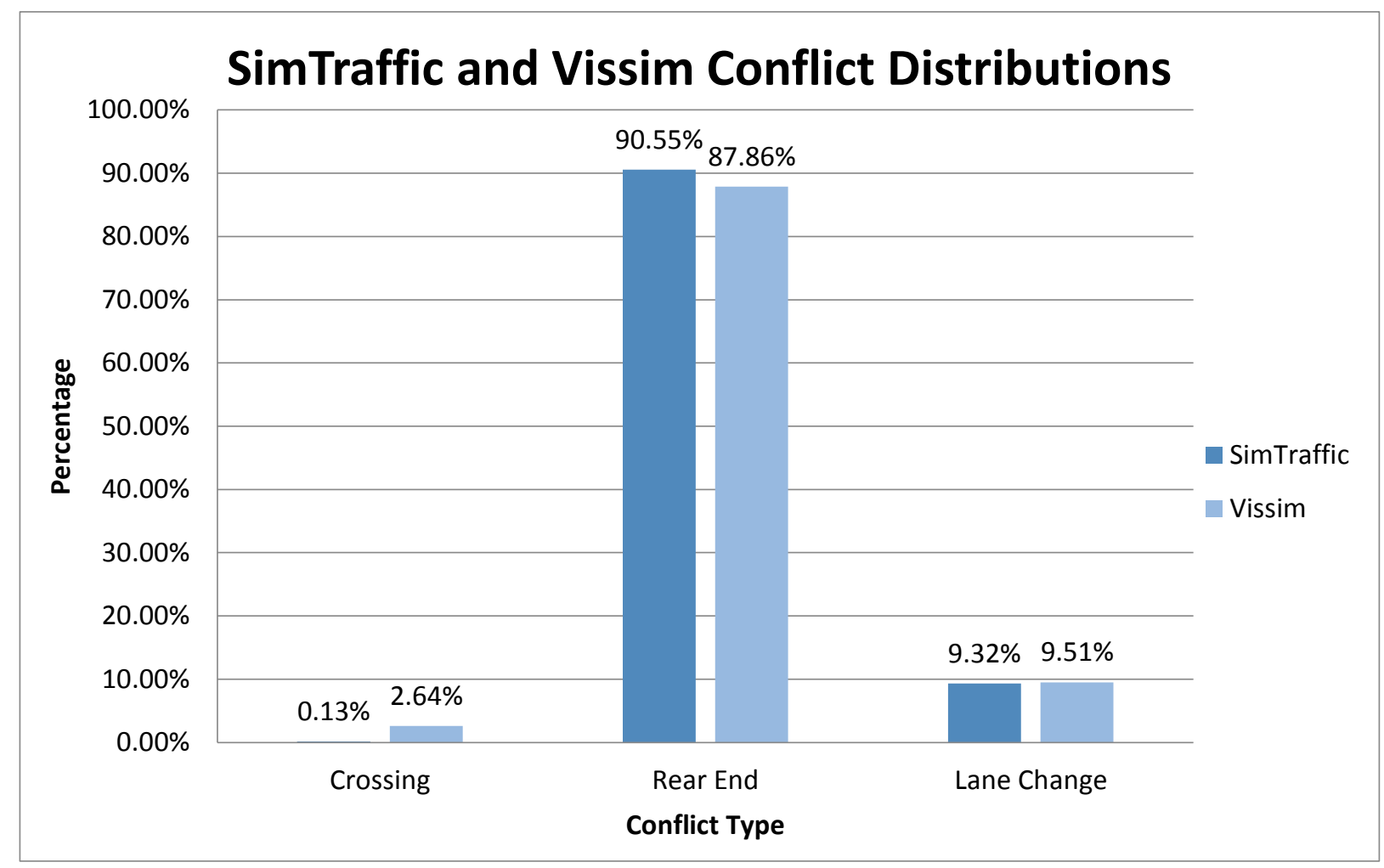

Figure 15: SimTraffic and Vissim Conflict Distributions

Two factors can explain why the amount of rear-end conflicts is much larger than crossing and lane-change. The first factor that contributes to the high estimates of rear-end conflicts is the method in which SSAM estimates conflicts. Figure 8 shows the conflict angle diagram used in SSAM to estimate conflicts. Conflicts with less than 30 degrees are classified as rear-end and conflicts between 30 and 85 degrees are classified as lane-change conflicts. Rearend conflicts do occur at smaller angles however, by using 30 degrees as the maximum angle some lane-change conflicts may be classified as rear-end (Saleem, 2012). The second factor which contributes to the high estimates of rear-end conflicts is the area used to identify intersection conflicts. The simulations were conducted for a 250 meter radius of the intersections 
and conflicts were identified only within a 50 meter radius of the intersection. Using conflicts within a 50 meter radius is necessary in order to be consistent with the method of assigning crashes to intersections however, within the included area very few vehicles will conduct lane changes (Saleem, 2012). Possible improvements to the conflict estimation process is altering the classification criteria which may then increase the amount of conflicts categorized as lanechange instead of rear-end. This study does not apply this possible improvement as there is no solid evidence to support a change in classification angles and there is no effective method of determining the optimum angles to apply.

\subsection{Conflict Estimation Technique Comparison}

When simulating traffic flow at the two-way stop controlled intersections, two programs were applied in order to compare their effectiveness in estimating conflicts. Simulations were conducted with each of the software packages. The following table summarizes the inputs used when initiating the traffic simulations.

Table 7: Traffic Simulation Inputs of SimTraffic and Vissim.

\begin{tabular}{|c|c|c|c|}
\hline Input & Description & SimTraffic & Vissim \\
\hline $\begin{array}{l}\text { Simulation } \\
\text { Duration }\end{array}$ & The amount of time the simulation represents & 60 minutes & 60 minutes \\
\hline $\begin{array}{l}\text { Number of } \\
\text { Simulations }\end{array}$ & $\begin{array}{l}\text { The amount of simulations conducted at each } \\
\text { intersection }\end{array}$ & 10 & 10 \\
\hline Seeding Time & $\begin{array}{l}\text { Initial simulation time before simulation } \\
\text { recording }\end{array}$ & 3 minutes & $\begin{array}{l}\text { Not } \\
\text { Applicable }\end{array}$ \\
\hline $\begin{array}{l}\text { Simulation } \\
\text { Resolution }\end{array}$ & How frequently vehicle positions are recalculated & $\begin{array}{l}0.5 \text { seconds } \\
\text { (fixed) }\end{array}$ & 0.1 seconds \\
\hline Random Seed & $\begin{array}{l}\text { Initializes a random number generator that } \\
\text { influences vehicle arrival variation }\end{array}$ & 10 & 10 \\
\hline $\begin{array}{l}\text { Random Seed } \\
\text { Increment }\end{array}$ & $\begin{array}{l}\text { Determines the difference between random seeds } \\
\text { when multiple simulation are conducted }\end{array}$ & $\begin{array}{l}\text { Not } \\
\text { Applicable }\end{array}$ & 10 \\
\hline
\end{tabular}


Initial crash prediction models were developed and evaluated in order to determine which software provided more accurate conflict results for the two-way stop controlled intersections. The models relate Total, Injury, and PDO crashes with Total, Crossing, Rear-end, and Lanechange conflicts (explanatory variable). The results of the coefficient estimates conducted with SAS provide an indication of the conflict estimation abilities of SimTraffic and Vissim. By analyzing the p-value results of each model, the significance of a coefficient estimate can be determined. The p-value results were compared between SimTraffic and Vissim in order to determine the more accurate model and overall the more effective conflict estimation method. Tables 8, 9, and 10 summarize the coefficient estimates as well as the dispersion parameters (K) and significance (p-value) for the SimTraffic and Vissim models. Table 11 illustrates which conflict estimation technique was more effective for each crash conflict model.

Crashes $=e^{\alpha} *$ Variable $^{\beta_{1}} *$ Variable $2^{\beta_{2}} * \ldots *$ Years (Equation 1) Where;
$\alpha=$ Intercept estimate
Variable1, Variable2, etc $=$ Explanatory variables selected
$\beta_{1}, \beta_{2}$, etc $=$ Coefficient estimates for the selected explanatory variables
Years $=$ Number of years of crash data 
Table 8: SimTraffic and Vissim Total Crash Conflict Models

\begin{tabular}{|c|c|c|c|c|c|c|}
\hline \multirow{2}{*}{$\begin{array}{l}\text { Crash } \\
\text { Type }\end{array}$} & \multirow{2}{*}{$\begin{array}{l}\text { Conflict } \\
\text { Type }\end{array}$} & \multirow[t]{2}{*}{ Coefficients } & \multicolumn{2}{|c|}{ SimTraffic } & \multicolumn{2}{|c|}{ Vissim } \\
\hline & & & Estimates & $\mathrm{Pr}>\mathrm{ChiSq}$ & Estimates & $\mathrm{Pr}>\mathrm{ChiSq}$ \\
\hline \multirow[t]{3}{*}{ Total } & Total & $\alpha$ & -0.5758 & $<0.0001$ & -0.8910 & $<0.0001$ \\
\hline & & $\beta 1$ & -0.0245 & 0.6425 & 0.1805 & 0.0012 \\
\hline & & $\mathrm{K}$ & 1.0015 & & 0.8946 & \\
\hline \multirow[t]{3}{*}{ Total } & Crossing & $\alpha$ & -0.8978 & 0.1951 & -0.3995 & 0.0020 \\
\hline & & $\beta 1$ & -0.2675 & 0.4394 & 0.2014 & 0.0464 \\
\hline & & K & 0.3389 & & 0.8830 & \\
\hline \multirow[t]{3}{*}{ Total } & Rear-end & $\alpha$ & -0.6238 & $<0.0001$ & -0.7438 & $<0.0001$ \\
\hline & & $\beta 1$ & -0.0190 & 0.7103 & 0.1425 & 0.0033 \\
\hline & & K & 1.0157 & & 0.8814 & \\
\hline \multirow[t]{3}{*}{ Total } & Lane-change & $\alpha$ & -0.5654 & $<0.0001$ & -0.5252 & $<0.0001$ \\
\hline & & $\beta 1$ & 0.0974 & 0.1811 & 0.1486 & 0.0316 \\
\hline & & $\mathrm{K}$ & 0.8996 & & 0.9517 & \\
\hline
\end{tabular}

Table 9: SimTraffic and Vissim Injury Crash Conflict Models

\begin{tabular}{|lllllll|}
\hline \multirow{2}{*}{$\begin{array}{l}\text { Crash } \\
\text { Type }\end{array}$} & \multirow{2}{*}{$\begin{array}{l}\text { Conflict } \\
\text { Type }\end{array}$} & Coefficients & \multicolumn{3}{c}{ SimTraffic } & \multicolumn{2}{c|}{ Vissim } \\
\cline { 5 - 7 } Injury & Total & $\alpha$ & Estimates & Pr $>$ ChiSq & Estimates & Pr $>$ ChiSq \\
& & $\beta 1$ & -1.6896 & $<0.0001$ & -1.9234 & $<0.0001$ \\
& & -0.0203 & 0.7394 & 0.1509 & 0.0162 \\
Injury & Crossing & $\alpha$ & 0.9209 & & 0.8769 & \\
& & $\beta 1$ & -2.9985 & 0.0029 & -1.5398 & $<0.0001$ \\
& & $\mathrm{~K}$ & -0.8383 & 0.0855 & 0.1716 & 0.1336 \\
Injury & Rear-end & $\alpha$ & 0.4425 & & 0.9251 & \\
& & $\beta 1$ & -1.6800 & $<0.0001$ & -1.7817 & $<0.0001$ \\
& & $\mathrm{~K}$ & -0.0409 & 0.4872 & 0.1104 & 0.0419 \\
Injury & Lane-change & $\alpha$ & 0.9774 & & 0.8540 & \\
& & $\beta 1$ & -1.7315 & $<0.0001$ & -1.6223 & $<0.0001$ \\
& & $\mathrm{~K}$ & 0.1875 & 0.0214 & 0.1105 & 0.1533 \\
& & & 0.7551 & & 0.9276 & \\
\hline
\end{tabular}


Table 10: SimTraffic and Vissim Property Damage Only Crash Conflict Models

\begin{tabular}{|c|c|c|c|c|c|c|}
\hline \multirow{2}{*}{$\begin{array}{l}\text { Crash } \\
\text { Type }\end{array}$} & \multirow{2}{*}{$\begin{array}{l}\text { Conflict } \\
\text { Type }\end{array}$} & \multirow[t]{2}{*}{ Coefficients } & \multicolumn{2}{|c|}{ SimTraffic } & \multicolumn{2}{|c|}{ Vissim } \\
\hline & & & Estimates & $\mathrm{Pr}>\mathrm{ChiSq}$ & Estimates & $\operatorname{Pr}>$ ChiSq \\
\hline \multirow[t]{3}{*}{ PDO } & Total & $\alpha$ & -0.9770 & $<0.0001$ & -1.3336 & $<0.0001$ \\
\hline & & $\beta 1$ & -0.0268 & 0.6288 & 0.1948 & 0.0009 \\
\hline & & $\mathrm{K}$ & 1.0944 & & 0.9549 & \\
\hline \multirow[t]{3}{*}{ PDO } & Crossing & $\alpha$ & -0.8007 & 0.2265 & -0.7849 & $<0.0001$ \\
\hline & & $\beta 1$ & 0.0390 & 0.9070 & 0.2212 & 0.0404 \\
\hline & & $\mathrm{K}$ & 0.2621 & & 0.9196 & \\
\hline \multirow[t]{3}{*}{ PDO } & Rear-end & $\alpha$ & -1.0531 & $<0.0001$ & -1.1905 & $<0.0001$ \\
\hline & & $\beta 1$ & -0.0094 & 0.8614 & 0.1623 & 0.0020 \\
\hline & & $\mathrm{K}$ & 1.1001 & & 0.9529 & \\
\hline \multirow[t]{3}{*}{ PDO } & Lane-change & $\alpha$ & -0.9457 & $<0.0001$ & -0.9363 & $<0.0001$ \\
\hline & & $\beta 1$ & 0.0593 & 0.4516 & 0.1696 & 0.0206 \\
\hline & & $\mathrm{K}$ & 1.0280 & & 1.0190 & \\
\hline
\end{tabular}

Table 11: Summary of Most Effective Conflict Estimation Techniques by Model

\begin{tabular}{|lll|}
\hline Crash Type & Conflict Type & $\begin{array}{l}\text { Most Effective Conflict } \\
\text { Estimation Technique }\end{array}$ \\
\hline Total & Total & Vissim \\
& Crossing & Vissim \\
& Rear-end & Vissim \\
& Lane-change & Vissim \\
Injury & Total & Vissim \\
& Crossing & SimTraffic \\
& Rear-end & Vissim \\
& Lane-change & SimTraffic \\
PDO & Total & Vissim \\
& Crossing & Vissim \\
& Rear-end & Vissim \\
& Lane-change & Vissim \\
\hline
\end{tabular}


Table 11 indicates that Vissim provided more significant results for majority of the developed models. This result is due to the calibration of the models. This study applied both SimTraffic and Vissim default models. In order for SimTraffic to provide more statistically significant results, the model inputs would have to be calibrated. For the purpose of this study, Vissim conflict results are applied when developing crash prediction models as they tend to yield more significant results than the SimTraffic conflict results. 


\section{Model Fitting and Evaluation}

This section begins by describing general crash prediction models and how their goodness-of-fit was evaluated. Afterwards, the specific models developed in this study are presented and evaluated. The following is a list of the types of models included in this section:

- Crash - Volume Models

- Crash - Delay Models

- Crash - Conflict Models

\subsection{General Crash Prediction Models and Goodness-of-Fit Evaluation}

The crash prediction models developed in this study follow the general crash prediction model form (Persaud et al., 2012):

Crashes $=e^{\alpha} *$ Variable $^{\beta_{1}} *$ Variable $^{\beta_{2}} * \ldots *$ Years (Equation 1) Where;

$$
\begin{aligned}
& \alpha=\text { Intercept estimate } \\
& \text { Variable1, Variable2, etc = Explanatory variables selected } \\
& \beta_{1}, \beta_{2} \text {, etc }=\text { Coefficient estimates for the selected explanatory variables } \\
& \text { Years }=\text { Number of years of crash data }
\end{aligned}
$$

Once the models were been developed, their goodness-of-fit was evaluated by analyzing the dispersion parameter, Mean Prediction Bias (MPB), Mean Absolute Deviation (MAD), Mean Squared Prediction Error (MSPE), Mean Squared Error (MSE), and CURE Plots.

As described earlier, crash data tend to be over-dispersed due to the variance being larger than the mean. If the dispersion parameter is equal to zero, the model reduces to the simpler Poisson model. If the dispersion parameter is greater than zero the variable is over-dispersed, and if the dispersion parameter is less than zero the variable is under-dispersed (UCLA, 2014). 
The Mean Prediction Bias (MPB) provides a measure of magnitude and direction of the average model bias in comparison with validation data. The smaller the MPB, the better the model predicts observed crashes (Oh, Lyon, Washington, Persaud, \& Bared, 2003). A positive MPB indicates an over-prediction of crashes and a negative MPB indicates an under-prediction of crashes.

Mean Absolute Deviation (MAD) is the absolute value of the total difference between the observed and predicted crash frequency divided by the sample size. MAD measures the average misprediction of the model. A MAD value close to zero indicates that, on average the model predicts the observed data well (Oh et al., 2003).

The Mean Squared Prediction Error (MSPE) is the sum of the squared differences between the observed and predicted crash frequencies divided by the sample size (Oh et al., 2003). MSPE is applied to assess the error associated with the crash data. Mean Squared Error (MSE) is the sum of the squared differences between the observed and predicted frequencies divided by the sample size minus the number of model parameters (Oh et al., 2003). The MSPE and MSE are compared in order to identify any over or under fitting of the models to the estimation data. If the MSPE is larger than the MSE, the models may have been over-fit to the estimation data.

In order to normalize the goodness-of-fit measures, the number of years of data should be considered (Oh et al., 2003). In the case of the MPB and the MAD results, the MPB per year and MAD per year results were determined by simply dividing by the amount of years of data. When calculating the MSPE per year and MSE per year, the results were divided by the square of the number of years since the MSPE and MSE are the mean values of the squared errors.

It is important to evaluate the models based on how they perform over the range of covariates. This evaluation applies the cumulative residual (CURE) method, which plots the difference between the observed and predicted crashes for each site and the $95 \%$ confidence limits. If there is no bias in the model, the plot of the cumulative residuals should oscillate around the $\mathrm{x}$-axis without systematic over and under-prediction, and stay within the confidence limits (Persaud et al., 2012). 


\subsection{Volume Crash Prediction Models}

\subsubsection{Crash - AADT Models}

Crash - AADT models were developed. These model crash type with entering AADT and is represented by Equation 2. Table 12 presents the results of the Crash - Entering AADT models.

Crash Type $=e^{\alpha} *(\text { Entering } A A D T)^{\beta_{1}} *$ Years

(Equation 2)

Table 12: Crash - Entering AADT Model Results

\begin{tabular}{|c|c|c|c|c|c|c|c|c|}
\hline \multirow{2}{*}{$\begin{array}{l}\text { Crash } \\
\text { Type }\end{array}$} & \multirow{2}{*}{$\begin{array}{l}\text { Volume } \\
\text { Type }\end{array}$} & \multirow[t]{2}{*}{ Coef } & \multicolumn{2}{|c|}{ All Intersections } & \multicolumn{2}{|c|}{3 Leg Intersection } & \multicolumn{2}{|c|}{4 Leg Intersections } \\
\hline & & & Estimates & $\operatorname{Pr}>\mathrm{ChiSq}$ & Estimates & $\mathrm{Pr}>\mathrm{ChiSq}$ & Estimates & $\operatorname{Pr}>$ ChiSq \\
\hline \multirow[t]{3}{*}{ Total } & AADT & $\alpha$ & -1.7612 & 0.3780 & 2.2662 & 0.4382 & -6.1522 & 0.0206 \\
\hline & & $\beta 1$ & 0.1285 & 0.5541 & -0.3099 & 0.3262 & 0.6123 & 0.0358 \\
\hline & & $\mathrm{K}$ & 1.0163 & & 1.0669 & & 0.8553 & \\
\hline \multirow[t]{3}{*}{ Injury } & AADT & $\alpha$ & -1.6407 & 0.4450 & 2.8183 & 0.3543 & -6.1594 & 0.0396 \\
\hline & & $\beta 1$ & -0.0037 & 0.9873 & -0.4974 & 0.1309 & 0.5039 & 0.1246 \\
\hline & & $\mathrm{K}$ & 1.0020 & & 0.9034 & & 0.9694 & \\
\hline \multirow[t]{3}{*}{ PDO } & AADT & $\alpha$ & -2.7751 & 0.1898 & 1.1048 & 0.7301 & -6.9135 & 0.0112 \\
\hline & & $\beta 1$ & 0.1940 & 0.3991 & -0.2245 & 0.5162 & 0.6447 & 0.0311 \\
\hline & & $\mathrm{K}$ & 1.0861 & & 1.2478 & & 0.8122 & \\
\hline
\end{tabular}

The Crash - AADT volume model results identify which model coefficients are significant. According to the p-value results, the four leg Crash - Entering AADT models for total and PDO crashes have significant coefficient estimates $(\mathrm{p}<0.10)$. For this intersection type, Tables 13 presents the goodness-of-fit results and the CURE plots are presented in Figures 16 and 17 . 
Table 13: Crash - Entering AADT Goodness-Of-Fit Results

\begin{tabular}{|ll|}
\hline & T Leg Results \\
MPB/Year & -0.001746 \\
MAD/Year & 0.088721 \\
MSE/Year & 0.023365 \\
MSPE/Year & 0.009569 \\
PPB/Year & PDO - AADT \\
MAD/Year & -0.001176 \\
MSE/Year & 0.059833 \\
MSPE/Year & 0.010543 \\
\hline
\end{tabular}

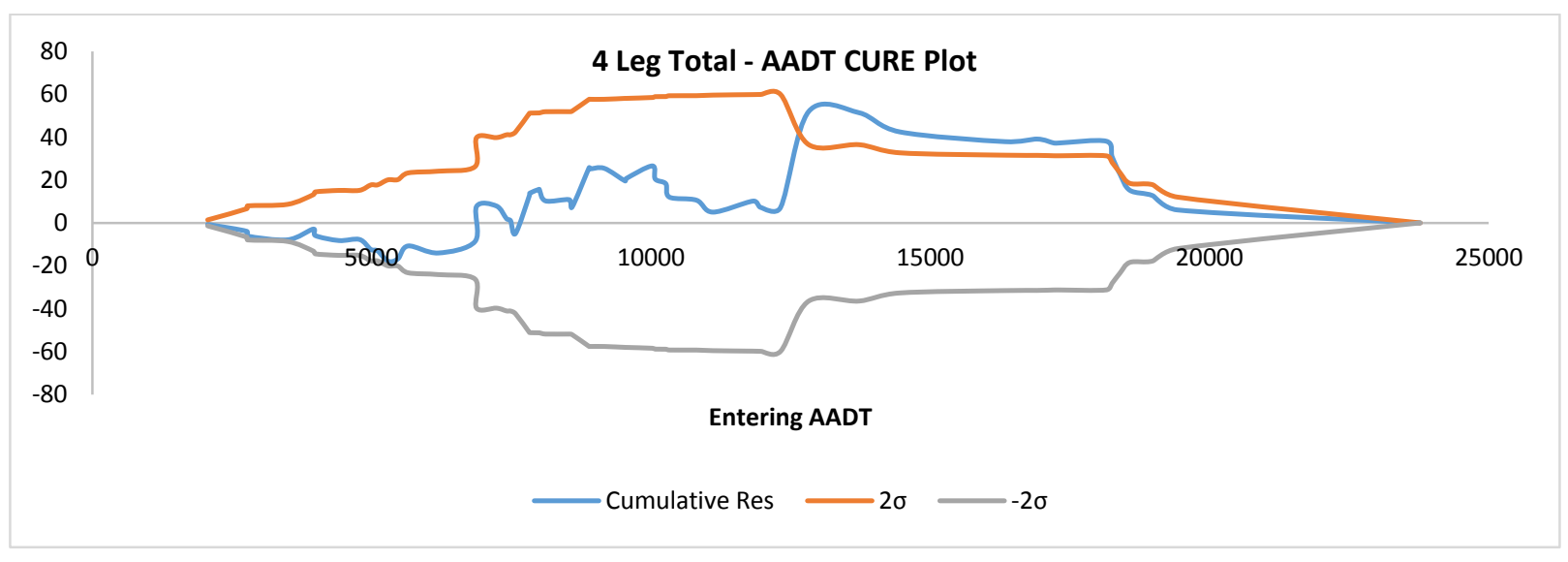

Figure 16: 4 Leg Total - AADT CURE Plot 


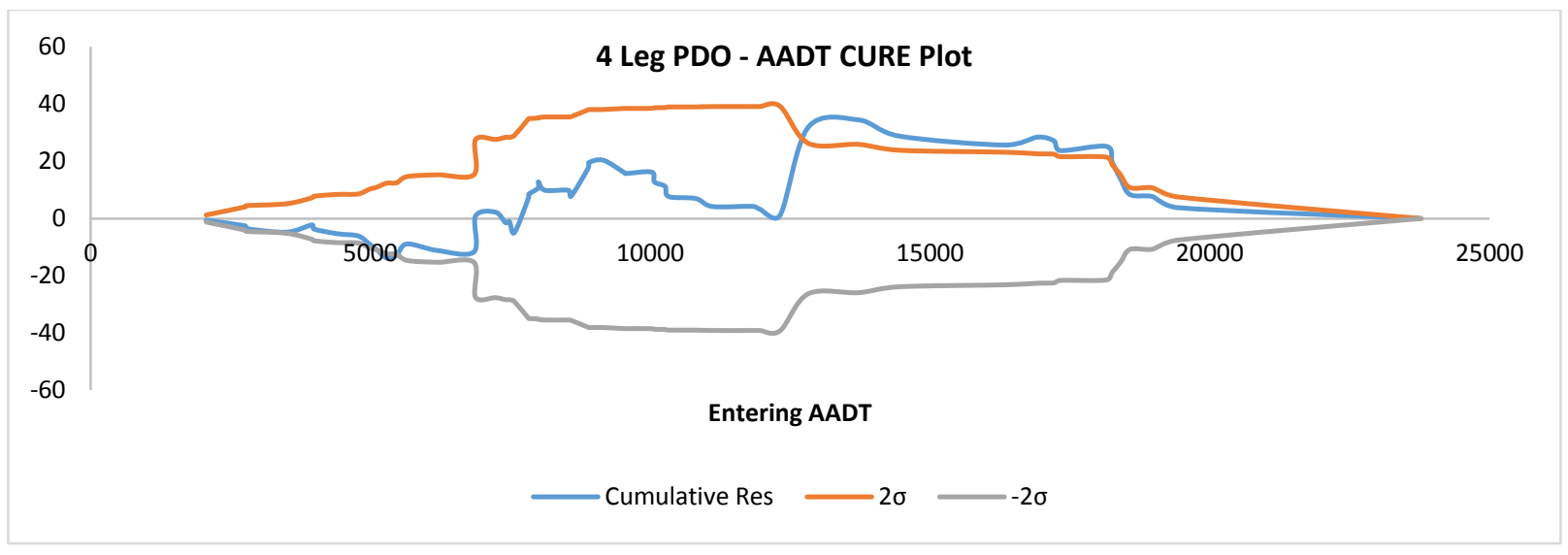

Figure 17: 4 Leg PDO - AADT CURE Plot

The MPB/Year and MAD/Year values are approximately zero thus illustrating that the model predicts the observed crashes well overall. The MSE/Year and MSPE/Year values are equal which indicates that the models are a good fit generally to the estimation data. Despite the results of the goodness-of-fit calculations, according to the CURE plots prediction biases are present in the models. These biases can be corrected by increasing sample size or introducing other variables to the model.

\subsubsection{Crash - Delayed Volume and Non-Delayed Volume}

Models that relate the crash frequency with the delayed and non-delayed volumes were developed. When analyzing each turning movement at an intersection, if there was a delay associated with a turning movement then that volume would be a delayed volume. If a turning movement had no associated delays, the volume would be a non-delayed volume. The delayed and non-delayed volumes were obtained using the Synchro intersection models. Equation 3 is a representation of the developed models and Table 14 presents the model results.

Crash Type $=e^{\alpha} *(\text { Delayed } V o l)^{\beta_{1}} *(\text { Non Delayed } V o l)^{\beta_{2}} *$ Years

(Equation 3) 
Table 14: Crash - Delayed and Non-Delayed Volume Model Results

\begin{tabular}{|c|c|c|c|c|c|c|c|c|}
\hline \multirow{2}{*}{$\begin{array}{l}\text { Crash } \\
\text { Type }\end{array}$} & \multirow{2}{*}{$\begin{array}{l}\text { Volume } \\
\text { Type }\end{array}$} & \multirow[t]{2}{*}{ Coef } & \multicolumn{2}{|c|}{ All Intersections } & \multicolumn{2}{|c|}{3 Leg Intersection } & \multicolumn{2}{|c|}{4 Leg Intersections } \\
\hline & & & Estimates & $\operatorname{Pr}>$ ChiSq & Estimates & Pr>ChiSq & Estimates & $\mathrm{Pr}>\mathrm{ChiSq}$ \\
\hline \multirow[t]{4}{*}{ Total } & \multirow{4}{*}{$\begin{array}{l}\text { Delayed } \\
\text { Volume and } \\
\text { Non- } \\
\text { Delayed } \\
\text { Volume }\end{array}$} & $\alpha$ & -1.9003 & 0.0752 & -0.8126 & 0.7044 & -5.3045 & 0.0024 \\
\hline & & $\beta 1$ & 0.1962 & 0.0415 & 0.0676 & 0.5686 & 0.5384 & 0.0013 \\
\hline & & $\beta 2$ & 0.0353 & 0.7269 & -0.0212 & 0.9393 & 0.2781 & 0.0616 \\
\hline & & $\mathrm{K}$ & 0.9596 & & 1.0478 & & 0.7488 & \\
\hline \multirow[t]{4}{*}{ Injury } & \multirow{4}{*}{$\begin{array}{l}\text { Delayed } \\
\text { Volume and } \\
\text { Non- } \\
\text { Delayed } \\
\text { Volume }\end{array}$} & $\alpha$ & -2.4575 & 0.0372 & -0.8382 & 0.7200 & -7.0751 & 0.0003 \\
\hline & & $\beta 1$ & 0.1473 & 0.1731 & -0.0385 & 0.7618 & 0.6145 & 0.0014 \\
\hline & & $\beta 2$ & -0.0050 & 0.9637 & -0.1033 & 0.7273 & 0.3306 & 0.0377 \\
\hline & & $\mathrm{K}$ & 0.9589 & & 0.9310 & & 0.7829 & \\
\hline \multirow[t]{4}{*}{ PDO } & \multirow{4}{*}{$\begin{array}{l}\text { Delayed } \\
\text { Volume and } \\
\text { Non- } \\
\text { Delayed } \\
\text { Volume }\end{array}$} & $\alpha$ & -2.4841 & 0.0268 & -1.6307 & 0.4828 & -4.8103 & 0.0104 \\
\hline & & $\beta 1$ & 0.2098 & 0.0358 & 0.1150 & 0.3699 & 0.4467 & 0.0118 \\
\hline & & $\beta 2$ & 0.0500 & 0.6409 & 0.0053 & 0.9860 & 0.2073 & 0.1959 \\
\hline & & $\mathrm{K}$ & 1.0288 & & 1.2191 & & 0.7550 & \\
\hline
\end{tabular}

The p-value results indicate that the four leg Crash - Delayed and Non-Delayed volume models show significant coefficient estimates $(\mathrm{p}<0.10)$. For this intersection type, the goodnessof-fit results are summarized in Table 15 and the CURE plots are presented in Figures 18 and 19. 
Table 15: Crash - Delayed and Non-Delayed Volume Goodness-Of-Fit Results

\begin{tabular}{|ll|}
\hline & 4 Leg Results \\
& Total - Delayed and Non-Delayed Volume \\
MPB/Year & -0.002899 \\
MAD/Year & 0.084098 \\
MSE/Year & 0.022926 \\
MSPE/Year & 0.022926 \\
& Injury - Delayed and Non-Delayed Volume \\
MPB/Year & -0.001035 \\
MAD/Year & 0.037740 \\
MSE/Year & 0.003272 \\
MSPE/Year & 0.003272 \\
\hline
\end{tabular}




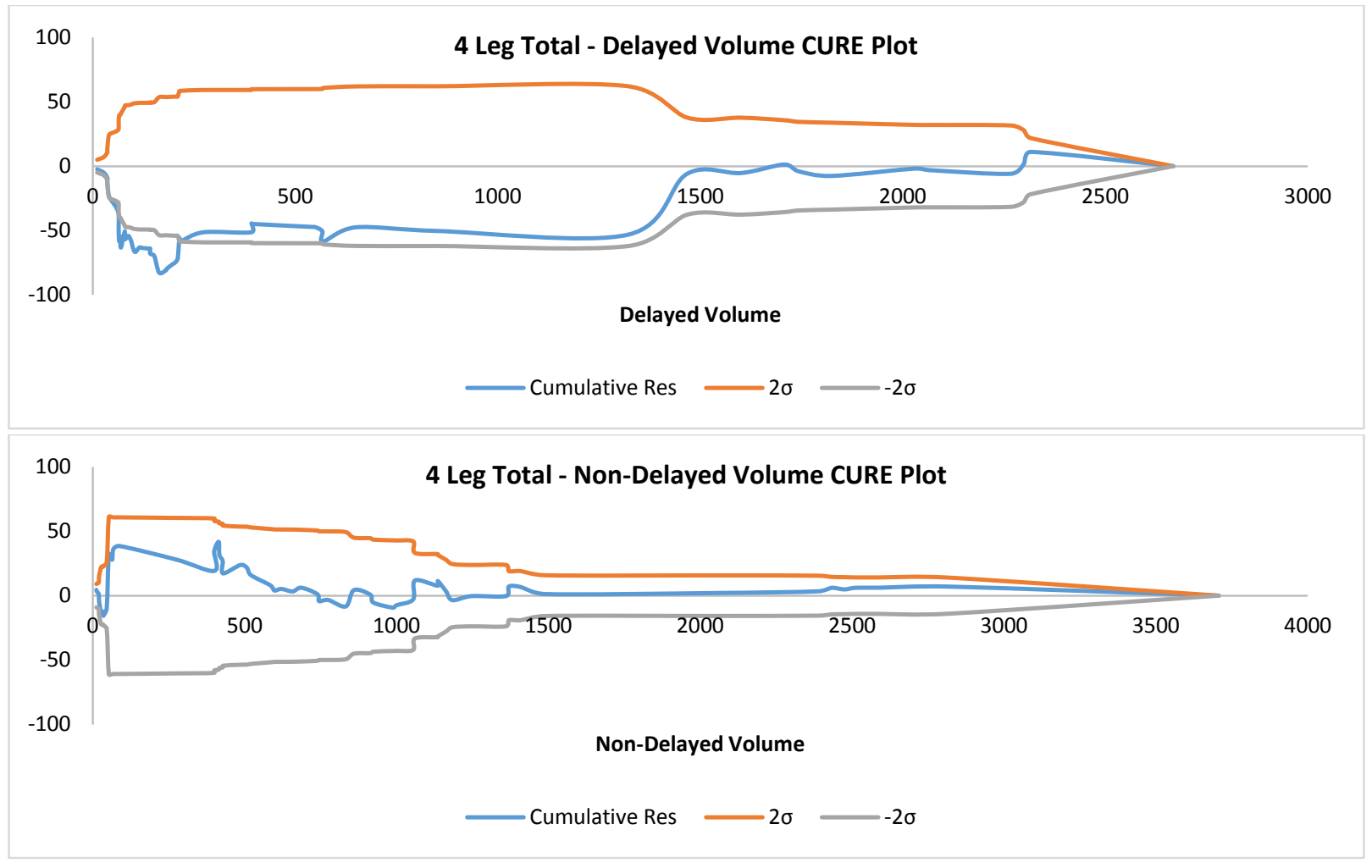

Figure 18: 4 Leg Total - Delayed and Non-Delayed Volume CURE Plots

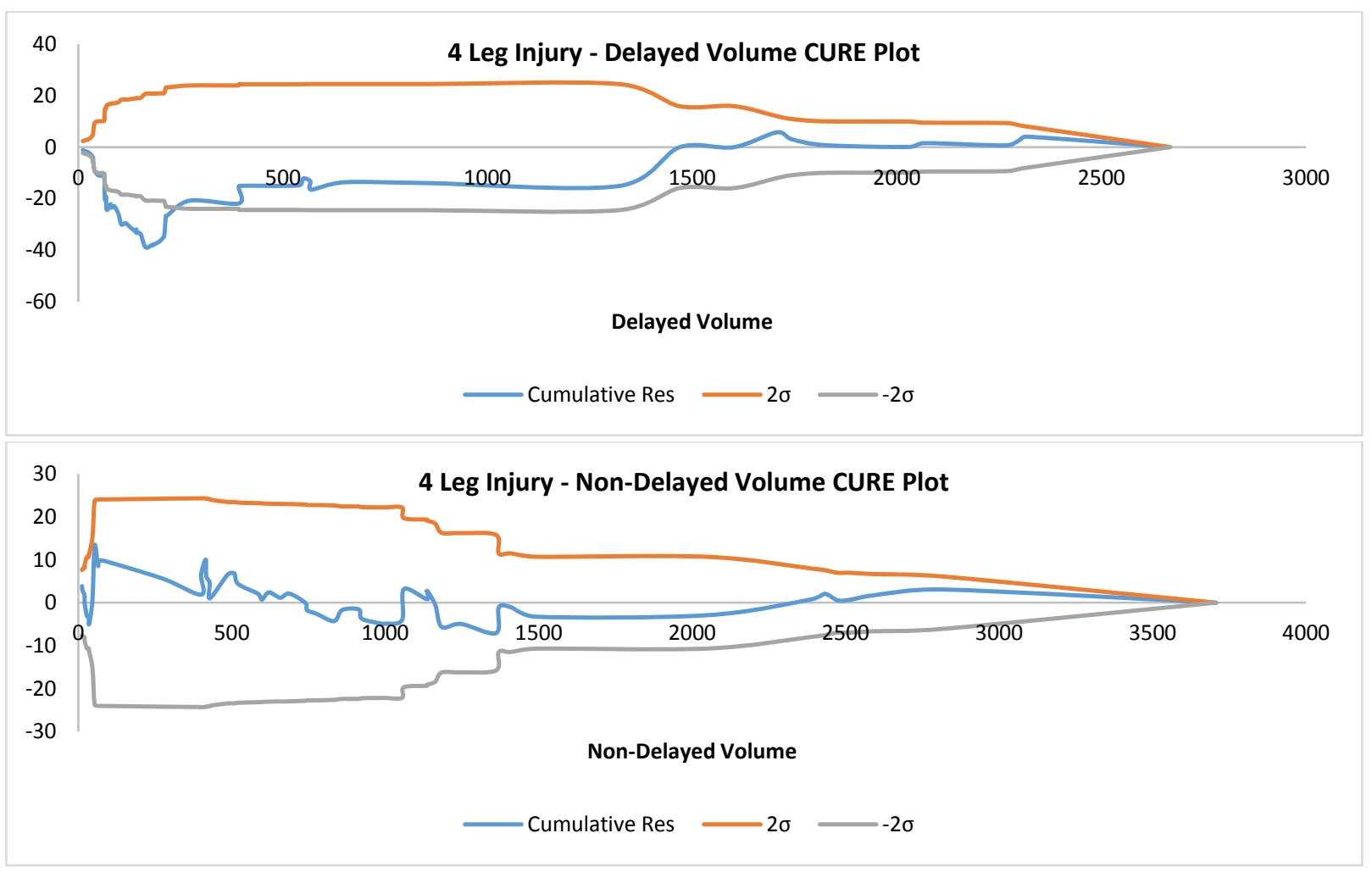

Figure 19: 4 Leg Injury - Delayed and Non-Delayed Volume CURE Plots 
The MPB/Year and MAD/Year results are approximately zero and MSE/Year and MSPE/Year are equal. These results indicate that the models fit the estimation data well. The CURE plot results do identify some prediction biases in the models but only in the case of the delayed volumes.

\subsubsection{Additional Crash - Volume Models Attempted}

The following Crash - Volume models were excluded due to the model results identifying no significant coefficient estimates.

- Crash - Major and Minor AADT

- Crash - Entering AADT and Peak Hour Factor (PHF)

- Crash - Entering AM Peak Volume

- Crash - Major and Minor AM Peak Volume

- Crash - Entering AM Peak Volume and PHF

- Crash - Conflicting Volume and AM Peak Volume

\subsection{Delay Crash Prediction Models}

\subsubsection{Crash - Total Delay Models}

Total delay was calculated by multiplying average delay results from Synchro with the AM Peak volumes. Crash data and total delay were modelled to develop the Crash - Total Delay models represented by Equation 4. Table 16 contains the Crash - Total Delay model results.

Crash Type $=e^{\alpha} *(\text { Total Delay })^{\beta_{1}} *$ Years

(Equation 4) 
Table 16: Crash - Total Delay Model Results

\begin{tabular}{|c|c|c|c|c|c|c|c|c|}
\hline \multirow{2}{*}{$\begin{array}{l}\text { Crash } \\
\text { Type }\end{array}$} & \multirow{2}{*}{$\begin{array}{l}\text { Delay } \\
\text { Type }\end{array}$} & \multirow[t]{2}{*}{ Coef } & \multicolumn{2}{|c|}{ All Intersections } & \multicolumn{2}{|c|}{3 Leg Intersection } & \multicolumn{2}{|c|}{4 Leg Intersections } \\
\hline & & & Estimates & $\mathrm{Pr}>\mathrm{ChiSq}$ & Estimates & $\operatorname{Pr}>$ ChiSq & Estimates & $\mathrm{Pr}>\mathrm{ChiSq}$ \\
\hline \multirow[t]{3}{*}{ Total } & $\begin{array}{l}\text { Total } \\
\text { Delay }\end{array}$ & $\alpha$ & -2.5182 & $<0.0001$ & -2.8575 & 0.0001 & -1.9176 & 0.0449 \\
\hline & & $\beta 1$ & 0.2372 & 0.0010 & 0.2997 & 0.0024 & 0.1658 & 0.1504 \\
\hline & & $\mathrm{K}$ & 0.8969 & & 0.9008 & & 0.8758 & \\
\hline \multirow[t]{3}{*}{ Injury } & $\begin{array}{l}\text { Total } \\
\text { Delay }\end{array}$ & $\alpha$ & -3.2444 & $<0.0001$ & -3.4749 & $<0.0001$ & -2.8623 & 0.0037 \\
\hline & & $\beta 1$ & 0.1929 & 0.0104 & 0.2116 & 0.0291 & 0.1590 & 0.1778 \\
\hline & & $\mathrm{K}$ & 0.8844 & & 0.8158 & & 0.9375 & \\
\hline \multirow[t]{3}{*}{ PDO } & $\begin{array}{l}\text { Total } \\
\text { Delay }\end{array}$ & $\alpha$ & -3.0905 & $<0.0001$ & -3.5035 & $<0.0001$ & -2.3185 & 0.0203 \\
\hline & & $\beta 1$ & 0.2565 & 0.0009 & 0.3103 & 0.0020 & 0.1584 & 0.1881 \\
\hline & & $\mathrm{K}$ & 0.9574 & & 1.0169 & & 0.8571 & \\
\hline
\end{tabular}

Analysis of the p-value results determine that the all intersection and three leg Crash Total Delay models show significant coefficient estimates $(\mathrm{p}<0.05)$. The goodness-of-fit results are summarized in Table 17. Figures 20 to 22 contain the variable CURE plots. 
Table 17: Crash - Total Delay Goodness-Of-Fit Results

\begin{tabular}{|c|c|c|}
\hline & All Int Results & 3 Leg Results \\
\hline & Total - Total Delay & Total - Total Delay \\
\hline MPB/Year & -0.000906 & -0.017708 \\
\hline MAD/Year & 0.038168 & 0.069680 \\
\hline MSE/Year & 0.003579 & 0.009087 \\
\hline \multirow[t]{2}{*}{ MSPE/Year } & 0.003579 & 0.009087 \\
\hline & Injury - Total Delay & Injury - Total Delay \\
\hline MPB/Year & -0.000152 & -0.000032 \\
\hline MAD/Year & 0.014128 & 0.021478 \\
\hline MSE/Year & 0.000481 & 0.001167 \\
\hline \multirow[t]{2}{*}{ MSPE/Year } & 0.000481 & 0.001167 \\
\hline & PDO - Total Delay & PDO - Total Delay \\
\hline MPB/Year & -0.000767 & -0.000482 \\
\hline MAD/Year & 0.027357 & 0.047415 \\
\hline MSE/Year & 0.001724 & 0.004148 \\
\hline MSPE/Year & 0.001724 & 0.004148 \\
\hline
\end{tabular}




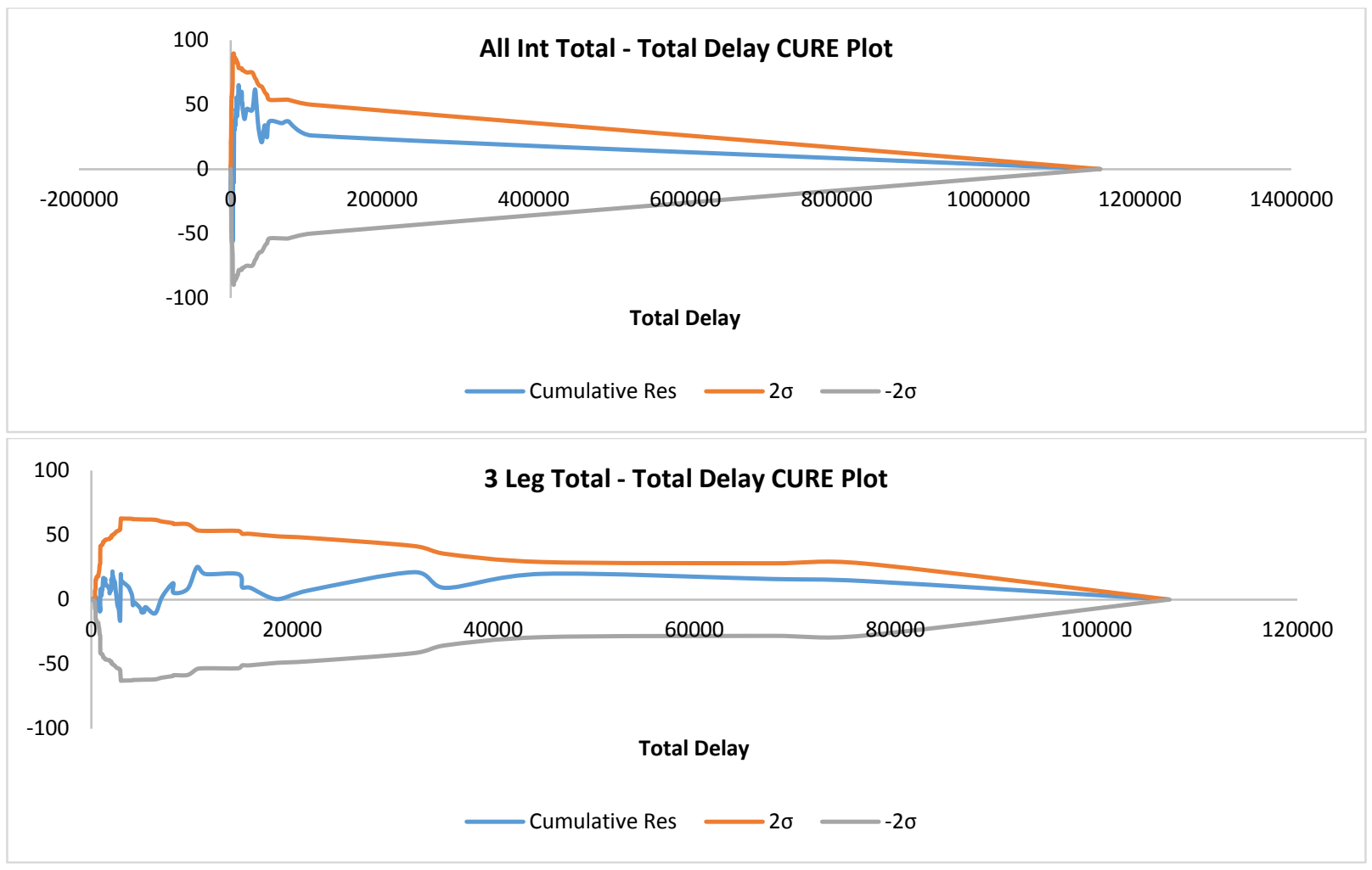

Figure 20: Total - Total Delay CURE Plots

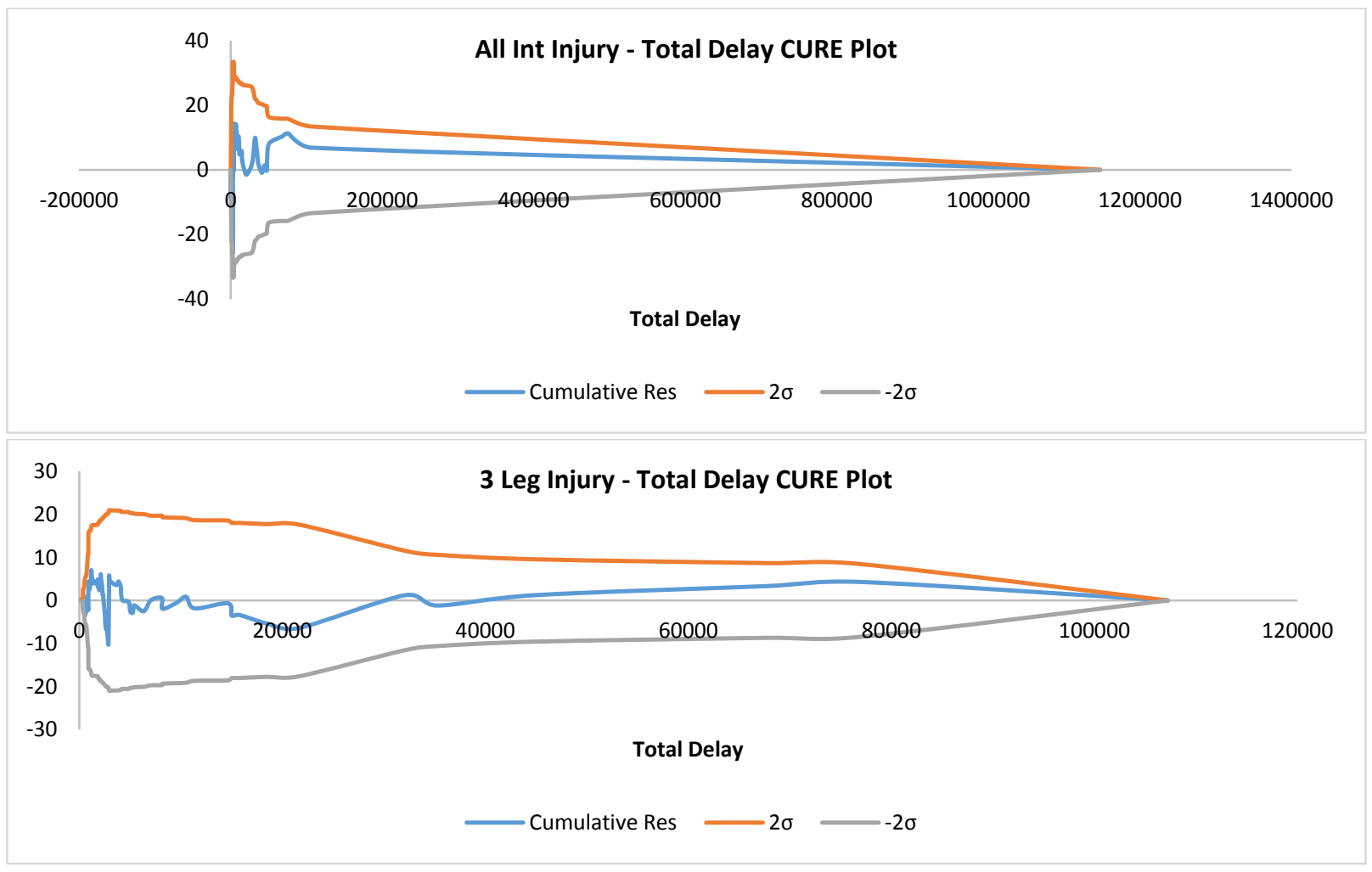

Figure 21: Injury - Total Delay CURE Plots 


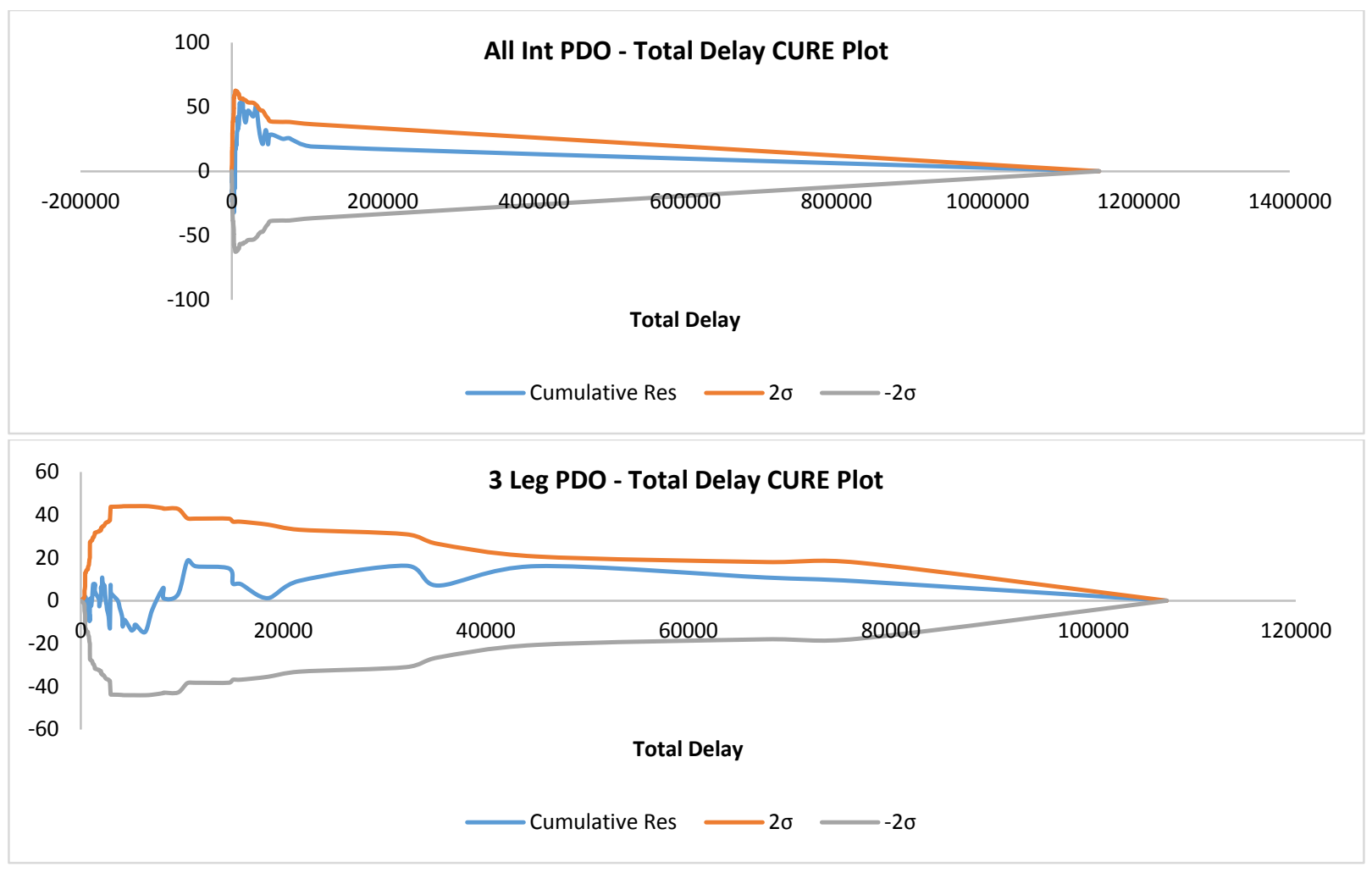

Figure 22: PDO - Total Delay CURE Plots

The goodness-of-fit results illustrate that the models fit the estimation data well. The $\mathrm{MPB} / Y$ ear and MAD/Year values are approximately zero and the MSE/Year and MSPE/Year values are equal. The CURE plots of the Crash - Total Delay models identify no prediction biases.

\subsubsection{Crash - Movement Delay Models}

Crash - Movement Delay models were developed. These models relate crash type with the total left turning movement (LTM) delay (Equation 5). The total LTM delay was calculated by summing the products of the left turning volumes and left turning delay at each intersection approach. Initially all of the possible turning movements were considered for these models, however only the left turning movement data provided satisfactory results. Table 18 present the results of the Crash - LTM Total Delay models.

Crash Type $=e^{\alpha} *(\text { LTM Total Delay })^{\beta_{1}} *$ Years

(Equation 5) 
Table 18: Crash - LTM Total Delay

\begin{tabular}{|c|c|c|c|c|c|c|c|c|}
\hline \multirow{2}{*}{$\begin{array}{l}\text { Crash } \\
\text { Type }\end{array}$} & \multirow{2}{*}{$\begin{array}{l}\text { Volume } \\
\text { Type }\end{array}$} & \multirow[t]{2}{*}{ Coef } & \multicolumn{2}{|c|}{ All Intersections } & \multicolumn{2}{|c|}{3 Leg Intersection } & \multicolumn{2}{|c|}{4 Leg Intersections } \\
\hline & & & Estimates & $\mathrm{Pr}>\mathrm{ChiSq}$ & Estimates & $\mathrm{Pr}>\mathrm{ChiSq}$ & Estimates & $\mathrm{Pr}>\mathrm{ChiSq}$ \\
\hline \multirow[t]{3}{*}{ Total } & $\begin{array}{l}\text { LTM Total } \\
\text { Delay }\end{array}$ & $\alpha$ & -3.0912 & $<0.0001$ & -2.5910 & 0.0030 & -3.8888 & 0.0001 \\
\hline & & $\beta 1$ & 0.3572 & 0.0002 & 0.2852 & 0.0205 & 0.4727 & 0.0011 \\
\hline & & $\mathrm{K}$ & 0.8677 & & 0.9391 & & 0.7570 & \\
\hline \multirow[t]{3}{*}{ Injury } & $\begin{array}{l}\text { LTM Total } \\
\text { Delay }\end{array}$ & $\alpha$ & -3.6973 & $<0.0001$ & -3.2157 & 0.0015 & -4.3934 & 0.0002 \\
\hline & & $\beta 1$ & 0.2889 & 0.0088 & 0.2085 & 0.1421 & 0.4035 & 0.0178 \\
\hline & & $\mathrm{K}$ & 0.9142 & & 0.9026 & & 0.8843 & \\
\hline \multirow[t]{3}{*}{ PDO } & $\begin{array}{l}\text { LTM Total } \\
\text { Delay }\end{array}$ & $\alpha$ & -3.7045 & $<0.0001$ & -3.1699 & 0.0006 & -4.5515 & $<0.0001$ \\
\hline & & $\beta 1$ & 0.3852 & $<0.0001$ & 0.3137 & 0.0153 & 0.5001 & 0.0008 \\
\hline & & $\mathrm{K}$ & 0.8797 & & 1.0145 & & 0.7041 & \\
\hline
\end{tabular}

When analyzing the p-value results of the LTM total delay models, all of the models except the three leg Injury - LTM Total Delay model have significant coefficient estimates (p close to 0.10). Table 19 summarizes the goodness-of-fit results and Figures 23 to 25 present the variable CURE plots. 
Table 19: Crash - LTM Total Delay Goodness-Of-Fit Results

\begin{tabular}{|c|c|c|c|}
\hline & All Int Results & 3 Leg Results & 4 Leg Results \\
\hline & $\begin{array}{l}\text { Total - LTM Total } \\
\text { Delay }\end{array}$ & $\begin{array}{l}\text { Total - LTM Total } \\
\text { Delay }\end{array}$ & $\begin{array}{l}\text { Total - LTM Total } \\
\text { Delay }\end{array}$ \\
\hline MPB/Year & -0.000265 & 0.000115 & -0.003106 \\
\hline MAD/Year & 0.037591 & 0.064597 & 0.094443 \\
\hline MSE/Year & 0.003314 & 0.008772 & 0.022902 \\
\hline \multirow[t]{2}{*}{ MSPE/Year } & 0.003314 & 0.008772 & 0.022902 \\
\hline & $\begin{array}{l}\text { Injury - LTM Total } \\
\text { Delay }\end{array}$ & $\begin{array}{l}\text { Injury - LTM Total } \\
\text { Delay }\end{array}$ & $\begin{array}{l}\text { Injury - LTM Total } \\
\text { Delay }\end{array}$ \\
\hline MPB/Year & 0.000002 & 0.000158 & -0.000695 \\
\hline MAD/Year & 0.014190 & 0.022002 & 0.038932 \\
\hline MSE/Year & 0.000477 & 0.001208 & 0.003332 \\
\hline \multirow[t]{2}{*}{ MSPE/Year } & 0.000477 & 0.001208 & 0.003332 \\
\hline & $\begin{array}{l}\text { PDO - LTM Total } \\
\text { Delay }\end{array}$ & $\begin{array}{l}\text { PDO - LTM Total } \\
\text { Delay }\end{array}$ & $\begin{array}{l}\text { PDO - LTM Total } \\
\text { Delay }\end{array}$ \\
\hline MPB/Year & -0.000228 & -0.000035 & -0.002062 \\
\hline MAD/Year & 0.026063 & 0.046938 & 0.060516 \\
\hline MSE/Year & 0.001539 & 0.004194 & 0.010305 \\
\hline MSPE/Year & 0.001539 & 0.004194 & 0.010305 \\
\hline
\end{tabular}




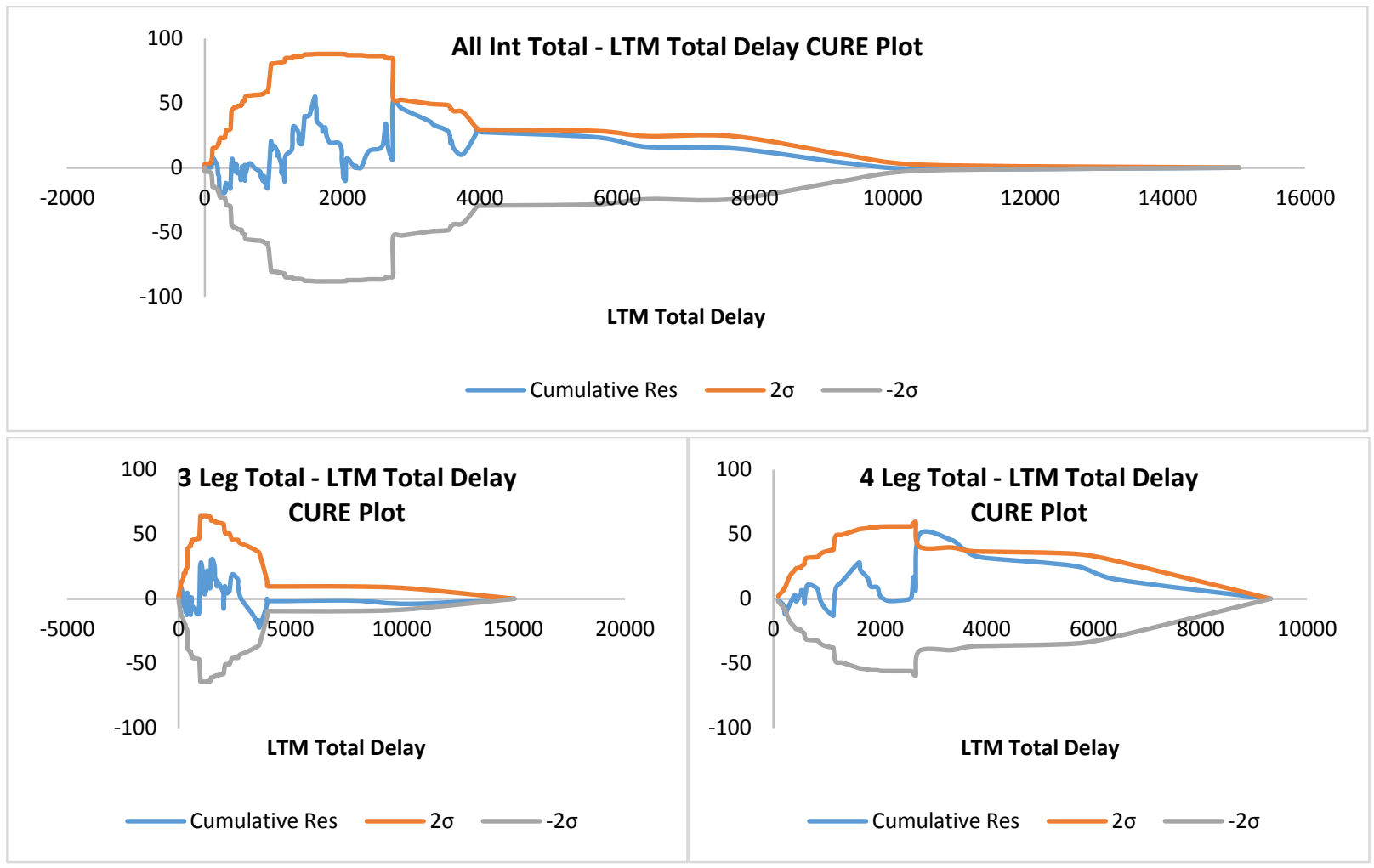

Figure 23: Total - LTM Total Delay CURE Plots

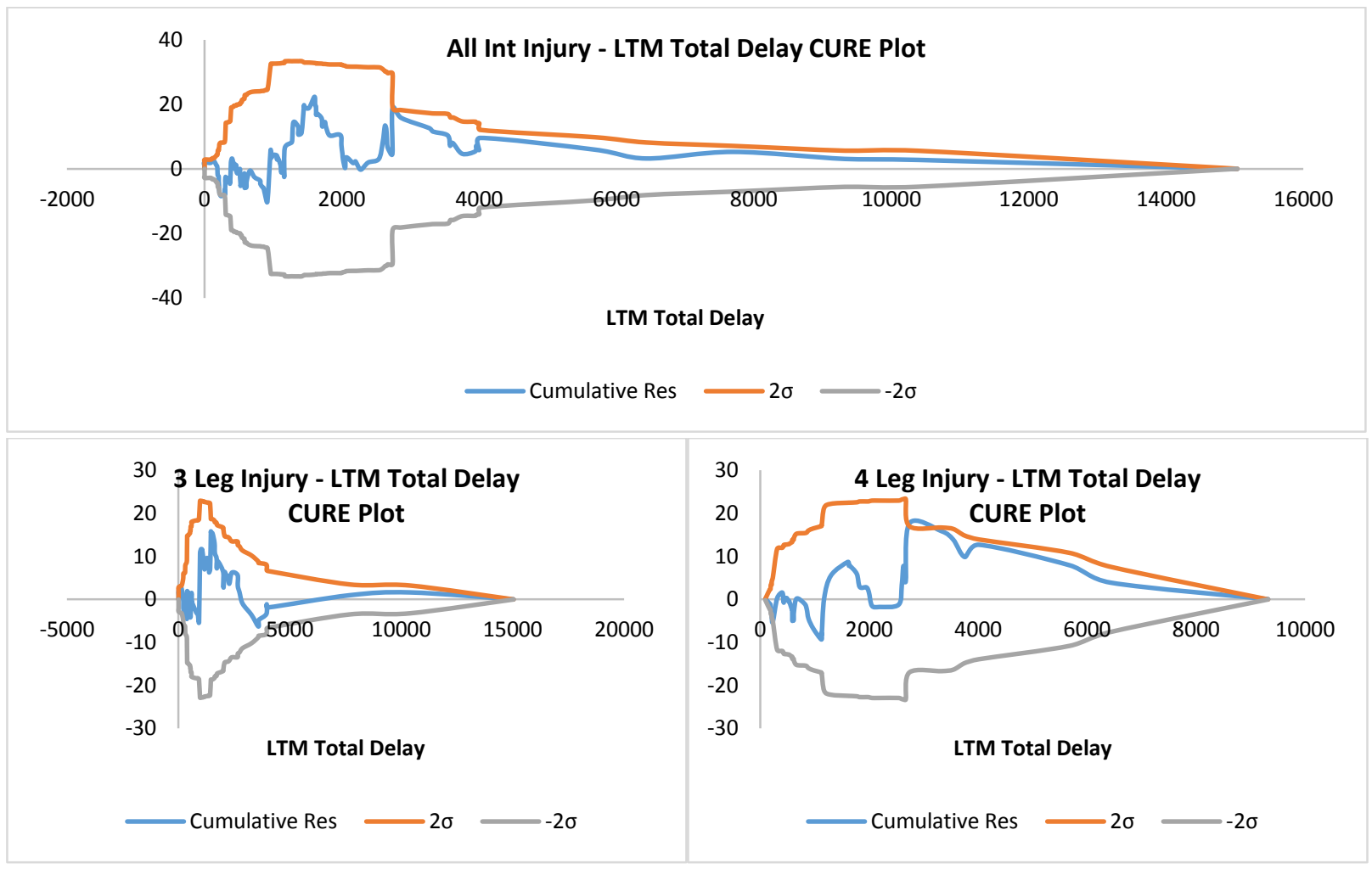

Figure 24: Injury - LTM Total Delay CURE Plots 


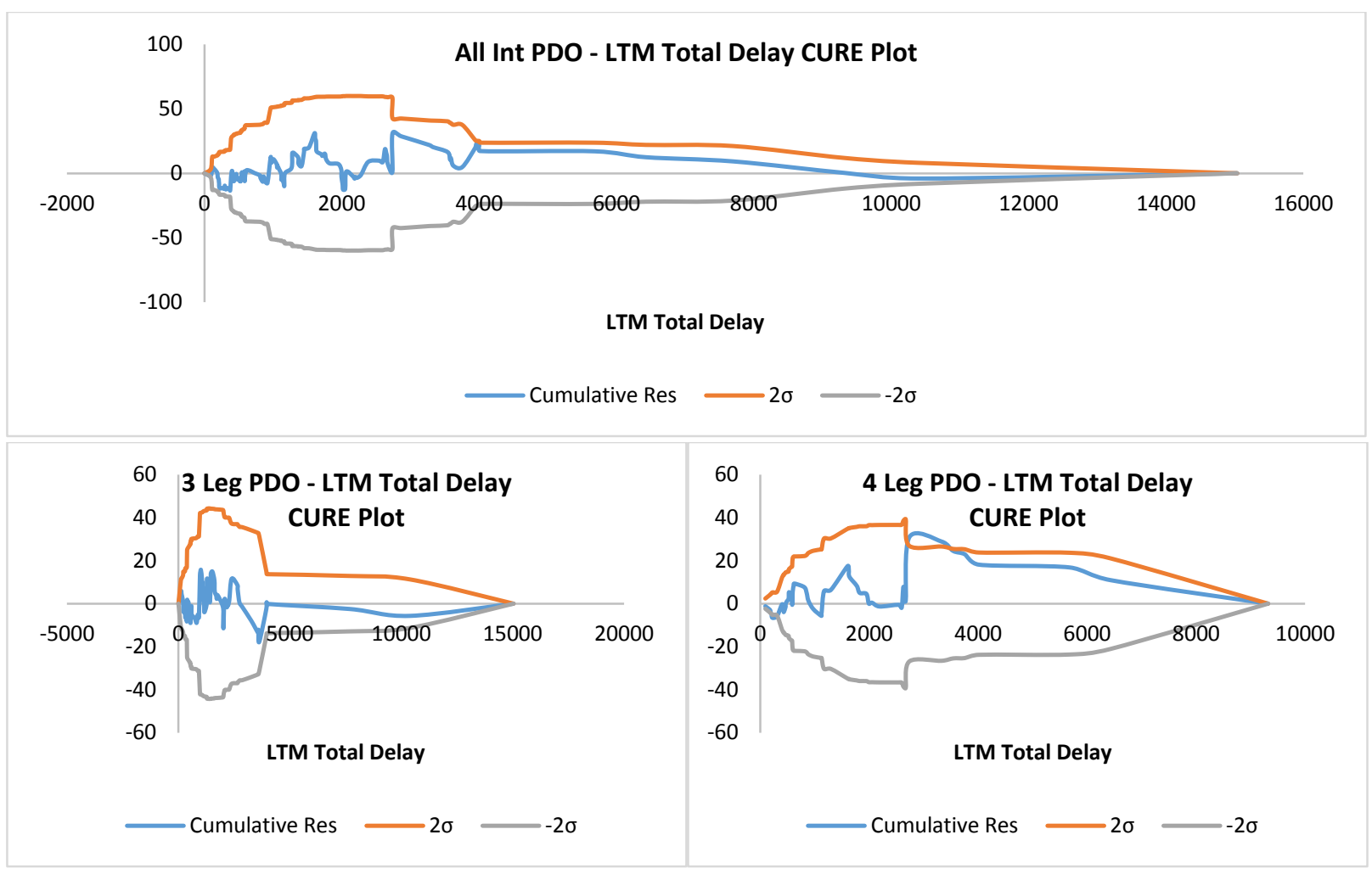

Figure 25: PDO - LTM Total Delay CURE Plots

The MPB/Year and MAD/Year for both model types are approximately zero, therefore the models predict the observed crashes well. The MSE/Year and MSPE/Year results are equal for all of the models, which is another indication that the models fit the estimation data well.

The LTM total delay model CURE plots show no biases in the all intersection and three leg models. The four leg LTM total delay models show some prediction biases. The prediction biases are present in the four leg models which indicates that increasing the sample size of four leg intersections would increase the model predictive capabilities.

\subsubsection{Additional Crash - Delay Models Attempted}

The following Crash - Delay models were excluded due to the model results identifying no significant coefficient estimates.

- Crash - Average Delay and Entering AADT

- Crash - Average Delay and Entering AM Peak Volume

- Crash - Left Turn Movement (LTM) Average Delay and LTM AM Peak Volume

- Crash - Average Delay, Delayed Volume, and Non-Delayed Volume 


\subsection{Conflict Crash Prediction Models}

\subsubsection{Crash - Conflict Models}

Crash - Conflict models were created that relate crash types to the estimated conflicts.

The models include crash data such as total, injury, PDO, and impact types. The crash data were modelled with conflicts such as total, crossing, rear-end, and lane-change. Equation 7 illustrates the Crash - Conflict model form and Tables 20 and 21 present the model results.

Crash Type $=e^{\alpha} *(\text { Conflict Type })^{\beta_{1}} *$ Years

(Equation 6)

Table 20: Total - Conflict Model Results

\begin{tabular}{|c|c|c|c|c|c|c|c|c|}
\hline \multirow{2}{*}{$\begin{array}{l}\text { Crash } \\
\text { Type }\end{array}$} & \multirow{2}{*}{$\begin{array}{l}\text { Conflict } \\
\text { Type }\end{array}$} & \multirow[t]{2}{*}{ Coef } & \multicolumn{2}{|c|}{ All Intersections } & \multicolumn{2}{|c|}{3 Leg Intersection } & \multicolumn{2}{|c|}{4 Leg Intersections } \\
\hline & & & Estimates & $\operatorname{Pr}>$ ChiSq & Estimates & $\operatorname{Pr}>$ ChiSq & Estimates & $\mathrm{Pr}>\mathrm{ChiSq}$ \\
\hline \multirow[t]{3}{*}{ Total } & Total & $\alpha$ & -0.8910 & $<0.0001$ & -0.8508 & $<0.0001$ & -0.9433 & $<0.0001$ \\
\hline & & $\beta 1$ & 0.1805 & 0.0012 & 0.1568 & 0.0500 & 0.2065 & 0.0064 \\
\hline & & $\mathrm{K}$ & 0.8946 & & 0.9828 & & 0.7635 & \\
\hline \multirow[t]{3}{*}{ Injury } & Total & $\alpha$ & -1.9234 & $<0.0001$ & -1.9445 & $<0.0001$ & -1.8668 & $<0.0001$ \\
\hline & & $\beta 1$ & 0.1509 & 0.0162 & 0.1153 & 0.1956 & 0.1753 & 0.0475 \\
\hline & & $\mathrm{K}$ & 0.8769 & & 0.8861 & & 0.8370 & \\
\hline \multirow[t]{3}{*}{ PDO } & Total & $\alpha$ & -1.3336 & $<0.0001$ & -1.2569 & $<0.0001$ & -1.4544 & $<0.0001$ \\
\hline & & $\beta 1$ & 0.1948 & 0.0009 & 0.1731 & 0.0448 & 0.2251 & 0.0039 \\
\hline & & $\mathrm{K}$ & 0.9549 & & 1.1298 & & 0.7251 & \\
\hline
\end{tabular}


Table 21: Impact Type - Conflict Model Results

\begin{tabular}{|c|c|c|c|c|c|c|c|c|}
\hline \multirow[t]{2}{*}{ Impact Type } & \multirow{2}{*}{$\begin{array}{l}\text { Conflict } \\
\text { Type }\end{array}$} & \multirow[t]{2}{*}{ Coef } & \multicolumn{2}{|c|}{ All Intersections } & \multicolumn{2}{|c|}{3 Leg Intersection } & \multicolumn{2}{|c|}{4 Leg Intersections } \\
\hline & & & Estimates & $\operatorname{Pr}>$ ChiSq & Estimates & $\mathrm{Pr}>\mathrm{ChiSq}$ & Estimates & $\mathrm{Pr}>\mathrm{ChiSq}$ \\
\hline \multirow[t]{3}{*}{ Rear-end } & Rear-end & $\alpha$ & -2.8805 & $<0.0001$ & -2.7649 & $<0.0001$ & -3.1528 & $<0.0001$ \\
\hline & & $\beta 1$ & 0.1654 & 0.0057 & 0.1626 & 0.0598 & 0.2092 & 0.0105 \\
\hline & & $\mathrm{K}$ & 0.5038 & & 0.7816 & & 0.0000 & \\
\hline \multirow[t]{3}{*}{ Sideswipe } & $\begin{array}{l}\text { Lane- } \\
\text { change }\end{array}$ & $\alpha$ & -3.3697 & $<0.0001$ & -3.4246 & $<0.0001$ & -3.2875 & $<0.0001$ \\
\hline & & $\beta 1$ & 0.2944 & 0.0095 & 0.3212 & 0.0537 & 0.2617 & 0.0934 \\
\hline & & $\mathrm{K}$ & 0.4051 & & 0.3935 & & 0.4034 & \\
\hline \multirow{3}{*}{$\begin{array}{l}\text { Turning } \\
\text { Movement }\end{array}$} & Crossing & $\alpha$ & -1.2785 & $<0.0001$ & -1.2051 & $<0.0001$ & -1.3792 & $<0.0001$ \\
\hline & & $\beta 1$ & 0.3501 & 0.0034 & 0.3989 & 0.0137 & 0.2881 & 0.1008 \\
\hline & & $\mathrm{K}$ & 1.0012 & & 1.0091 & & 0.9760 & \\
\hline
\end{tabular}

The p-value results of the Crash - Conflict models illustrate that all of developed models have significant coefficient estimates (or close to significant for $\mathrm{p}=0.10$ ). Tables 22 and 23 summarize the goodness-of-fit results and Figures 26 to 31 present the variable CURE plots. 
Table 22: Total - Conflict Goodness-Of-Fit Results

\begin{tabular}{|llll|}
\hline & All Int Results & 3 Leg Results & 4 Leg Results \\
& Total - Total & Total - Total & Total - Total \\
MPB/Year & -0.000623 & -0.000650 & -0.002427 \\
MAD/Year & 0.038530 & 0.067493 & 0.090870 \\
MSE/Year & 0.003364 & 0.009166 & 0.021909 \\
MSPE/Year & 0.003364 & 0.009166 & 0.021909 \\
& Injury - Total & Injury - Total & Injury - Total \\
MPB/Year & -0.000257 & -0.000244 & -0.001137 \\
MAD/Year & 0.014463 & 0.022259 & 0.040583 \\
MSE/Year & 0.000476 & 0.001222 & 0.003259 \\
MSPE/Year & 0.000476 & 0.001222 & 0.003259 \\
& PDO - Total & PDO - Total & PDO - Total \\
MPB/Year & -0.000347 & -0.000394 & -0.001210 \\
MAD/Year & 0.026781 & 0.048453 & 0.059705 \\
MSE/Year & 0.001579 & 0.004448 & 0.009839 \\
MSPE/Year & 0.001579 & 0.004448 & 0.009839 \\
\hline
\end{tabular}




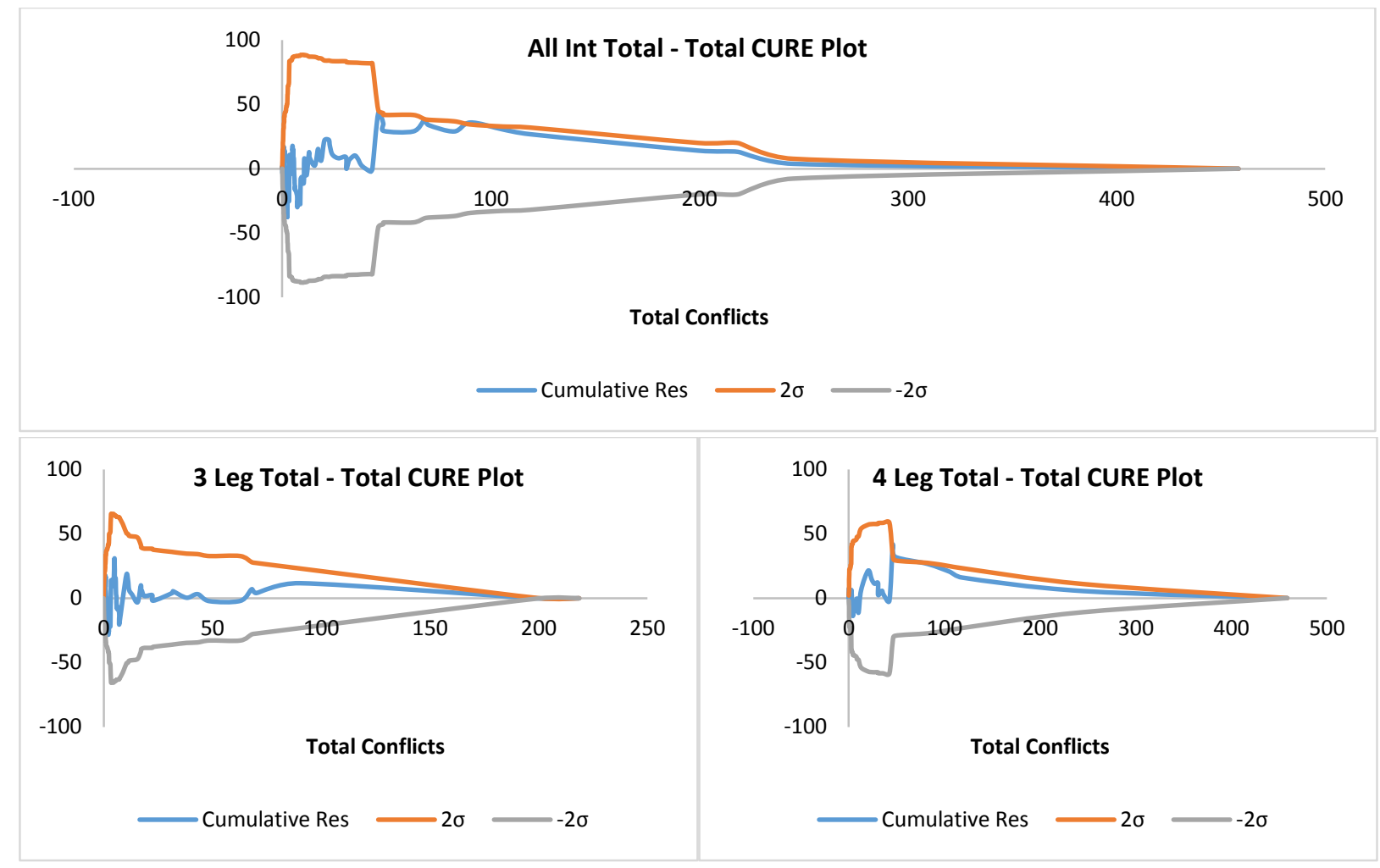

Figure 26: Total - Total CURE Plots

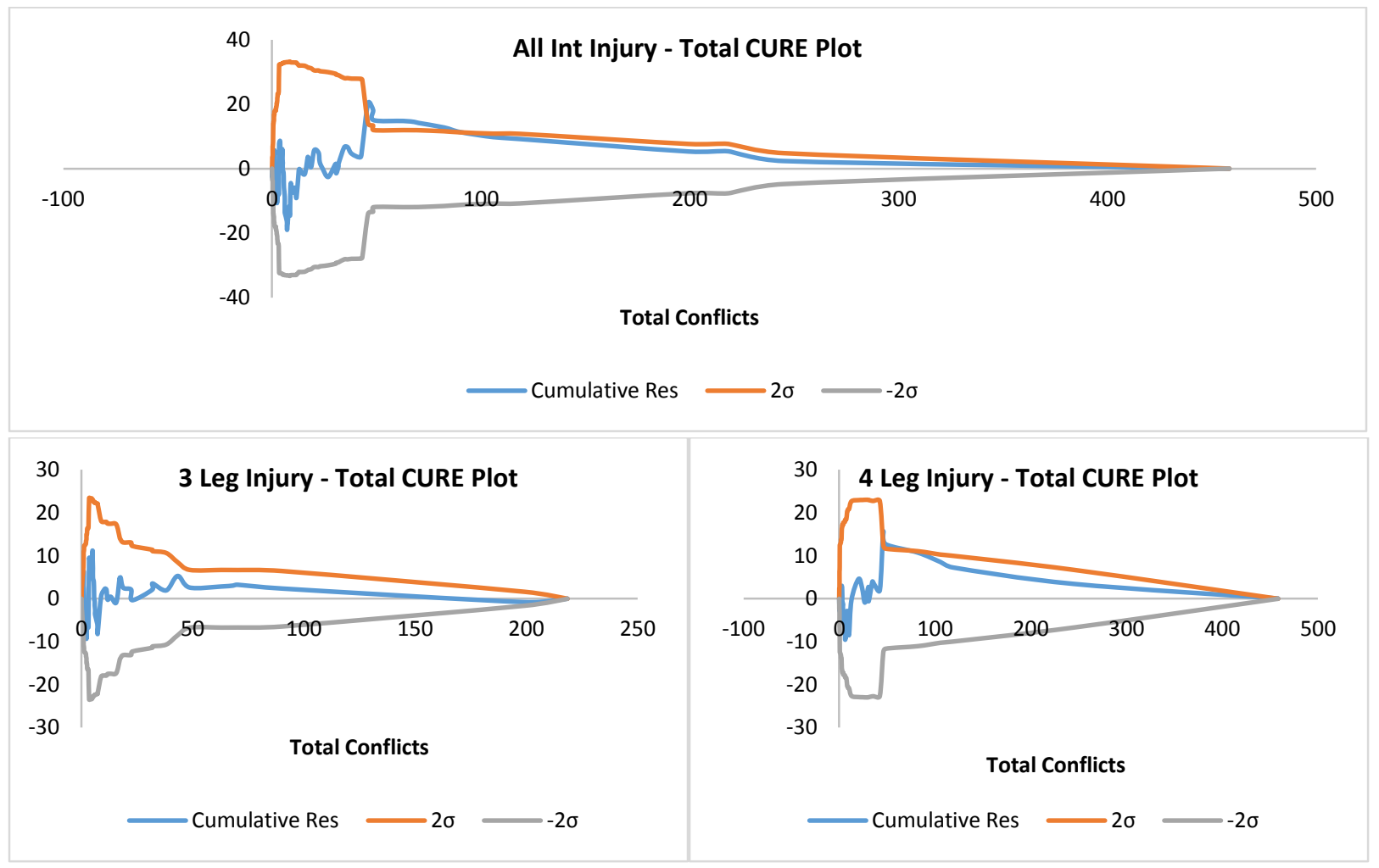

Figure 27: Injury - Total CURE Plots 


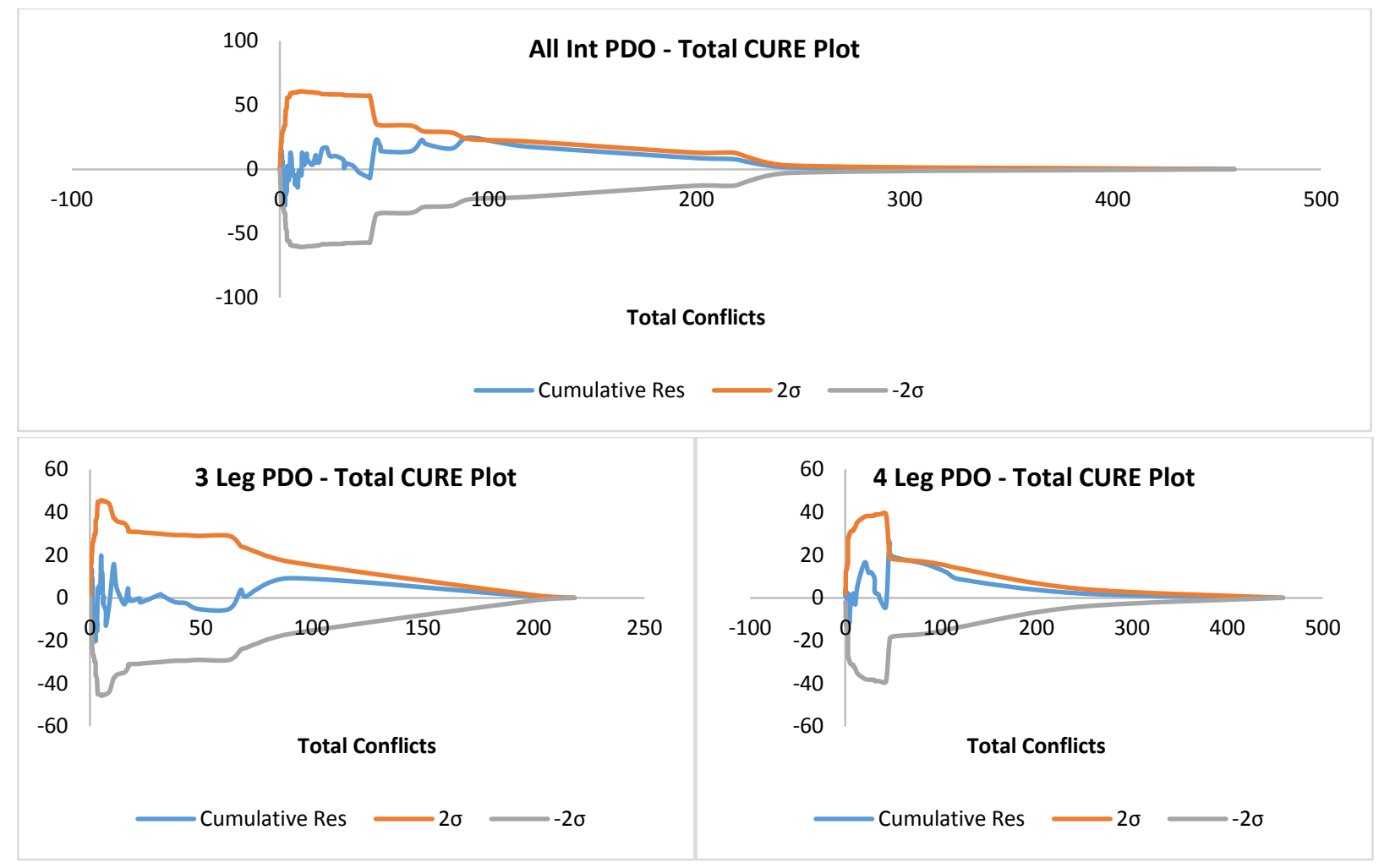

Figure 28: PDO - Total CURE Plots 
Table 23: Impact Type - Conflict Goodness-Of-Fit Results

\begin{tabular}{|c|c|c|c|}
\hline & All Int Results & 3 Leg Results & 4 Leg Results \\
\hline & Rear-end - Rear-end & Rear-end - Rear-end & Rear-end - Rear-end \\
\hline MPB/Year & -0.000170 & -0.000164 & -0.000525 \\
\hline MAD/Year & 0.006196 & 0.011957 & 0.011963 \\
\hline MSE/Year & 0.000071 & 0.000279 & 0.000202 \\
\hline \multirow[t]{2}{*}{ MSPE/Year } & 0.000071 & 0.000279 & 0.000202 \\
\hline & Sideswipe - Lane-change & Sideswipe - Lane-change & Sideswipe - Lane-change \\
\hline MPB/Year & -0.000036 & -0.000160 & 0.000073 \\
\hline MAD/Year & 0.004043 & 0.006467 & 0.010581 \\
\hline MSE/Year & 0.000027 & 0.000073 & 0.000172 \\
\hline \multirow[t]{2}{*}{ MSPE/Year } & 0.000027 & 0.000073 & 0.000172 \\
\hline & $\begin{array}{l}\text { Turning Movement - } \\
\text { Crossing }\end{array}$ & $\begin{array}{l}\text { Turning Movement - } \\
\text { Crossing }\end{array}$ & $\begin{array}{l}\text { Turning Movement - } \\
\text { Crossing }\end{array}$ \\
\hline MPB/Year & 0.000266 & 0.001766 & -0.001768 \\
\hline MAD/Year & 0.016367 & 0.029238 & 0.036373 \\
\hline MSE/Year & 0.000599 & 0.001604 & 0.003898 \\
\hline MSPE/Year & 0.000599 & 0.001604 & 0.003898 \\
\hline
\end{tabular}




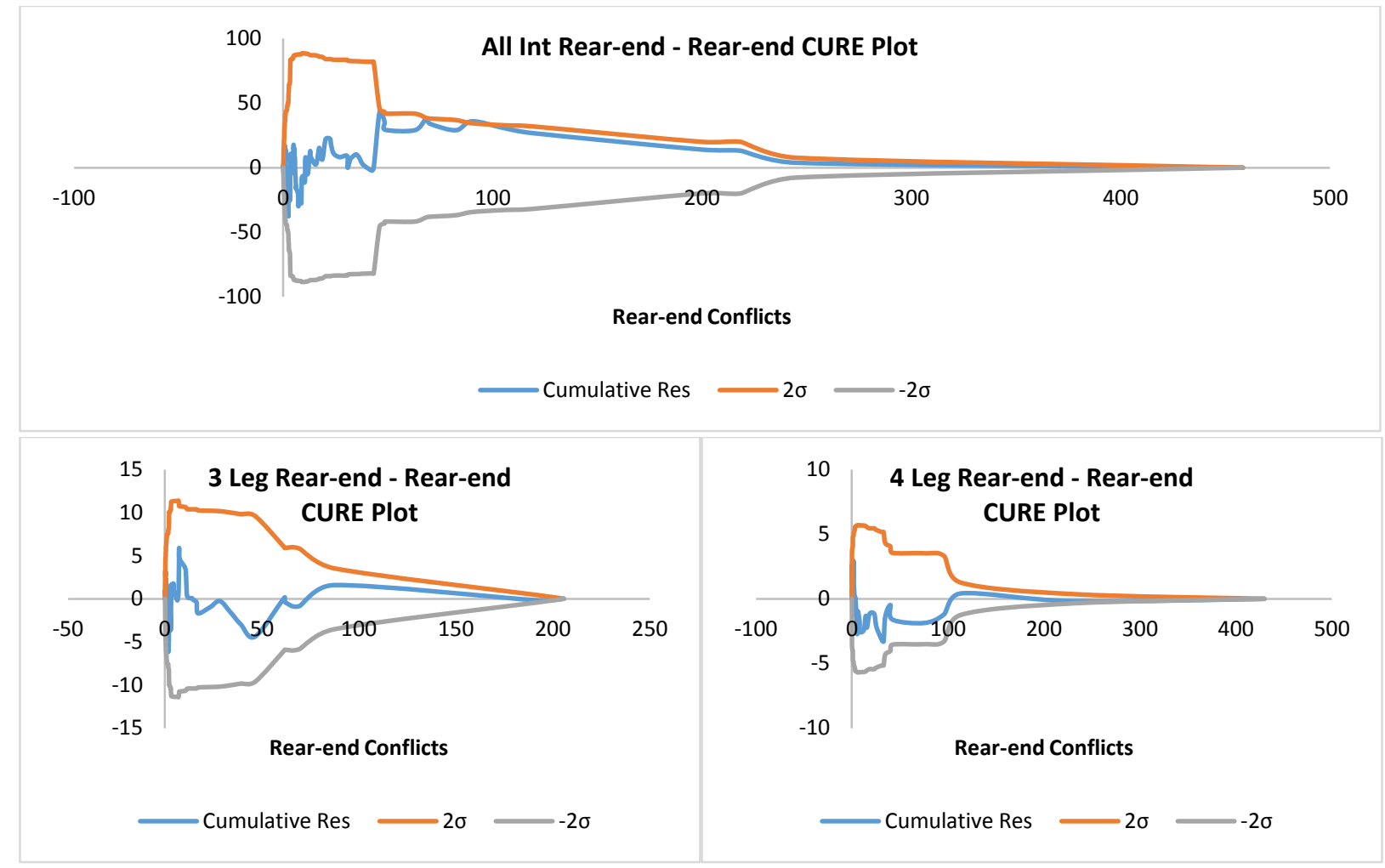

Figure 29: Rear-end - Rear-end CURE Plots

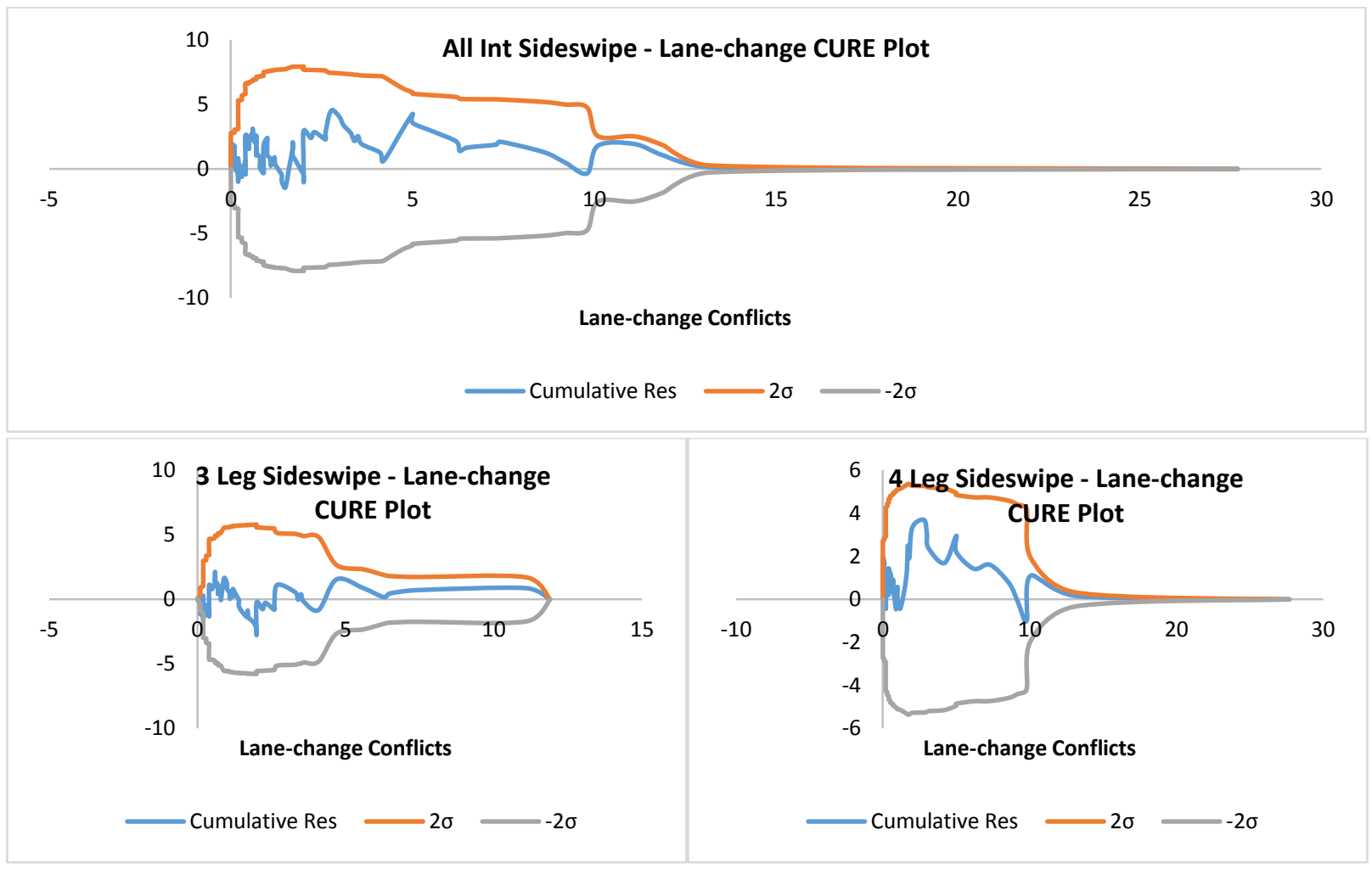

Figure 30: Sideswipe - Lane-change CURE Plots 


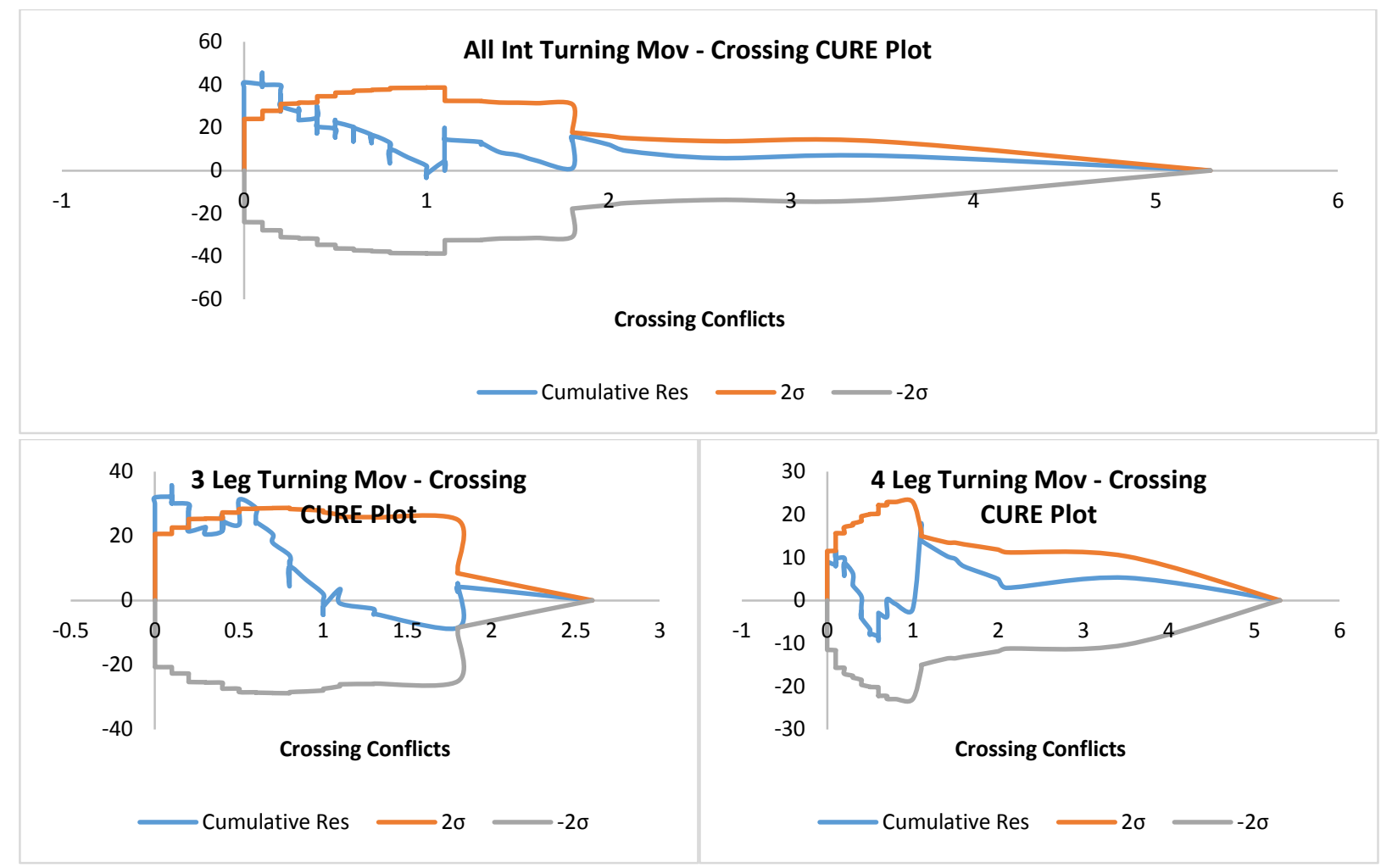

Figure 31: Turning Movement - Crossing CURE Plots

The Crash - Conflict models predict the observed crashes demonstrate a good fit to the data because the MPB/Year and MAD/Year values are approximately zero and the MSE/Year and MSPE/Year values are equal. Overall the CURE plots display very little prediction biases in the models. The Crash - Conflict models provide more significant results than those of the Crash - Volume and Crash - Delay models. The Crash - Conflict models provide consistent results for the all intersection, three leg, and four leg intersection models. The conflict models are more effective because of their ability to capture the intersection geometry and operation. By incorporating intersection geometry, the models improve on the predictive capabilities of the Crash - Volume models. Inclusion of the intersection operation improves on the results of the Crash - Delay models. 


\subsubsection{Additional Crash - Conflict Models Attempted}

The following Crash -Conflict models were excluded due to the model results identifying no significant coefficient estimates.

- Crash - Conflict and PHF

- Crash - Conflict and Total Delay

\subsection{Crash Prediction Model Comparison}

One of the objectives of this study was to illustrate the effectiveness of applying surrogate safety measurements in developing crash prediction models. Analysis of the developed models illustrate the predictive capabilities of the different model types. The volume crash prediction models provide valid models only for the four leg two-way stop controlled intersections. Both the delay and conflict crash prediction models provide significant models that predict crashes well for all of the intersections groups. These results indicate that the use of surrogate safety measures in developing crash prediction models was more effective than applying the traditional crash volume modelling approach.

When comparing the results of the delay and conflict crash prediction models, both effectively predict crashes for all intersection groups. A major difference between these model types is the required data assembly method. The delay model data can be assembled by modelling the intersections using Synchro. Synchro provides the volumes and average delays of each movement individually which can then be used to calculate the total delay. The conflict models require more effort to assemble the required data as the intersections are first modelled, then simulations are conducted to estimate conflicts. Although conflict data require more effort to collect, the use of conflicts provides additional impact type prediction models. Both of delay and conflict crash prediction models have advantages and disadvantages, however they both provide adequate models for predicting crashes at two-way stop controlled intersections. 


\subsection{Discussion}

To provide alternative methods of evaluating safety at two-way stop controlled intersections, this study explored the development of crash prediction models with various explanatory variables. The following summarizes the models developed in this study:

- Volume Crash Prediction Models which modelled crash frequency with entering AADT and conflicting volumes

- Delay Crash Prediction Models which modelled crash frequency and impact type with total delay and left turning movement total delay

- Conflict Crash Prediction Models that modelled crash frequency and impact type with estimated conflicts

The developed models were initially evaluated with their p-value results. If the model coefficient estimates were deemed significant $(p<0.10)$, the models were then evaluated with the following goodness-of-fit measures:

- The Mean Prediction Bias (MPB)

- Mean Absolute Deviation (MAD)

- The Mean Squared Prediction Error (MSPE)

- Mean Squared Error (MSE)

- Cumulative Residual (CURE) plots

The developed Volume Crash Prediction Models provided many successful model combinations. Overall, the volume crash prediction four leg intersection models had significant coefficient estimates and met the goodness-of-fit requirements.

The Crash - Total Delay models satisfied the goodness-of-fit test and yielded CURE plots that illustrate some model prediction bias. Similarly, the Crash - LTM Total Delay models provided models for all intersection groups that met the goodness-of-fit requirements and had CURE plots that show only minor prediction biases.

The Conflict Crash Prediction Models consistently provided the desired results for all three intersection groups. These models satisfied the goodness-of-fit tests and only a few illustrated prediction biases according to the CURE plots. 
Analysis of the developed models illustrate the predictive capabilities of the different model types. The volume crash prediction models only provide models for the four leg two-way stop controlled intersections. Both the delay and conflict crash prediction models provide more significant models that predict crashes well for all of the intersections groups. These results indicate that the use of surrogate safety measures in developing crash prediction models was more effective than applying the traditional crash volume modelling approach.

When comparing the results of the delay and conflict crash prediction models, both effectively predict crashes for all intersection groups. A major difference between these model types is the data collection techniques. Delay data were determined by modelling the intersections, while conflict data required modelling, simulations, and conflict analysis. Both these models have advantages and disadvantages, however they both provide models for predicting crashes at two-way stop controlled intersections.

Overall, the models with significant coefficient estimates satisfied the goodness-of-fit tests. However, CURE plots did identify biases in some of the models. These model biases are due to the sample sizes of the three and four leg two-way stop controlled intersections not being large enough. By including more two-way stop controlled intersections in the study, these biases can be adjusted and perhaps even yield significant coefficient estimates in more of the models. 


\section{Applications of Crash-Delay and Crash-Conflict Models in Evaluating the Implementation of a Major Approach Left Turn Lane at Three Leg Intersections}

This portion of the study presents an application of the developed crash prediction models. The purpose of this chapter is to provide an alternate approach to crash based evaluations of intersection improvements. Overall the intersection improvement illustrates the benefits of applying surrogate safety measures as a means of evaluation.

The potential effect of introducing a left turning lane on a major approach of a three leg intersection was explored. The expected change in crashes was identified by analyzing the total delay and simulated conflicts before and after implementation and then using these estimates and the calibrated models to predict crashes. With the before and after predicted crashes, the crash modification factors (CMF) were determined. The CMFs were then compared to a before and after evaluation conducted by Harwood, Bauer, Potts, Torbic, Richard, Rabbani, and Griffith, (2003). The results of this study were included in the Highway Safety Manual (AASHTO, 2010).

The intersections were selected based on whether the improvement could be implemented. 30 three leg two-way stop controlled intersections were identified as candidates for the added major approach left turning lane. The before and after versions of these intersections were modelled using Synchro and the total delay data were collected. The intersections were then imported into Vissim where the traffic simulations were conducted. The results of the simulations were analyzed with SSAM and the before and after conflicts were estimated.

\subsection{Before and After Implementation Total Delay and Conflict Results}

Table 24 presents the average total delay results for the intersections before and after implementation of the left turning lane. On average the total delay has not been reduced significantly. This is due to the fact that majority of the delay occurs at the minor approach. Vehicles at the minor approach have to wait for a suitable gap to make their movement, which is not very frequent at busy intersections. 
Table 24: Before and After Implementation Total Delay Results

\begin{tabular}{|c|c|c|l|}
\hline & Before & After & \% Change \\
\hline Average Total Delay (s) & 2220.420 & 1922.997 & -13.39 \\
\hline
\end{tabular}

Table 25 summarizes the before and after implementation conflict estimation results. There were large reductions in the total, rear-end, and lane-change conflicts but an increase in the crossing conflicts. The rear-end conflicts are reduced because the left turning vehicles have their own lane to wait and make their turn instead of obstructing the thru traffic. The lane-change conflicts are reduced because the left turn lane will create less congestion for the thru vehicles and create gaps for lane changes to be made. The crossing conflicts have increased but the average still remains small compared to the other conflict types. The crossing conflicts increased due to the additional traffic and distance the minor left turning vehicles have to cross.

Table 25: Before and After Implementation Conflict Results

\begin{tabular}{|l|l|l|l|}
\hline \multirow{2}{*}{ Conflict Type } & \multicolumn{3}{|c|}{ Average Conflicts } \\
\cline { 2 - 4 } & Before & After & \% Change \\
\hline Total & 7.16 & 2.31 & -67.78 \\
\hline Rear-end & 5.33 & 0.99 & -81.31 \\
\hline Lane-change & 1.47 & 0.43 & -71.04 \\
\hline Crossing & 0.35 & 0.88 & +150.00 \\
\hline
\end{tabular}

The models developed in this study were utilized in predicting the crash frequencies due to the changing total delay and conflicts. 


\subsection{Total Delay Crash Modification Factor Results}

Crash prediction models developed in this study were used to determine the total, injury, and PDO crashes occurring before and after the left turning lane was implemented. Equations 7 , 8 , and 9 illustrate the crash prediction models used. Table 26 summarizes the results of the before and after crash frequency predictions.

Total Crashes $=e^{-2.8575} *(\text { Total Delay })^{0.2997} *$ Years

(Equation 7)

Injury Crashes $=e^{-3.4749} *(\text { Total Delay })^{0.2116} *$ Years

(Equation 8)

PDO Crashes $=e^{-3.5035} *(\text { Total Delay })^{0.3103} *$ Years

(Equation 9)

Table 26: Total Delay Crash Modification Factor Results

\begin{tabular}{|l|l|l|l|l|l|}
\hline \multirow{2}{*}{ Crash Type } & \multicolumn{2}{|l|}{ Average Predicted Crashes } & \multicolumn{2}{|c|}{ CMF Range } & \multirow{2}{*}{ Average CMF } \\
\cline { 2 - 6 } & \multicolumn{1}{|c|}{ Before } & After & Min & Max & \\
\hline Total & 6.48 & 6.21 & 0.80 & 1.00 & 0.96 \\
\hline Injury & 1.80 & 1.74 & 0.85 & 1.00 & 0.97 \\
\hline PDO & 3.68 & 3.52 & 0.79 & 1.00 & 0.96 \\
\hline
\end{tabular}

The results of the total delay crash prediction models identify very little reduction in crash frequency. This is due to the total delay mainly being influenced by the minor approach. The implementation of a major approach left turn lane would not have a significant impact on the minor approach delays. 


\subsection{Conflict Crash Modification Factor Results}

Crash prediction models were used to determine the total, injury, PDO, rear-end, sideswipe, and turning movement crashes occurring before and after the left turning lane was implemented. Equations 10 to 15 illustrate the crash prediction models applied. Table 27 summarizes the results of the before and after crash frequency predictions.

Total Crashes $=e^{-0.8508} *(\text { Total Conflicts })^{0.1568} *$ Years

(Equation 10)

Injury Crashes $=e^{-1.9445} *(\text { Total Conflicts })^{0.1153} *$ Years

(Equation 11)

PDO Crashes $=e^{-1.2569} *(\text { Total Conflicts })^{0.1731} *$ Years

(Equation 12)

Rear - end Crashes $=e^{-2.7649} *(\text { Total Conflicts })^{0.1626} *$ Years

(Equation 13)

Sideswipe Crashes $=e^{-3.4246} *(\text { Total Conflicts })^{0.3212} *$ Years

(Equation 14)

Turning Movement Crashes $=e^{-1.2051} *(\text { Total Conflicts })^{0.3989} *$ Years $\quad$ (Equation 15$)$

Table 27: Conflict Crash Modification Factor Results

\begin{tabular}{|l|l|l|l|l|l|}
\hline \multirow{2}{*}{ Crash Type } & \multicolumn{2}{|c|}{ Average Predicted Crashes } & \multicolumn{2}{c|}{ CMF Range } & \multirow{2}{*}{ Average CMF } \\
\cline { 2 - 5 } & \multicolumn{1}{|c|}{ Before } & After & Min & Max & \\
\hline Total & 6.19 & 5.28 & 0.63 & 1.09 & 0.86 \\
\hline Injury & 1.96 & 1.75 & 0.71 & 1.06 & 0.89 \\
\hline PDO & 4.22 & 3.54 & 0.60 & 1.10 & 0.85 \\
\hline Rear-end & 0.83 & 0.54 & 0.12 & 1.12 & 0.64 \\
\hline Sideswipe & 0.36 & 0.20 & 0.22 & 1.04 & 0.51 \\
\hline Turning Movement & 1.87 & 2.94 & 0.07 & 2.95 & 1.38 \\
\hline
\end{tabular}


The results of the conflict crash prediction models identify reductions in crash frequency due to implementation of the improvement. Total, injury and PDO crash frequency demonstrate similar reductions with resulting CMFs ranging from 0.85 to 0.89 . When analyzing individual impact types, rear-end and sideswipe impacts show large reductions in crash frequency. These reductions could be due to the added left turning lane reducing congestion for the thru movement. Turning movement crashes were increased and this is due to the minor left turning movements having to cross more traffic and lanes. Overall the conflict crash prediction models provide more significant results because they are better able to account for the operation and geometric aspects of the improvement than the delay models.

\subsection{Discussion}

Analysis of the implementation of a left turning lane on a major three leg intersection approach identifies a reduction in crash frequency. Both conflicts and total delay crash prediction models were explored. However, the conflict based crash prediction models provided more significant results due to their ability to capture both the operational and geometric aspects of the intersections. Conflict crash prediction models were utilized in determining the CMFs for total, injury, PDO, rear-end, sideswipe, and turning movement crashes. Total, injury, and PDO crashes displayed similar reductions with CMFs ranging from 0.85 to 0.89 . Rear-end and sideswipe crash frequencies illustrated significant reductions with CMFs of 0.64 and 0.51 respectively. Turning movement crash frequency experienced an increase with a CMF of 1.38. The conflict based CMFs for total crashes range from 0.63 to 1.09 . This range of CMF results identify that some of these intersections see a significant reduction in crash frequency due to the implementation of the major approach left turn lane. This illustrates the effectiveness of applying surrogate safety measurements, as the change in crash frequency associated with an improvement can be estimated for each intersection before implementation. This ensures that intersection improvements can be made to only the intersections that would benefit from them.

The validity of the CF estimation approach was assessed by comparing the CMFs with those in the Highway Safety manual for this treatment. Those CMFs are based on a study by Harwood et al. (2003) who conducted a before and after evaluation of the safety effects of providing left and right turn lanes at intersections. They collected 9 to 13 years of crash data for 
280 improved intersections as well as 300 similar unimproved intersections. Their crash based empirical Bayes before and after evaluation identified a CMF of 0.67 for three leg urban twoway stop controlled intersections. The results presented in thesis for the same improvement identify a CMF of 0.86 , with individual values that range from 0.63 to 1.09 . Several intersections had CMFs that were within the range of the 0.67 CMF determined in Harwood's (2003) study. Although the aggregate CMFs differ between the two studies, the fact that the use of surrogate safety measures can provide results within the range of a crash based before and after study is encouraging. 


\section{Conclusion}

The purpose of this study was to develop, and analyze the predictive capabilities of crash prediction models that could be used in evaluating safety at two-way stop controlled intersections. This study included 133 two-way stop controlled intersections of which, 78 were three leg and 55 were four leg intersections. The geometric characteristics and turning movement counts were utilized in modelling each intersection in Synchro. These models were imported into SimTraffic and Vissim and microscopic simulations were conducted. The simulation results were analyzed with SSAM in order to obtain the required conflict data. SAS was then used to generate models which related various explanatory variables to crash frequency.

The crash prediction models were developed for all intersections and then for three and four leg intersections separately. These models relate crashes with traffic volumes, estimated conflicts, and intersection delays. The generated models were then evaluated based on the pvalues of the coefficient estimates. Once significant models were identified, they were further tested with various goodness-of-fit methods. The goodness-of-fit methods consisted of the Mean Prediction Bias, the Mean Absolute Deviation, the Mean Squared Prediction Error, the Mean Squared Error, and plots of Cumulative Residuals.

The developed models provided many successful model combinations. The volume crash prediction four leg intersection models had significant coefficient estimates and met the goodness-of-fit requirements. The delay crash prediction models met the goodness-of-fit requirements and had CURE plots that show minor prediction biases. The conflict crash prediction models also provided models that met the goodness-of-fit requirements. Interestingly, the Crash - Volume models were only able to predict crashes at four leg intersections well. While the Crash - Delay models, specifically the left turning movement total delay models and Crash - Conflict models predict crashes well for all intersection groups. These results indicate that the use of surrogate safety measures in developing crash prediction models was more effective than applying the traditional crash volume modelling approach.

Overall, the models that exhibited significant coefficient estimates satisfied the goodnessof-fit measures as well. The CURE plots did identify that some of the models had prediction biases, which are likely due to the sample size of the study. 
SimTraffic and Vissim simulation software were compared utilizing the initial p-value results in order to determine which conflict estimation technique was more effective. Vissim provided more significant results than SimTraffic, but with proper calibration it is possible that the SimTraffic results could be improved.

The potential of the developed models for doing safety assessments was illustrated by using them to evaluate the change in crash frequency following the addition of a hypothetical left turn lane on a major approach of three leg intersections. The total delay and estimated conflicts were first determined. These data were then used in the appropriate crash prediction model to predict crash frequency before and after the implemented improvement to determine the crash modification factor (CMF). The CMF results differed significantly between the delay model results and the conflict model results. Total crashes saw a reduction of $4 \%$ and $14 \%$ according to the delay and conflict models respectively. These results differ due to the limitations of the delay models in capturing the geometric characteristics of the intersections. The use of conflicts incorporates both the operational and geometric aspects of the intersections. A before and after evaluation conducted by Harwood et al. (2003) identified a CMF of 0.67. The CMF determined in this study was 0.86 and several intersections had CMFs that were within the range of the 0.67 CMF determined in Harwood's (2003) study. Although the aggregate CMFs differ between the two studies, the fact that the use of surrogate safety measures provided results within the range of a crash based before and after evaluation is promising.

Future research for this study could be to introduce more two-way stop controlled intersections into the study, which would reduce model prediction biases and perhaps yield significant coefficient estimates in more of the models. The results of this study can also be applied in determining additional crash modification factors. This can be achieved by applying an improvement to the intersection models, simulating conflicts, and applying the Crash Conflict models to determine the crash frequencies. These before and after crash frequencies can then be used to estimate CMFs of the improvement made. 


\section{References}

AASHTO (2010). Highway Safety Manual. American Association of State Highway and Transportation Officials (AASHTO). Washington, DC.

Caliendo, C., \& Guida, M. (2012). Microsimulation Approach for Predicting Crashes at Unsignalized Intersections Using Traffic Conflicts. Journal of Transportation Engineering, 138(12), 1453-1467.

Chen, Y., Persaud, B., Sacchi, E., \& Bassani, M. (2013). Investigation of models for relating roundabout safety to predicted speed. Accident Analysis \& Prevention, 50, 196-203.

Cunto, F., \& Saccomanno, F. F. (2008). Calibration and validation of simulated vehicle safety performance at signalized intersections. Accident Analysis \& Prevention, 40(3), 11711179.

D’Agostino, C. (2014). A stochastic approach to safety management of roadway segment. PhD in Transportation Engineering Dissertation. Catania, Italy 2014.

El-Basyouny, K (2006). Field Validation for Surrogate Safety Assessment Methodology (SSAM) Using a Multi-Purpose Micro-Simulation. MASc Thesis, University of British Columbia, 2006.

El-Basyouny, K., \& Sayed, T. (2013). Safety performance functions using traffic conflicts. Safety Science, 51(1), 160-164.

Gettman, D., Pu, L., Sayed, T., \& Shelby, S. G. (2008). Surrogate safety assessment model and validation: Final report (No. FHWA-HRT-08-051).

Google Maps. (2014). [Study Area - GTA, Toronto, Ontario] [Street Map]. Retrieved from http://maps.google.com/maps/ms?ie=UTF\&msa=0\&msid=217509114984913710519.000 4f094c5d65cc36f108

Google Maps. (2014). [Unsignalized Intersections - GTA, Toronto, Ontario] [Street Map]. Retrieved from https://mapsengine.google.com/map/edit?mid=z4Mo9P5Vgy8.kXHHOVXMs1hk 
Harwood, D. W., Bauer, K. M., Potts, I. B., Torbic, D. J., Richard, K. R., Rabbani, E. R. K., ... \& Griffith, M. S. (2003). Safety effectiveness of intersection left-and right-turn lanes. Transportation Research Record: Journal of the Transportation Research Board, 1840(1), 131-139.

Hauer E., Ng J., Lovell J. (1988). Estimation of safety at signalized intersections, Transportation Research Record, 1185, Transportation Research Board, National Research Council, Washington D. C., 1988, pp. 48-61.

Hauer, E., \& Bamfo, J. (1997, November). Two tools for finding what function links the dependent variable to the explanatory variables. In Proceedings of the ICTCT 1997 Conference (pp. 05-05).

Hauer, E. (2001). Overdispersion in modelling accidents on road sections and in Empirical Bayes estimation. Accident Analysis \& Prevention, 33(6), 799-808.

Husch, D., \& Albeck, J. (2012). Synchro Studio 8 user guide. Trafficware Ltd., Sugar Land, TX.

Hydén, C. (1987). The development of a method for traffic safety evaluation: The Swedish Traffic Conflicts Technique. BULLETIN LUND INSTITUTE OF TECHNOLOGY, DEPARTMENT, (70).

Jovanis P. P., Chang H. L. (1986). Modeling the relationship of accidents to miles traveled, Transportation Research Record, 1068, Transportation Research Board, National Research Council, Washington D.C., 1986, pp. 42-51.

Kim, S. J., Kim, W., \& Rilett, L. R. (2005). Calibration of microsimulation models using nonparametric statistical techniques. Transportation Research Record: Journal of the Transportation Research Board, 1935(1), 111-119.

Laureshyn, A., Svensson, Å., \& Hydén, C. (2010). Evaluation of traffic safety, based on microlevel behavioural data: Theoretical framework and first implementation. Accident Analysis \& Prevention, 42(6), 1637-1646.

Lord, D., \& Park, P. Y. J. (2008). Investigating the effects of the fixed and varying dispersion parameters of Poisson-gamma models on empirical Bayes estimates. Accident Analysis \& Prevention, 40(4), 1441-1457. 
Lyon, C., Haq, A., Persaud, B., \& Kodama, S. T. (2005). Safety performance functions for signalized intersections in large urban areas: development and application to evaluation of left-turn priority treatment. Transportation Research Record: Journal of the Transportation Research Board, 1908(1), 165-171.

Menneni, S., Sun, C., \& Vortisch, P. (2009). Integrated microscopic and macroscopic calibration for psychophysical car-following models. In TRB 88th annual meeting compendium of papers DVD, Washington.

Miaou S., Lum H. (1993). Modeling vehicle accident and highway geometric design relationships, Accidents Analysis and Prevention, Vol. 25, No. 6, 1993, pp. 689-709.

Mitra, S., \& Washington, S. (2007). On the nature of over-dispersion in motor vehicle crash prediction models. Accident Analysis \& Prevention, 39(3), 459-468.

MTO. (2007). Ontario Traffic Manual - Book 12 - Traffic Signals. Toronto, Ontario : Ontario Ministry of Transportation

Oh, J., Lyon, C., Washington, S., Persaud, B., \& Bared, J. (2003). Validation of FHWA crash models for rural intersections: Lessons learned. Transportation Research Record: Journal of the Transportation Research Board, 1840(1), 41-49.

Park, B. B., \& Schneeberger, J. D. (2003). Microscopic Simulation Model Calibration and validation: case study of VISSIM simulation model for a coordinated actuated Signal system. Transportation Research Record: Journal of the Transportation Research Board, 1856(1), 185-192.

Park, B., Won, J., \& Yun, I. (2006). Application of microscopic simulation model calibration and validation procedure: Case study of coordinated actuated signal system. Transportation Research Record: Journal of the Transportation Research Board, 1978(1), 113-122.

Perkins, D and Harris, J (1967). Criteria for Traffic Conflict Characteristics. Report GMF 632, General Motors Corporation, Warren, MI. 
Persaud, B., Saleem, T., Lyon, C., and Chen, Y., (2012). Safety Performance Functions for Estimating the Safety Benefits of Proposed or Implemented Countermeasures. A report prepared for Transport Canada under Canada's National Road Safety Research and Outreach Program, Ryerson University, 2012.

PTV, A. (2013). Vissim 6 user manual. Karlsruhe, Germany.

Pu, L., \& Joshi, R. (2008). Surrogate Safety Assessment Model (SSAM): Software User Manual (No. FHWA-HRT-08-050).

RSCC. (2011). Road Safety in Canada. Retrieved from: https://www.tc.gc.ca/media/documents/roadsafety/tp15145e.pdf

SAS Institute. (2013). What's New in SAS 9.4. SAS Institute Inc, SAS Campus Drive, Cary, North Carolina.

Sachi, E., Sayed, T., and deLeur, P., (2013). A Comparison of Collision-Based and ConflictBased Safety Evaluations: The Case of Right Turn Smart Channels. Accident Analysis and Prevention: 59, pp. 260-266, 2013.

Saleem, T. (2012). Evaluation of the Predictive Capabilities of Simulated Peak Hour Conflict Based Crash Prediction Models. MASc Thesis, Ryerson University, 2012.

Sayed, T., Brown, G., and Navin, F. (1994). Simulation of Traffic Conflicts at Unsignalized Intersections with TCS-Sim. Accident Analysis and Prevention, Vol.26, Issue 5, pp. 593607, 1994.

Sayed, T., \& Rodriguez, F. (1999). Accident prediction models for urban unsignalized intersections in British Columbia. Transportation Research Record: Journal of the Transportation Research Board, 1665(1), 93-99.

Tarko, A., Davis, G., Saunier, N., Sayed, T., \& Washington, S. (2009). Surrogate measures of safety. White paper, ANB20 (3) Subcommittee on Surrogate Measures of Safety.

Trafficware. (2013). Synchro Studio Brochure: Planning and Analysis Software. Trafficware. Retrieved from: http://www.trafficware.com/documents/SynchroStudio03012013.pdf. 
Transport Canada (2007). Analysis and Estimation of the Social Cost of Motor Vehicle Collisions in Ontario. TP 14800E (08/2007). Retrieved from: http://www.tc.gc.ca/media/documents/roadsafety/TP14800E.pdf

Transport Canada. (2011). Canadian Motor Vehicle Traffic Collision Statistics 2011. Retrieved from: https://www.tc.gc.ca/eng/motorvehiclesafety/resources-researchstats-menu847.htm

UCLA. (2014).SAS Annotated Output: Negative Binomial Regression. UCLA: Statistical Consulting Group. Retrieved from: http://www.ats.ucla.edu/stat/sas/output/sas_negbin_output.htm

University of North Carolina Highway Safety Research Centre. Funded by U.S. Department of Transportation Federal Highway Administration. Collision Modification Factors Clearinghouse. Retrieved 2014, from: http://www.cmfclearinghouse.org/detail.cfm?facid=2968

World Health Organization. (2004). World Report on Road Traffic Injury Prevention, ISBN 924-156260-9, World Health Organization, Geneva, 2004. Retrieved from: http://whqlibdoc.who.int/publications/2004/9241562609.pdf?ua=1 